University of South Florida

DIGITAL COMMONS

Digital Commons @ University of

@ UNIVERSITY OF SOUTH FLORIDA

South Florida

January 2013

\title{
Do Mathematics and Reading Competencies Integrated into Career and Technical Education Courses Improve High School Student State Assessment Scores
}

Kristin Bowles Pierce

University of South Florida, eclare13@aol.com

Follow this and additional works at: https://digitalcommons.usf.edu/etd

Part of the Curriculum and Instruction Commons, and the Other Education Commons

\section{Scholar Commons Citation}

Pierce, Kristin Bowles, "Do Mathematics and Reading Competencies Integrated into Career and Technical Education Courses Improve High School Student State Assessment Scores" (2013). USF Tampa Graduate Theses and Dissertations.

https://digitalcommons.usf.edu/etd/4563

This Dissertation is brought to you for free and open access by the USF Graduate Theses and Dissertations at Digital Commons @ University of South Florida. It has been accepted for inclusion in USF Tampa Graduate Theses and Dissertations by an authorized administrator of Digital Commons @ University of South Florida. For more information, please contact digitalcommons@usf.edu. 
Do Mathematics and Reading Competencies Integrated into Career and Technical Education Courses Improve High School Student State Assessment Scores?

by

\author{
Kristin B. Pierce \\ A dissertation submitted in partial fulfillment \\ of the requirements for the degree of \\ Doctor of Philosophy \\ Department of Adult, Career, and Higher Education \\ College of Education \\ University of South Florida \\ Major Professor: Victor Hernandez-Gantes, Ph.D. \\ William Blank, Ph.D. \\ Yi-Hsin Chen, Ph.D. \\ Edward C. Fletcher, Ph.D. \\ Date of Approval: \\ March 29, 2013
}

Keywords: interdisciplinary, contextual, multidisciplinary, correlated, thematic

Copyright (C) 2013, Kristin B. Pierce 


\section{DEDICATION}

To my amazing husband, Blake, for unwavering support, encouragement, and love;

To my son, Ethan, and daughter, Clare, for being the light and joy in my life;

To my mom, Molly M. Gardner, and dad, Dr. Frederick A. Bowles, for the gift of unconditional love; and

To my friends for celebrating life’s successes 


\section{ACKNOWLEDGMENTS}

Heartfelt thanks to my advisor and major professor, Dr. Victor Hernandez-

Gantes, whose professional guidance and steadfast dedication to high quality scholarship developed my skills as a researcher and an educator. Dr. Hernandez exemplifies the qualities of a first rate professor: Outstanding researcher, caring mentor, challenging instructor, and person of compassion and character. For these reasons, he has earned my unwavering gratitude and professional respect. Much appreciation and thanks also go out to committee members, Dr. Bill Blank and Dr. Edward Fletcher, for their career and workforce expertise and contributions in the areas of curriculum integration, educational reform, and authentic learning. Equally, thank you to Dr. Yi-Hsin Chen for his guidance in crafting a research methodology and in guiding statistical analyses. Special thanks to Dr. William Black for filling the position of outside chairperson. 


\section{TABLE OF CONTENTS}

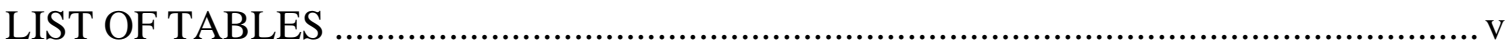

LIST OF FIGURES .........................................................................................

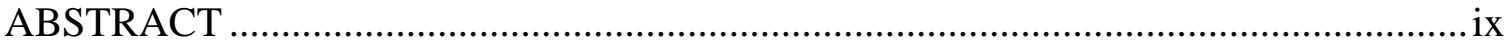

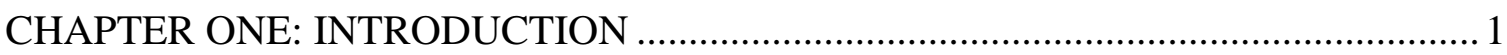

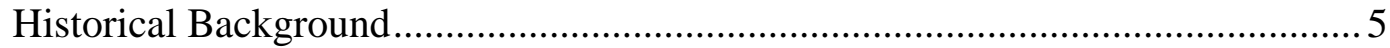

Vocational education reform movement ...................................................

Academic education reform movement ………………............................ 8

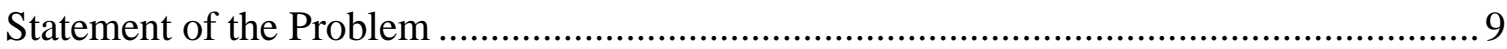

Statement of Purpose and Research Questions ................................................................ 11

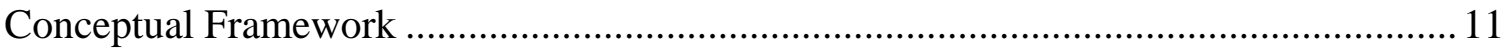

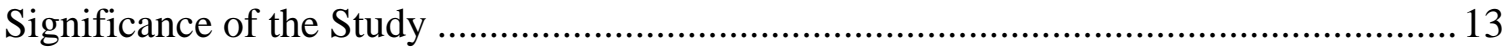

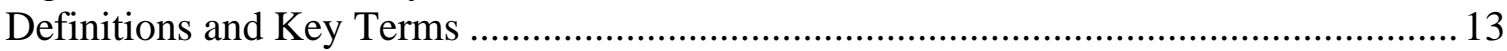

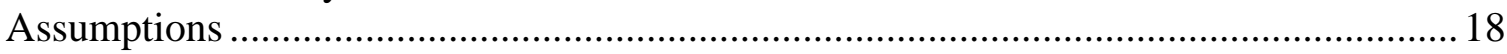

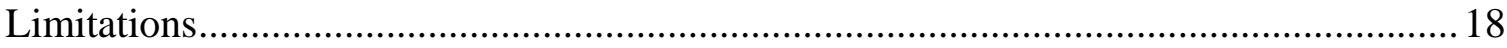

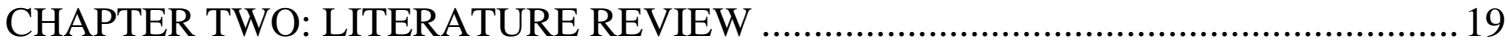

Student Achievement: A Road Still under Construction.......................................... 19

Academic achievement........................................................................... 20

International achievement .................................................................... 23

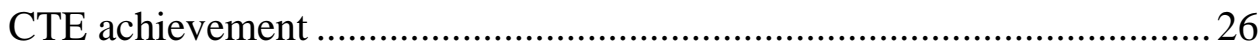

Curriculum Integration: A Reform Strategy …………………………………....28

Historical development........................................................................... 30

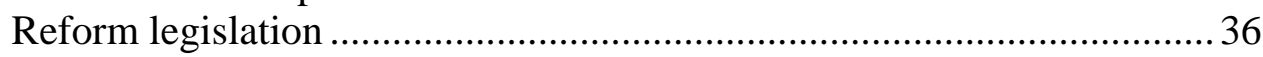

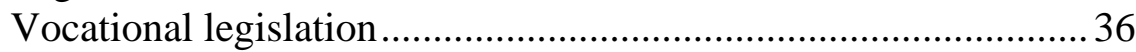

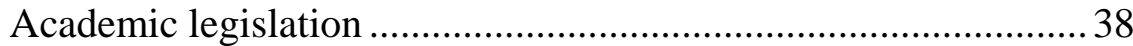

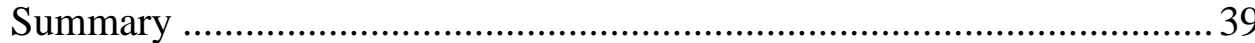

Curriculum Integration: Deconstructing the Basics ………………….................. 40

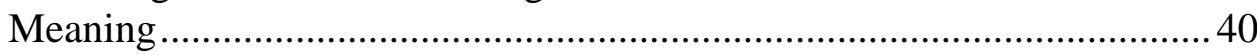

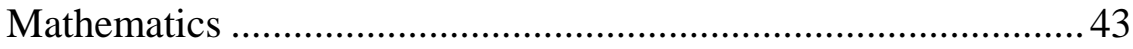

Reading/Language arts .............................................................. 44

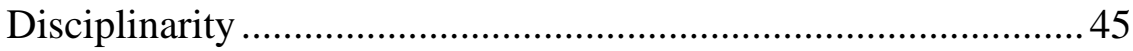

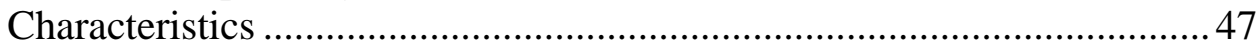

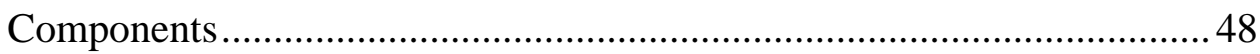

Integrative domain......................................................................... 48

Integrative form ........................................................................ 49

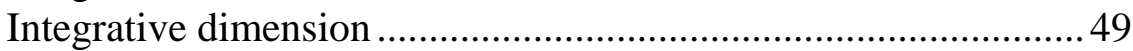


Integrative objectives ......................................................... 50

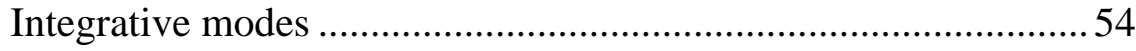

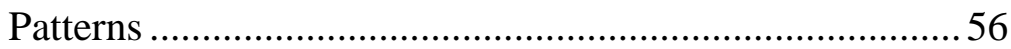

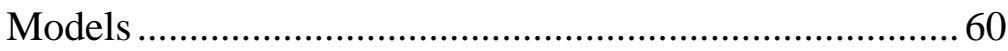

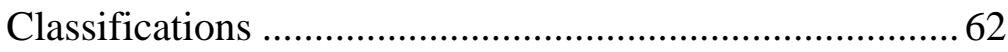

Practical applications..................................................66

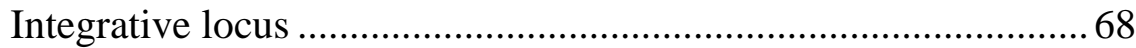

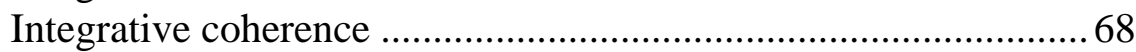

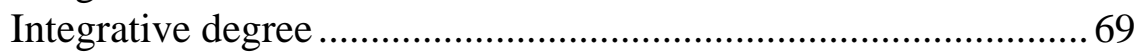

Perspectives on integrative components....................................69 69

Curriculum Integration: Implications for Practice .......................................... 70

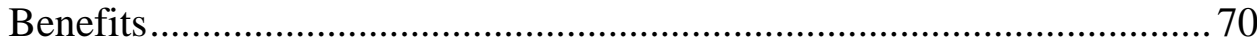

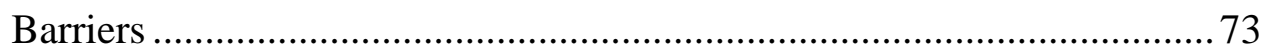

District and school leadership .................................................. 73

Subject-centered approach .................................................... 74

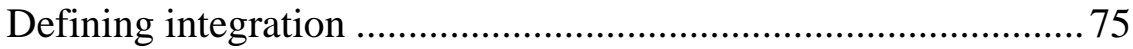

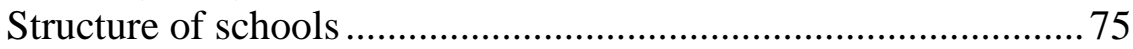

Role of the teacher.................................................................... 76

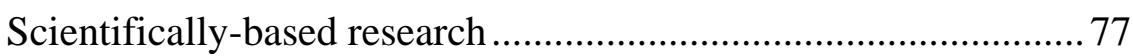

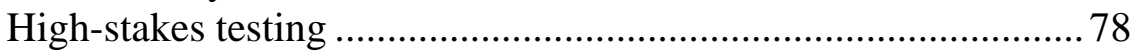

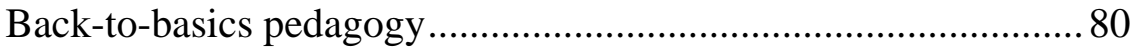

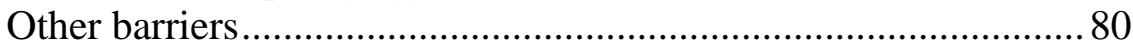

Curriculum Integration: Promising Practices .................................................. 81

National Council of Teachers of Mathematics (NCTM) ......................... 82

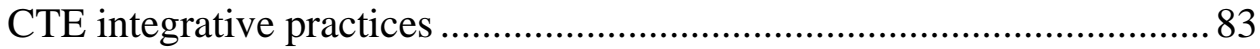

National Research Center for Career and Technical

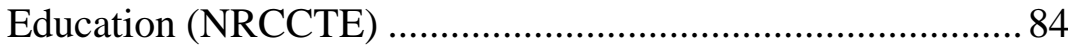

NRCCTE: Math-in-CTE ............................................. 84

NRCCTE: Whole-School Reform .................................. 85

NRCCTE: Authentic Literacy in CTE ............................ 85

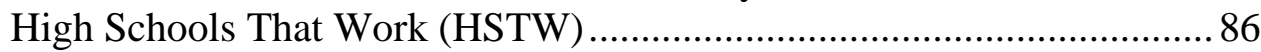

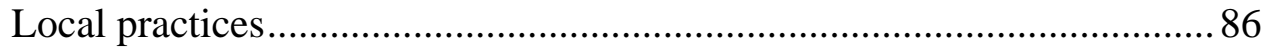

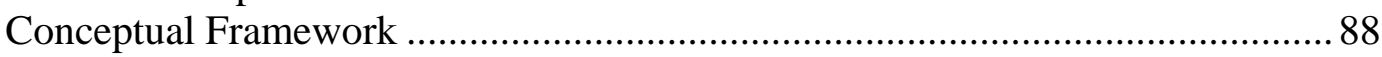

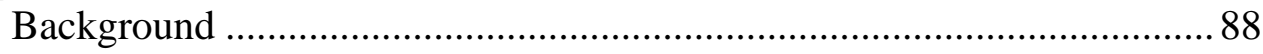

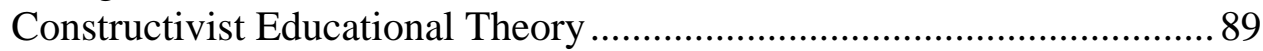

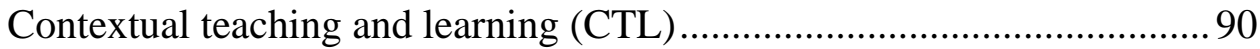

CTE/FCAT Connection Model ........................................................... 92

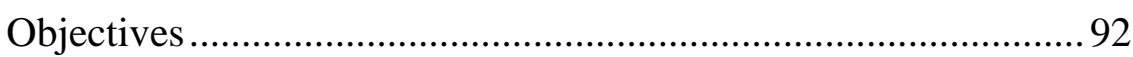

Crosswalk development .............................................. 93

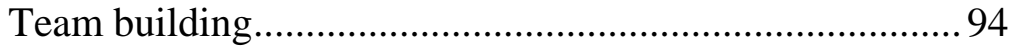

Professional development.............................................95

Integrated unit development .........................................96

Implementation........................................................ 100

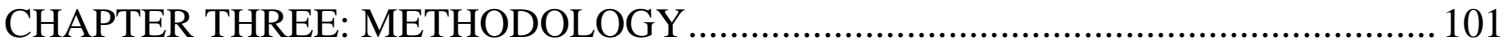

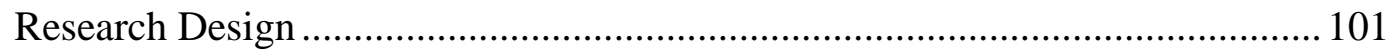




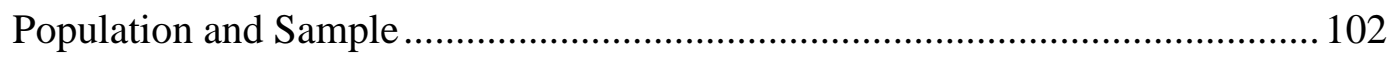

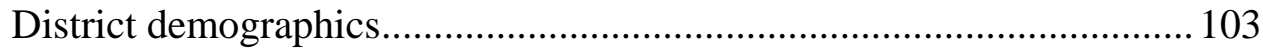

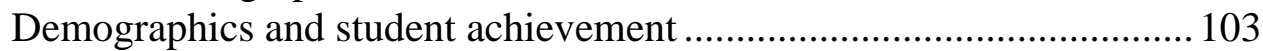

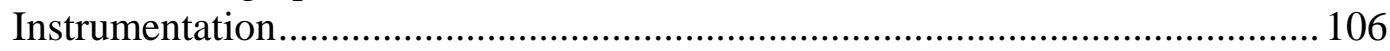

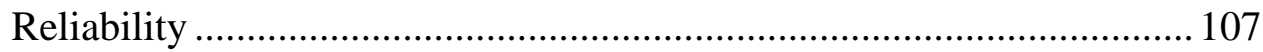

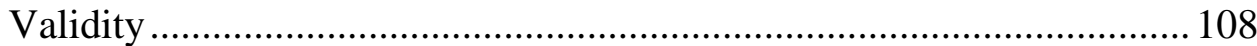

Data Collection and Analysis ............................................................................... 109

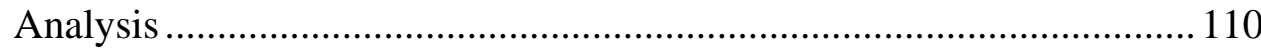

Analysis of co-variance (ANCOVA) .......................................110

ANCOVA assumptions ................................................... 111

Multiple regression...................................................................... 112

Multiple regression assumptions .....................................112

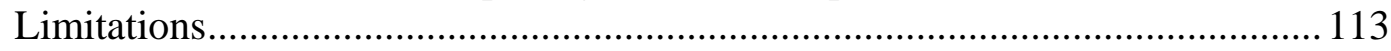

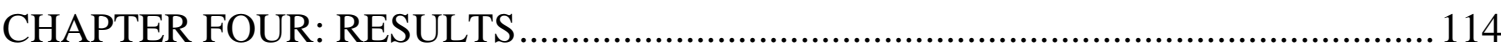

Descriptive Statistics ................................................................................114

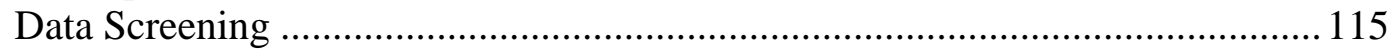

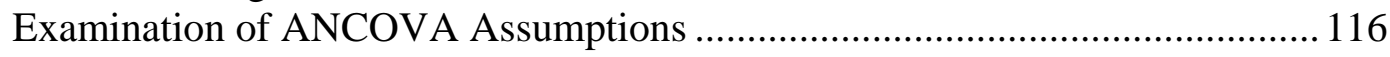

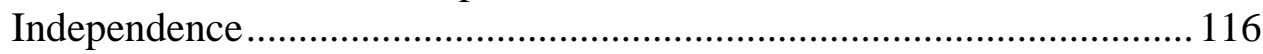

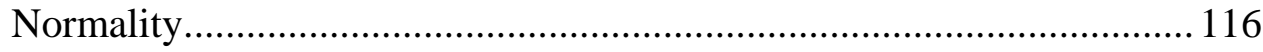

Homogeneity of variance (homoscedasticity) .........................................117

Homogeneity of regression slope .......................................................... 118

Examination of Multiple Regression Assumptions.................................................119

Multicollinearity ................................................................................. 119

Linear relationship between covariates and dependent variable ...............120

Independent errors .............................................................................. 123

Normally distributed errors ................................................................. 123

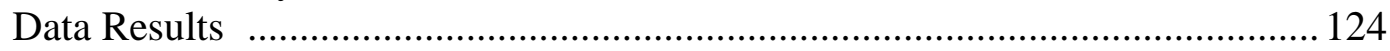

ANCOVA analysis: Reading............................................................... 124

Multiple regression analysis: Reading …………………..................... 127

ANCOVA analysis: Mathematics ......................................................... 128

Multiple regression analysis: Mathematics ............................................... 130

CHAPTER FIVE: DISCUSSION, IMPLICATIONS, AND

RECOMMENDATIONS …………………………......................................132

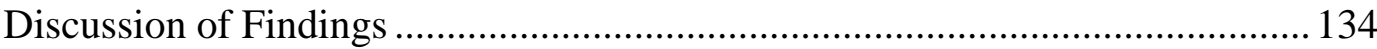

Negligible differences in mathematical achievement ...............................134

Significant differences in reading achievement ....................................... 137

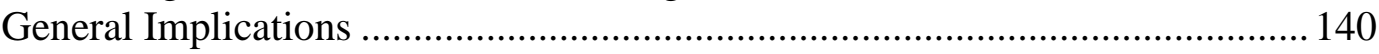

Value beyond academic achievement .................................................... 140

Curriculum and instruction implications .................................................. 141

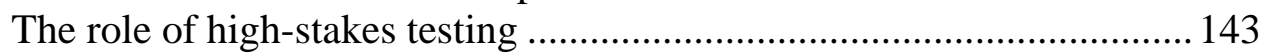

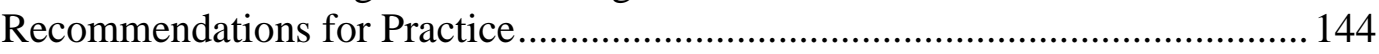

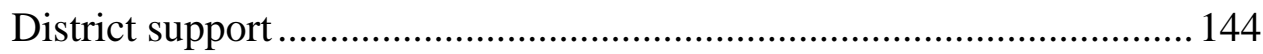

Professional development..................................................................... 144

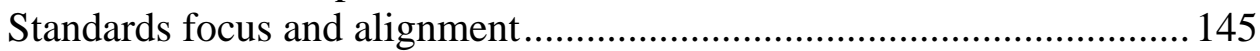


Emphasis on contextual teaching and learning ................................... 146

Recommendations for Research ................................................................... 148

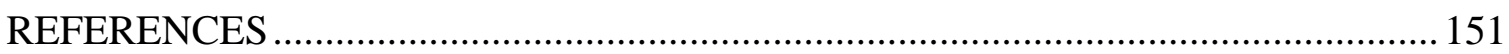

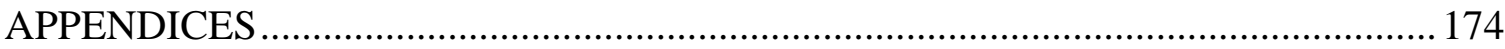

Appendix A: Course Crosswalk Reports.......................................................... 175

Appendix B: CTE Lead Teacher Agreement and Compensation

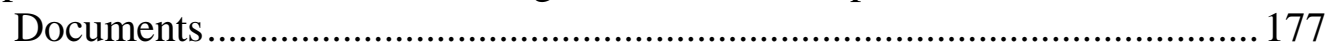

Appendix C: Project Development Worksheets ............................................. 179 


\section{LIST OF TABLES}

Table 1.1: CTE Courses By Program Area ............................................................ 12

Table 3.1: High School Students by Race Scoring At or Above Grade Level on the 2004 FCAT 105

Table 3.2: High School Demographics by Race, Gender, and Socio-Economic Status in 2004-2005

Table 3.3: FCAT Achievement Level Definitions for Reading and Mathematics.

Table 3.4: Grade 9 and 10 FCAT DSS and Scale Achievement Levels for Reading and Mathematics

Table 3.5: Cronbach's Alpha Coefficients for FCAT Mathematics and Reading Grades 9 and 10 SSS from 2003-2006 and KR-20 Coefficient for 2005-2006 108

Table 3.6: FCAT Correlations Between Mathematics and Reading SSS Test and NRT Test 109

Table 4.1: Gender Distribution Across Groups ..................................................... 115

Table 4.2: $\quad$ Ethnic Distribution Across Groups ......................................................... 115

Table 4.3: Grade Level Distribution Across Groups ............................................... 116

Table 4.4: $\quad$ Skewness and Kurtosis Statistics for Post-Test Scores ............................. 117

Table 4.5: Homogeneity of Regression Slope: Summary ANOVA Reading.............. 119

Table 4.6: Homogeneity of Regression Slope: Summary ANOVA Mathematics

Table 4.7: Reading Data: Descriptive Statistics by Covariate and Dependent Variable 125

Table 4.8: Reading Data: Descriptive Statistics by Group ....................................... 125

Table 4.9: $\quad$ Reading Data: Pearson Correlation Coefficients.................................... 126 
Table 4.10: Reading Data: ANCOVA Parameter Estimates

Table 4.11: Reading Data: Summary of Multiple Regression - Forward

Selection

Table 4.12: Mathematics Data: Simple Statistics by Covariate and Dependent Variable 128

Table 4.13: Mathematics Data: Simple Statistics by Group 129

Table 4.14: Mathematics Data: Pearson Correlation Coefficients 129

Table 4.15: Mathematics Data: ANCOVA Parameter Estimates 130

Table 4.16: Mathematics Data: Summary of Multiple Regression - Forward Selection 131 


\section{LIST OF FIGURES}

Figure 2.1: Trends in NAEP reading and mathematics average scores for 9, 13, and 17 year old students ................................................................ 23

Figure 2.2: The patterns of curriculum integration: A comparative matrix...................57

Figure 2.3: The models of curriculum integration: A comparative matrix .................... 61

Figure 2.4: The classifications of curriculum integration: A comparative matrix..........63

Figure 2.5: The continuum of curriculum integration ...........................................69

Figure 2.6: CTE/FCAT Connection graphic organizer............................................. 93

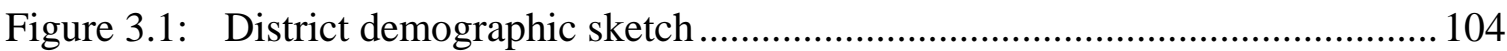

Figure 4.1: Fit diagnostics for reading and mathematics post-test scores ................... 118

Figure 4.2: Reading data scatterplot: Post-Test scores and prior achievement by group

Figure 4.3 Reading data scatterplot: Post-Test scores and prior achievement by gender for control and treatment groups

Figure 4.4 Reading data scatterplot: Post-Test scores and prior achievement by grade for control and treatment group

Figure 4.5 Mathematics data scatterplot: Post-Test scores and prior achievement by group

Figure 4.6 Mathematics data scatterplot: Post-Test scores and prior achievement by gender for control and treatment groups

Figure 4.7 Mathematics data scatterplot: Post-Test scores and prior achievement by grade for control and treatment groups

Figure 4.8 Reading data: Histogram and probability plot for post-test scores

Figure 4.9 Mathematics data: Histogram and probability plot for post-test scores 
Figure 5.1 The Framework for Learning in the $21^{\text {st }}$ Century as developed by the Partnership for $21^{\text {st }}$ Century Skills

Figure A1: Business Computer Programming 1 course crosswalk, page 1 .................... 175

Figure A2: Digital Design 1 course crosswalk, page 1................................................176

Figure B1： CTE Lead Teacher Compensation document..........................................177

Figure B2: CTE Lead Teacher Agreement document .................................................... 178

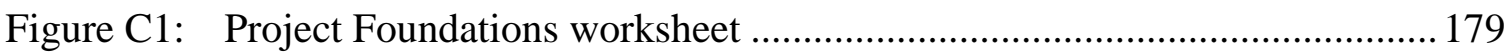

Figure C2: Project Connection worksheet.................................................................. 180

Figure C3: Math Connection worksheet........................................................................ 181

Figure C4: FCAT Math Extended Response worksheet ................................................. 182

Figure C5: FCAT Math Extended Response Rubric worksheet...................................... 183 


\begin{abstract}
A quasi experimental study tested a contextual teaching and learning (CTL) model for integrating reading and mathematics competencies through 13 introductory Career and Technical Education (CTE) courses. Volunteer CTE Lead Teachers with assistance from academic teachers, developed integrated units. The purpose of this study was to determine whether students who participated in CTE courses that integrated core mathematics and reading standards performed better on a test of mathematics and reading skills compared to students who participated in traditional, non-integrated courses. The treatment group consisted of students in the 13 introductory courses taught by the CTE Lead Teachers and the control group consisted of students in all other sections of the 13 introductory courses not taught by CTE Lead Teachers. After a 26 week intervention, $9^{\text {th }}$ and $10^{\text {th }}$ grade student Florida Comprehensive Assessment Test (FCAT) reading and mathematics scores were analyzed to determine if the mean change in post-test scores was greater in the treatment group than the mean change in scores in the control group. An ANCOVA and multiple regression analysis of quantitative data revealed that the integrated CTE courses were statistically significant in improving reading treatment group scores, but not statistically significant in improving mathematics treatment group scores. The study is significant because it seeks to address a gap in the literature on academic and CTE integration and to provide evidence that a partnership between academics and CTE can contribute to student achievement as measured by state assessments.
\end{abstract}




\section{CHAPER ONE: INTRODUCTION}

Despite the call in the early 1980’s for enhanced educational rigor, and subsequent reform movement in the 1990s, U.S. secondary student mathematics and reading performance has remained almost flat for the last three decades (Rampey \& Donahue, 2009). In the face of 30 years of increased academic course requirements and accountability measures, this lackluster performance indicates that American students’ basic skills have not improved over time (Ravitch, 2008). Furthermore, research indicates that the academic performance of occupational concentrators, or vocational education students, falls well below that of non-occupational concentrators (Silverberg, Warner, Fong, \& Goodwin, 2004). Moreover, since the inception of No Child Left Behind (NCLB) legislation, this uninspiring trend in student performance has continued, with gains occurring mostly at the elementary level and steady, gradual declines occurring during the middle and high school years (Center on Education Policy, 2007; McMurrer \& Kober, 2011). Even more alarming is the widening gap between U.S. student performance in mathematics, science, literacy, and problem-solving, and that of international students (Beaton et al., 1999; Fleischman, Hopstock, Pelczar, \& Shelley, 2010; Gonzales et al., 2004; Gonzales et al., 2008; Lemke et al., 2004; Mullis et al., 2000).

In response to the demands for increased academic rigor, the mathematics community developed national standards designed to guide reform efforts in restructuring the content, teaching, and assessment of mathematics education to reflect 
mathematical understanding through various interrelated experiences (National Council of Teachers of Mathematics, 2000). Similarly, language and literacy educators advocated a set of teaching methodologies known collectively as whole language in which reading, listening, speaking, and writing were linked in meaningful contexts and for relevant purposes (McKenna, Robinson, \& Miller, 1990). During this time, vocational education also began to update programs to meet $21^{\text {st }}$ century workforce needs and to include integrative language in new legislation (Carl D. Perkins Act, 1990; Carl Perkins Act, 1998). As a result, a revitalized vocational education, coined career and technical education (CTE), began to develop more rigorous programs that fostered integration between academics and CTE.

As policymakers met to reauthorize the federal Elementary and Secondary Education Act in 2001, the need to strengthen the accountability provisions of the law was paramount in its reauthorization. The subsequent NCLB act required states to set achievement goals for all groups of students; to use high-stakes assessments as the measure of student success; and to hold schools and systems accountable for student progress toward meeting those goals (Weiner \& Hall, 2004). As such, student achievement on high-stakes tests has become a national, state, and local priority. NCLB tests the Adequate Yearly Progress (AYP) of schools and requires that all students have the opportunity to meet academic achievement benchmarks (Florida Department of Education Bureau of Public School Options, 2006; U.S. Department of Education, 2005). The Florida A++ Plan/House Bill 7087 also grades schools from A to F based on the scores of students taking the Florida Comprehensive Assessment Test (FCAT). The academic benchmarks for the FCAT are the Sunshine State Standards (SSS) and include 
standards in language arts, mathematics, and science (Florida Department of Education, 2006; Florida Department of Education, 2005). With accountability playing the starring role, student success on high-stakes tests has become a critical outcome of teaching and learning in secondary education.

Unfortunately, merely increasing academic course taking; implementing accountability measures based on high-stakes standardized test scores; and eliminating interest-based electives may not be the cure for ailing secondary student performance. An educational environment that compartmentalizes and segments learning, emphasizing an academic/college preparatory education for some and workforce education for others, is outdated in our technology-driven, knowledge society (Castellano, Stringfield, \& Stone, 2003; Cutshall, 2003; Rojewski, 2002; Silverberg et al., 2004). Today, all secondary students must learn to apply knowledge and skills to unpredictable, real-world problems and situations; master high literacy (reading and writing), mathematics and science skills; have a deep understanding of factual knowledge; draw from interpersonal and social skills; and develop cognitive processes to solve problems (Doolittle \& Camp, 1999).

An effective combination of academics and CTE, or curriculum integration, can address the common goal of preparing high school students to work and learn as career interests combined with rigorous and relevant coursework have a "significant positive relationship on student achievement, in that higher expectations lead to higher educational and occupational attainment” (Akos, Lambie, Milsom, \& Gilbert, 2007). Curriculum integration, then, is an educational strategy that unifies historically disconnected subjects, and views learning through a multiple perspective lens, one that 
encourages inquiry in a contextual manner. Additionally, curriculum integration incorporates the common learnings, as well as the social and life skills that help students build connections and understanding among topics. For example, a science teacher and a family and consumer sciences teacher collaborate on a culinary safety and sanitation unit or a mathematics teacher and a computer programming teacher design a game simulation unit. Integration, then, requires that the curriculum move beyond prescribed content to content determined by student interest for the fusion of education and occupations (Beane, 1995; Grubb, 1995a).

Curriculum integration resurfaced post-A Nation at Risk as a strategy to meet the uncertainty in the future workforce and to improve student engagement and learning (Stasz, Kaganoff, \& Eden, 1994). However, these efforts also reignited an age-old academic vs. vocational debate, resulting in a flurry of literature and research on curriculum integration, written from multiple perspectives. Curriculum integration, as a strategy for teaching and learning, became mired in pedagogical conflict and diluted by a myriad of meanings that ultimately led to its ambiguity (Case, 1991). Consequently, early CTE integrated practices within secondary schools lacked definitive parameters, failed to provide clear guidelines, and could not be measured in terms of effectiveness (Stasz et al., 1994). And, although academic reform efforts were integrative in nature, they were also discipline-bound, emphasizing connections between related academic subjects rather than between academics and CTE. Moreover, national performancebooster academic programs were written in a one-size-fits-all context, thus ignoring the significance that regional, local, demographic, social, cultural, and career factors have on student engagement and learning. To that end, research indicates most nationally 
developed programs have either limited to no success in improving student performance or have no empirical research to substantiate their effectiveness (Slavin, Cheung, Groff, \& Lake, 2008; Slavin, Lake, \& Groff, 2008). In general, little research exists on the effectiveness of locally-developed, integrated curriculum that embeds academic skills into CTE courses.

\section{Historical Background}

For most of the 1800s, academic and vocational education were synonymous, with schools providing students with a common curriculum deemed suitable for any future (Beane, 1997; Etim, 2005; Grubb, 1995a). In the late 1800’s, as a result of the manual training movement, the first occupational content was introduced into common school learning. The goal of occupational content in the common school curricula was to broaden the educational experience for students, rather than to develop job-specific skills. Although the manual training movement maintained the common school philosophy, ultimately, it pioneered a separation between academic and vocational disciplines that shaped the face of secondary education for over 100 years (Grubb, 1995a). The stage was set by the Smith-Hughes Act of 1917, which mandated the creation of separate vocational schools to meet changing labor force requirements due to a shift from an agrarian to a local-industrialized economy (Alt, \& Librera, 2000; Grubb, 1995a; Levesque, Lauen, Teitelbaum, Alt, \& Librera, 2000; Lynch, 2000). Separate vocational schools, then, abandoned the common school learning in favor of job specific skill training; thereby narrowing the scope of vocational education (Grubb, 1995a). This resulted in a comprehensive, discipline-based curriculum for the college-bound student and narrow, job-specific training for the student entering the workforce. In the ensuing 
$40+$ years, vocational education remained relatively unchanged providing training in job-specific skills (Levesque, et al., 2000; Lynch, 2000; Hayward \& Benson, 1993; Wonacott, 2003). Subsequent vocational legislation through the 1970's promoted some changes, but did not alter its fundamental focus or curricular structure (Wonacott, 2003). As such, the separation between academic and vocational education remained amidst diverse philosophical, educational, and funding goals (Bragg, 1999; Castellano, et al., 2003).

Then, in the early 1980's, beginning with a report entitled A Nation at Risk (National Commission on Excellence in Education, 1983), public education came under siege for its lack of academic rigor and mediocre status compared to education in other countries, thus concentrating national attention on the need for whole school reform. The call for drastic reform was fueled by economic concerns that U.S. global competitiveness was contingent on the quality of public education. Concurrently, American business indicated a shortage of basic skills in the workforce, calling for integrated education and training in broad occupational skill competencies (Finch, 1999; Grubb, 1995a; Lee \& Ready, 2009; Hayward \& Benson, 1993). This prompted radical reforms in the 1990's in both academic and vocational education. While academic reform sought to make education more rigorous and contextually relevant for students (National Council of Teachers of Mathematics, 1989; Conference Board of the Mathematical Sciences, 1983; Council on Advancing Adolescent Literacy, 2009), vocational education sought to enhance the academic rigor to better prepare students for further education and/or work (Finch, 1999; Gordon, 2006; Lynch, 2000; Threeton, 2007). 
Vocational education reform movement. The vocational education reform movement was propelled in the 1990s by a U.S. Department of Labor report entitled, The Secretary's Commission on Achieving Necessary Skills (SCANS), which identified what students need to know to be successful in the workplace (Secretary's Commission on Achieving Necessary Skills, 1991). According to SCANS (1991) the high performance workplace necessitated a solid foundation in basic knowledge skills, thinking skills, and personal qualities such as responsibility, self-management, and integrity. The SCANS report represented the first time employers were able to clearly communicate that the technological workforce required a combination of basic academic skills fused with occupational skills (SCANS). Vocational reform legislation in the 1990s (Carl D. Perkins Act, 1990; Tech Prep Education Act, 1990; School-to-Work Opportunities Act, 1994; and Carl D. Perkins Act, 1998) included, for the first time, language supporting the development and integration of academic and job-related skills for all students (Lynch, 2000). The focus of the Perkins II Act (1990) and other subsequent vocational legislation was to build workforce preparation through updated, rigorous programs that included the integration of academic and vocational education; partnerships between education and American business; and connections between school and work. The common denominator in the programs emerging from vocational legislation was a focus on the integration of academic and vocational education through approaches such as applied academics, project-based learning, capstone projects, and work-related experiences. New program designs also came about at this time, such as career academies, career magnets, and career pathways. High Schools That Work, for example, was a school consortium initiative that focused on the integration of 
mathematics, reading, science, and technology instruction into vocational education (Finch, 1999; Gordon, 2006; Lynch, 2000; Castellano, et al., 2003). This movement led to a shift from vocational education to career and technical education reflecting the new emphasis in the field (Grubb 1995a; Grubb, 1997; Lynch, 2000; Wonacott, 2003).

Academic education reform movement. In academic education, the reform movement called for a shift from knowledge reproduction to knowledge production emphasizing doing and understanding in contextual situations (National Council of Teachers of Mathematics, 1989; Conference Board of the Mathematical Sciences, 1983; Council On Advancing Adolescent Literacy, 2009). In mathematics, the influential reports, Everybody Counts: A Report to the Nation on the Future of Mathematics Education (National Research Council, 1989) and Curriculum and Evaluation Standards for School Mathematics (National Council of Teachers of Mathematics, 1989) stressed the importance of mathematical literacy, life-long learning, and informed citizenry in a technological world. Reform in mathematics, then, called for enhanced skills in reasoning and problem-solving; communication; and understanding of mathematical relationships. This movement led to the development of curriculum and evaluation standards for school mathematics in 1989. Similarly, in reading, the back-to-basics approach was crystallized by the Commission on Reading in its influential report, Becoming a Nation of Readers (Anderson, Hiebert, Scott \& Wilkerson, 1985), which emphasized reading as a holistic, whole-language process. That is, reading and writing were woven into the content of all core classes for students to be prepared for higher education, employment, and citizenship (Council on Advancing Adolescent Literacy, 2009). The whole language movement, then, emphasized learning through real-life 
experiences in reading and writing for student construction of knowledge (Roberts \& Kellough, 1996).

\section{Statement of the Problem}

In spite of efforts to update and enrich its programs for the enhancement of academic learning, CTE was still viewed by many as detached from core academics and suitable for only non-college bound students, potential dropouts, and other students with special needs. That is, CTE was seen as necessary for instructing students in low skilled employment, but not necessary for teaching the academic and technological skills necessary for a global workforce (Cutshall, 2003). However, the workforce of the $21^{\text {st }}$ century required new entrants to have both basic skill competency and specific/applied skill training to quickly adapt to change and solve complex, societal problems in an uncertain knowledge economy (Christensen, 2008).

This problem was exacerbated in an era of high-stakes accountability that emphasized increased high school academic requirements and coursework, thus, resulting in the reduction of CTE and other elective credit completions (Austin \& Mahlman, 2002; Levesque, et al., 2000). Accordingly, in this rewards/punishment milieu, educational leaders vehemently protected and supported academic curricula (mathematics, language arts, and science) that actively achieved state and federal accountability benchmarks. Core courses, then, with direct links to high-stakes testing were more likely to be funded, whereas elective programs with indirect ties were marginalized or eliminated. Moreover, many states adopted teach-to-the-test strategies as a form of curricular control to meet yearly NCLB and state reform progress targets, that allowed schools to emphasize tested content and de-emphasize non-tested content 
(Au, 2007). One such strategy, academic remedial education, required students scoring below grade level to add academic courses in lieu of interest-based courses such as agriculture, business, or the arts (Jennings \& Rentner, 2006). In this back-to-basics milieu districts and schools hesitated to commit the resources (i.e. time, funding, scheduling, and training) necessary to develop integrative efforts. This, in turn, hindered the sustainability of such efforts between CTE and academic subjects (Venville, Wallace, Rennie, \& Malone, 2002).

Moreover, despite the call for integrated curriculum, the ambiguous use of the term made clarifying the nature of integration almost impossible (Czerniak, Weber, Sandmann, \& Ahern, 1999). This confusion was due, in part, because program parameters lacked clarity; approaches to and degrees of integration varied; and purposes for adopting integrative models were diverse (Stasz et al., 1994). The unfocused definition of integration also inhibited the development of a research base for designing, carrying out, and analyzing integrative efforts. In addition, most early curriculum integration studies were qualitative in nature with an emphasis the psychological and holistic aspects of integration, resulting in little empirical research to substantiate the impact of integration on student achievement as measured by high-stakes testing (Castellano, et al, 2003; Czerniak et al., 1999; Mason, 1996; Roehler, Fear, \& Herrman, 1998). In addition, virtually no research exists on student achievement as a result of locally-developed curriculum integrating mathematics and reading content into CTE courses. 


\section{Statement of Purpose and Research Questions}

Little data existed on how the integration of academic and CTE learning experiences might impact student performance on high-stakes tests. Thus, the purpose of this study was to determine whether students who participated in CTE courses that integrated core mathematics and reading standards performed better on a test of mathematics and reading skills compared to students who participated in traditional, non-integrated courses. To meet the proposed purpose, the following research questions drove the study:

1. Did CTE coursework that integrated core reading standards improve student achievement as measured by the FCAT performance of $9^{\text {th }}$ and $10^{\text {th }}$ grade CTE students compared to $9^{\text {th }}$ and $10^{\text {th }}$ grade students in non-integrated coursework?

2. Did CTE coursework that integrated core mathematics standards improve student achievement as measured by the FCAT performance of $9^{\text {th }}$ and $10^{\text {th }}$ grade CTE students compared to $9^{\text {th }}$ and $10^{\text {th }}$ grade students in non-integrated coursework? The set of CTE integrated units were part of a district-wide curriculum integration initiative between academic and CTE teachers. Each course featured lessons integrating mathematics and reading standards in CTE context. Thirteen introductory courses in multiple CTE program areas provided the basis for data collection in the study (see Table 1).

\section{Conceptual Framework}

The integrated units featured in this study were rooted in constructivist educational theory and contextual teaching and learning (CTL) strategies, which served as the conceptual framework. This framework was grounded in the idea that rigorous 
Table 1.1

CTE Courses by Program Area

\begin{tabular}{lll}
\hline PROGRAM & COURSE & COURSE \# \\
\hline Agriculture & Agriculture Foundations 1 & 8106810 \\
Business & Business Systems \& Technology & 8209020 \\
& Business Computer Programming 1 & 8206010 \\
& Digital Design 1 & 8209510 \\
Diversified & Diversified Career Technology Principles & 8303010 \\
Family/Consumer & Culinary Operations 1 & 8515210 \\
& Early Childhood Education 1 & 8503211 \\
Health Science & Health Science 1 & 8417100 \\
Industrial/Technology & Drafting/Illustrative Design Technology 1 & 8600810 \\
& +Construction Technology & 8600710 \\
& +Building Construction Technology 1 & 8720310 \\
Marketing & $*$ Marketing Essentials & 8827110 \\
& $*$ Fashion Essentials & 8806010 \\
\hline
\end{tabular}

+Projects written for use in both courses $\quad$ *Projects written for use in both courses.

mathematics and reading standards integrated into relevant CTE courses were more

likely to result in higher performance on a standardized measure of achievement as compared to non-integrated courses. Grounded in the work of Dewey, Piaget, and Vygotsky, constructivist pedagogy is a theory of knowledge that focuses on cognitive development and deep understanding. Constructivism contends that the creation of meaning is an active, emergent process developed through interactions and experiences with the social environment (von Glasersfeld, 2005; Fosnot \& Perry, 2005; Richardson, 2003; Brown, 1998). Building on constructivist principles, CTL is a constructivist teaching and learning strategy that unites concept and practice, thereby fostering deep understanding for the retention of knowledge and skills. CTL enables teachers to connect subject matter content to real world situations and allows students to find meaning in the learning process. CTL practices can transcend disciplines so that students connect learning to life, solve problems, and think critically. As a constructivist 
pedagogy utilizing CTL strategies, the CTE/FCAT Connection intervention incorporated academic standards into CTE courses for integrated learning (Berns \& Erickson, 2001; Markham, Larmer, \& Ravitz, 2003).

\section{Significance of the Study}

CTE in the $21^{\text {st }}$ century is firmly rooted in the integration of academic and occupational skills, as well as technological attainment for the future workforce. However, an enduring negative stereotype of vocational education; an emphasis on back-to-basics and accountability; and an empirical research void, have left the future of CTE as a partner in school reform in a dubious position (Bloyd, 2006). The study is significant because it sought to address a gap in the literature on academic and CTE integration which may help slow the phasing out of CTE programs courses. In addition, it may provide evidence that a partnership between academics and CTE can contribute to student achievement as measured by state assessments, as well as prepare students for the advanced technological and knowledge-based workplace.

\section{Definitions and Key Terms}

Accountability - measurable proof that teachers, schools, districts, and states are teaching students a common core of knowledge and skills; accountability is measured by student standardized tests and schools are judged on their results (McBrien \& Brandt, 1997).

Back-To-Basics Movement - an essentialist reform movement emphasizing competency-based teaching and learning in the common core (language arts, mathematics, science, and social studies). 
Behaviorist Teaching and Learning Theory - an essentialist theory of teaching and learning that measures observable behaviors produced by a learner's response to stimuli. Behaviorism has roots in Essentialist educational philosophy and assumes that learners are passive and that behaviors are determined by external forces in the environment. Teaching in a behaviorist learning environment is competency-based, focusing on behaviors and skills as the goal of learning.

Brain-Based Learning - approaches to schooling that rely on brain research to support and develop improved teaching strategies; contextual teaching and learning strategies help the brain make connections for retention of knowledge (McBrien \& Brandt, 1997).

Career and Technical Education (CTE) - a planned, job preparatory program of courses that culminate in workforce direct entry, certification, licensure, and/or postsecondary education.

Cognitive Learning Theory - refers to theory that stimuli enter a learner’s memory; are selected and organized for storage; and retrieved from memory that contain facts, meanings/definitions, procedures, parts to whole structure, criteria for evaluation, and ways of creating.

Cognitivism - a theory that holds that learning involves the construction or reshaping of mental schemata to form a learner's schema (see also constructivism).

Competency-Based Education - refers to students performing the competencies called for by stated objectives (also known as education that is performance-based, results-driven, and outcome-based). 
Competency-Based Training (CBET) - a behaviorist teaching practice that groups skills required for an occupation and standardizes them to performance on the job; results are measurable.

Construct Educational Theory - a progressivist philosophy that suggests knowledge is constructed by the learner in an emergent, self-regulatory process tied to both cultural and social perspectives. Teaching in a constructivist learning environment focuses on cognitive development and deep understanding, and is contextual in nature.

Contextual Teaching and Learning (CTL) - a constructivist practice of teaching and learning that relates subject matter content to real world situations (authentic learning) in an interdisciplinary; problem, project, cooperative, service learning, or work-based environment. CTL uses students’ past knowledge and experiences (internal contexts) and conducts activities in school, home, community, workplace, and Internet (external contexts).

Cooperative learning - an approach that organizes instruction using small learning groups in which students work together to achieve learning goals.

Curriculum - indicates that which is planned and encouraged for teaching and learning; may refer to all the courses offered at a given school, or all the courses offered at a school in a particular area of study (McBrien \& Brandt, 1997).

Essentialist Educational Philosophy - a conservative educational philosophy that supports a common core of knowledge with an emphasis on intellectual and moral standards delivered to students in a systematic, disciplined way. The 
foundation of the curriculum is fundamental knowledge/skills and academic rigor. Behaviorism is an essentialist learning theory.

Florida Comprehensive Assessment Test (FCAT) - the standardized test used in the primary and secondary public schools of Florida to test language arts, mathematics, and science knowledge.

High-Stakes Testing - refers to the tests being used at various grade levels to determine student achievement, promotion, and rewards to schools and even to individual teachers and students.

Holistic Learning - a theory of education that places importance on the complete experience of learning and the ways in which the separate parts of the learning experience are interrelated (McBrien \& Brandt, 1997).

Integrated Curriculum - a holistic curriculum that transcends the discipline and is organized around real problems and issues that are of personal and social significance to students; curricular content is determined by the students; integrated curriculum is a component of CTL.

Interdisciplinary Curriculum - an organization of the curriculum in which content is drawn from several subject areas to focus on a particular topic or theme; combines subject matter to enhance learning in two or more of the disciplines, but keeps the disciplines distinct and in focus; curricular content is determined by the teacher; interdisciplinary curriculum is a component of CTL (McBrien \& Brandt, 1997); also called multidisciplinary, transdisciplinary, multi-subject, and cross-disciplinary. 
Interdisciplinary Thematic Unit (ITU) - a study with a basic theme that crosses the boundaries of two or more disciplines (also called integrated thematic instruction, thematic instruction, and thematic unit).

Problem-based learning - an approach that engages learners in problem-solving investigations that integrate skills and concepts from many content areas. This approach includes gathering information around a question, synthesizing it, and presenting findings to others.

Progressivist Educational Philosophy - A holistic educational philosophy that suggests students create meaning through individual, active experiences in the physical and cultural context. Constructivism is a progressivist learning theory.

Project-Based Learning (PBL) - A CTL model that organizes learning around the use of authentic projects based on challenging questions or problems.

Service learning - an approach that provides a practical application of newly acquired (or developing) knowledge and skills to needs in the community through projects and activities.

Standards-Based Education - a process of teaching, learning, and assessment that focuses on national, state, and local educational benchmarks; standards are statements of what students are expected to know and be able to do at specified grade levels.

Sunshine State Standards (SSS) - Florida’s benchmarks for student grade level standards. 
Whole-Language Learning - a point of view that focuses on meaning production, risktaking in learning, independence in producing language, and the use of a variety of print materials in reading, writing, and other communication situation.

Work-based learning - an approach in which workplace, or workplace-like, activities are integrated with classroom content for the benefit of students and often businesses.

\section{Assumptions}

A major assumption of the CTE/FCAT Connection study was that the academic and CTE teachers supported curriculum integration. In addition, it was assumed that the CTE Lead Teachers taught the CTE/FCAT Connection intervention during the time specified and for the full 26 weeks as verified by an online teaching timeline and weekly class visitations.

\section{Limitations}

The scope of the CTE/FCAT Connection study was limited to 13 introductory CTE courses (see Table 1.1) and 19 CTE Lead Teachers. Furthermore, the integrated units infused only mathematics and reading competencies, which at the time of the study, were the only standards tested on the FCAT. Another limitation was that the level of integration between CTE and academic courses represented the low end of the integration continuum. 


\section{CHAPTER 2: LITERATURE REVIEW}

The purpose of this study was to determine whether students who participated in CTE courses that integrated core mathematics and reading standards performed better on a test of mathematics and reading skills compared to students who participated in traditional, non-integrated CTE courses. The review of literature commences with a discussion on student achievement in the three decades since A Nation at Risk and an appraisal of curriculum integration as a reform strategy. This introduction sets the stage for a deconstruction of the basics of curriculum integration including its meaning, characteristics, and components, as well as the implications for practice. The review of literature concludes with an examination of the promising practices of curriculum integration and a conceptual framework for the study.

\section{Student Achievement: A Road Still under Construction?}

The report entitled A Nation at Risk and the ensuing No Child Left Behind (NCLB) legislation set in motion a movement intended to increase the accountability of schools through high-stakes testing of student academic performance; to increase the achievement levels of all students; and to decrease the achievement gap between low and high performing students and between socio-economic groups (Fletcher, 2006). At the core of the NCLB movement was the back-to-basics pedagogy, requiring states to determine core academic standards, and holding schools liable for student progress through standardized testing of language arts, reading, and mathematics standards. 
The foundation of the back-to-basics teaching and learning movement was an emphasis on language arts, mathematics, social studies, and science; discipline and subject-bound contexts; teacher-centered instruction using lecture, drill, memorization; a traditional system of letter grading and testing; grade promotion and graduation based on high-stakes test scores; a reduction in the number of 'fluff' courses and social services (i.e. driver education, guidance services, physical education, drug education); the elimination of electives; and an increase the number of required courses (Brodinsky, 1977). The question is, what has been the impact of this movement on student academic achievement? What follows depicts a road still under construction to increased student achievement as evidenced by national and international trends on student achievement.

Academic achievement. The Center on Education Policy (2007) conducted a study to determine whether recent NCLB legislation had success in boosting student achievement in more recent years. "Of the 22 states with percentage proficient and effect size data, five made moderate gains in reading and mathematics across all grade spans and more states showed declines in reading and mathematics achievement at the high school level than elementary or middle school level" (Center on Education Policy, 2007). State-by-state achievement trends in this study reveal that high school students in Florida posted moderate-to-large declines in student reading achievement and only moderate gains in student mathematics achievement. Furthermore, the study indicates that most achievement gains for students in Florida occurred at the elementary level, with gradual declines during the middle and high school years. Another Center on Education Policy report (McMurrer \& Kober, 2011) examined state test data through 2009. The results mirror earlier findings in that high school scores on state language arts 
and mathematics tests rose in most states, but in smaller proportions when compared to $4^{\text {th }}$ and $8^{\text {th }}$ grades. State testing data also shows a lack of progress and widening gaps between various groups of high school students at the advanced level; however, Florida was one of 21 states with gains at the advanced level in language arts and one of 24 states with gains at the advanced level in mathematics (McMurrer \& Kober, 2001). An estimated 48\% of public schools nationally did not make AYP in 2011, an increase of 39\% from 2010 and the largest percentage since the inception of NCLB. The estimated percentage of schools by state that did not make AYP varied greatly from $11 \%$ in Wisconsin to 89\% in Florida (Usher, 2011).

National Assessment of Educational Progress (NAEP) reports largely confirmed these trends on academic achievement. The National Center for Educational Statistics (NCES) has monitored academic progress by way of a congressionally mandated NAEP project. Through a series of trend assessments, NAEP has examined advancement towards higher reading, mathematics, and science standards for over three decades (Campbell, Hombo, \& Mazzeo, 2000). For example, on reading, only the lowest performing 17 year old students showed any gains from 1971 to 199l. The middle and upper performing students had average scores in 1999 that reflected similar scores in 1971. Only marginal, statistically insignificant gains occurred in $12^{\text {th }}$ grade reading over the 28 year period (Campbell, et al., 2000). The 2005 NCES study observed reading assessment trends between 1992 and 2004 and placed average reading scores for high school seniors at 286 on a $0-500$ scale. In $2004,12^{\text {th }}$ graders scored lower in reading than in 1992, but scores were not appreciably different from scores in 2002. Excluding the students performing at the $90^{\text {th }}$ percentile, reading score declines were seen across 
most of the performance distribution in 2004 as compared to 1992. NAEP achievement levels (basic, proficient, and advanced) identified what students should know and be able to do at each grade. For reading, the percentage of students performing at or above basic decreased from $80 \%$ in 1992 to $73 \%$ in 2004, and the percentage of students performing at or above the proficient level decreased from 40\% to 35\% (Grigg, Donahue, \& Dion, 2007). Although, the average reading score for 17 year old students did increase from the 2004 NAEP (283) to the 2008 NAEP (286), the average reading score for 17 year olds was not significantly different from that in 1971 (Rampey \& Donahue, 2009).

Regarding mathematics performance, between 1973 and 1982, the average score for $12^{\text {th }}$ graders declined on the NAEP mathematics assessment; yet, since that time and until 1999, a gradual, ten point gain has occurred. Thus, the mathematics scores of 17 year olds were slightly higher in 1999 than in 1973 (Grigg et al., 2007). The NCES 2004 mathematics assessment was based on a new framework and results could not be directly compared to previous years. For the 2004 NAEP $12^{\text {th }}$ grade mathematics assessment, a 0-300 scale was set with an average score of 150. Student mathematics performance scores ranged from 105 at the $10^{\text {th }}$ percentile to 194 at the $90^{\text {th }}$ percentile. Twenty-three percent of 17 year old students performed at or above proficient on the mathematics assessment, whereas 39\% performed below basic (Grigg et al., 2007). The average mathematics score for $12^{\text {th }}$ graders did not change from the 2004 NAEP to 2008 NAEP, nor was the average score significantly different from that in 1973 (Rampey \& Donahue, 2009) (see Figure 2.1). 


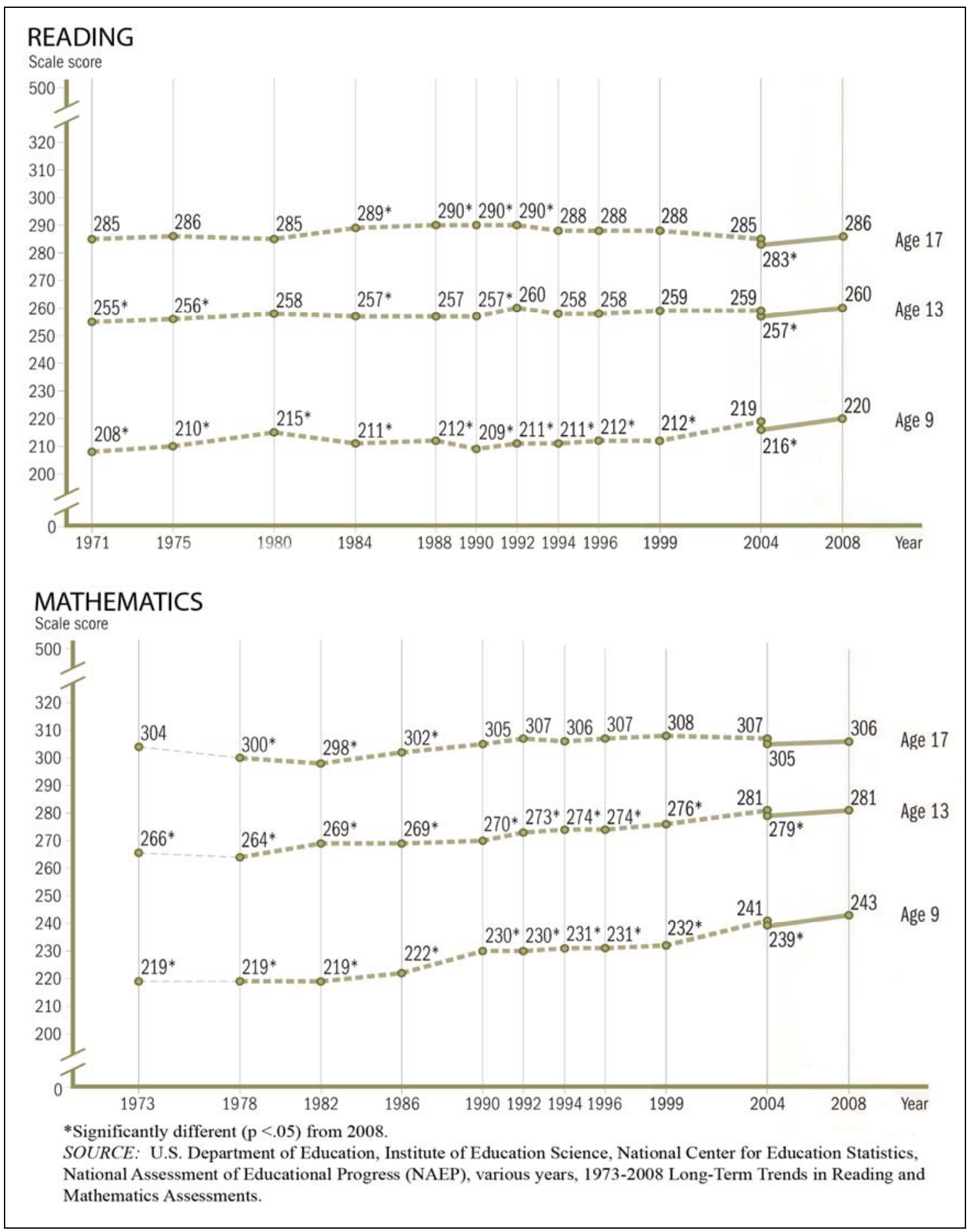

Figure 2.1: Trend in NAEP reading and mathematics average scores for 9, 13, and 17 year old students.

International achievement. Over the past 15 years, major international studies have assessed student performance in nearly 50 counties. International comparisons 
allow for the monitoring of U.S. educational progress on a global scale, and help academics and educators identify important educational issues. Two pertinent international studies were reviewed: Trends in International Mathematics and Science Study (TIMSS) and the Program for International Student Assessment (PISA). Sponsored by the International Association for the Evaluation of Educational Achievement (IEA), the TIMSS project generated data in 1995, 1999, 2003, and 2007 on the mathematics and science achievement of U.S. $8^{\text {th }}$ grade students compared to that of students in other countries. When ranked internationally in the 1999 TIMSS, U.S. students, including advanced students, were some of the lowest performers in mathematics (502), falling below the international average (521). However, U.S. mathematics performance did show improvement over a 12 year period between 1995 (492) and 2007 (508). No measurable change occurred in average U.S. mathematics performance between 1999 and 2007; thus, indicating that the increase in performance occurred between 1995 and 1999. As indicated by performance on the 2007 TIMSS, U.S. students continued to fall behind the high-scoring students of Hong Kong, Singapore, Japan, and Chinese Taipei. Moreover, only 6\% of U.S. students reached the TIMSS advanced level, compared to Chinese Taipei (45\%), Korea (40\%), Singapore (40\%), Hong Kong (31\%), Japan (26\%), and Hungary (10\%) (Beaton et al, 1999; Gonzales et al., 2004; Gonzales et al., 2008; Mullis et al., 2000).

The PISA study has largely confirmed international trends emerging out of TIMSS data. The PISA project, a system of international testing that focuses on the capabilities of 15 year old students in reading, mathematics, and science literacy, is conducted every three years. Among the 26 Organization for Economic Cooperation 
and Development (OECD) countries that have participated since 2000, the 2009 PISA scores indicated that the U.S. still ranked low overall; however, performance has increased since the 2006 PISA. The primary focus for the 2009 PISA, reading literacy, was defined as follows:

"Reading literacy is understanding, using, reflecting on and engaging with written texts, in order to achieve one's goals, to develop one's knowledge and potential, and to participate in society" (Fleischman, et al., 2010, p. 7).

Combined reading literacy scale results on the 2009 PISA indicated that the reading scores of U.S. 15 year old students have dropped since 2000 (i.e. the last time reading was the primary assessment domain). That is, the U.S ranked $12^{\text {th }}$ in reading literacy overall and $8^{\text {th }}$ in the reading achievement of the highest performing students. In addition, the 2009 PISA evaluated three reading literacy subscales: Accessing/retrieving information; integrating/interpreting; and reflecting/evaluating. Results for the reflecting/evaluating subscale revealed that the U.S. had a higher average score than the OECD average (512 versus 494), whereas on the other two subscales, the U.S. average was not measurably different from the OECD average. In summary, between 2000 and 2009, no measurable difference existed between the average score of U.S. students in reading literacy $(2000=504 ; 2003=495 ; 2009=500)$ (Fleischman et al., 2010).

Mathematics literacy and problem-solving were the primary focus of the 2003

PISA. Mathematics literacy was defined as follows:

"an individual's capacity to identify and understand the role that mathematics plays in the world, to make well-founded judgments and to use and engage with mathematics in ways that meet the needs of that individual's life as a constructive, concerned and reflective citizen" (Lemke et al., 2004, p. 5). 
The average mathematics literacy and problem-solving scores for the U.S. in 2003 were lower than the average for the OECD countries. That is, "U.S. students were less mathematically literate than students in 20 of the other 28 OECD countries and 3 of the 10 non-OECD countries” (Lemke et al., 2004, p. 13). Moreover, the U.S. performed below average in all mathematics subscale areas: Space/shape; change/relationships; quantity; and uncertainty. PISA 2009 results mirrored the 2003 results, with the U.S. average score lower than 17 of the 33 OECD countries. In summary, between 2003(483) and 2009 (487), no measurable difference existed between the average score of U.S. students in mathematics literacy. Furthermore, U.S. mathematics literacy average scores were lower than the OECD average scores in both 2003 and 2009, indicating that U.S. students continued to lag behind their international counterparts (Lemke et al., 2004).

The 2003 PISA also assessed student problem-solving abilities, with problemsolving defined as follows:

"an individual's capacity to use cognitive processes to confront and resolve real, cross-disciplinary situations where the solution is not immediately obvious, and where the literacy domains or curricular areas that might be applicable are not within a single domain of mathematics, science, or reading"(Lemke et al., 2004, p. 22).

The U.S. scores were lower than the OECD average in problem-solving ability. That is, U.S. students had lower scores than students in 25 of the 38 countries (22 OECD and 3 non-OECD countries). And, U.S. high achievers, those scoring in the top $10 \%$ in the U.S., were also outperformed by OECD counterparts (Lemke et al., 2004).

CTE achievement. How does student achievement compare in the context of career and technical education? From 1990 to 2005 the academic course taking patterns 
of high school graduates who participated in CTE programs and courses increased, making them more prepared for college and careers than CTE students in the past (Levesque et al., 2008; Silverberg et al., 2004). As indicated by NAEP test scores, between 1994 and 2000, CTE concentrators increased reading performance by 8 scale points and mathematics performance by 11 scale points. Students taking no CTE course work also increased performance, but by only 4 points in reading with no increase in mathematics (Silverberg et al., 2004). However, in another interpretation of these results, indications were that increases could be the result of increased graduation requirements and the back-to-basics focus on academic subjects rather than CTE course content (Levesque et al., 2008; Plank, 2001; Silverberg et al., 2004). Moreover, "both analyses of high school student data and randomized controlled studies indicate that, on average, vocational courses and programs do not themselves 'add value' to academic achievement as measured by test scores” (Silverberg et al., p. 269).

To some education experts uninspiring student performance indicates a failure of back-to-basics and NCLB to impact achievement. According to Ravitch, (2008), 2007 TIMSS scores do not speak well for NCLB with only small gains in mathematics achievement despite the heavy investments in high-stakes testing. To this end, critics of NCLB and high-stakes testing suggest that boosting student achievement scores should not be the primary goal of schools, because the high scores of our international counterparts are indicative of contextual teaching and learning strategies (Guisbond \& Neill, 2004).

"In other countries - including several Asian ones that outperformed the United States on both the PISA and TIMSS academic work if far more likely to be presented through exercises that students encounter every day. In those nations, a lesson is 
presented through a real world situation........Students later move on to more complicated tests of that skill, all the while maintaining an understanding of its application in everyday problems" (Cavanagh, 2005, p. 2).

Yet for others, the back-to-basics movement and NCLB legislation are ways to ensure that schools educate students to much higher standards, and as such, see the performance gains since NCLB as a sign that U.S. student basic skills are improving as a result of state and federal mandates (Kilpatrick, 2009). According to Orlich (2004), several studies corroborate this message: For example, a 2002 PISA reading literacy survey found that U.S. students were among the highest scorers in reading. Interestingly, these same students were also said to be some of the least engaged in the world (Orlich, 2004). A comparative study of student performance between the U.S.

and other G8 nations, revealed that U.S. $8^{\text {th }}$ grade mathematics and science achievement was at about the median. Another study comparing 35 countries on reading literacy indicated that only Sweden outperformed the U.S. (Orlich). Moreover, the perception that the U.S. performed poorly overall in comparison to international countries may not be accurate as such assessments typically focus on mathematics and ignore performance in other subject areas (Boe \& Shin, 2005).

\section{Curriculum Integration: A Reform Strategy}

The trends in student achievement have given pause to educators, policymakers, and researchers and curriculum integration has been spotlighted as a potential reform strategy over the past two decades; however, integration is not a new idea. In the quest to improve learning, the idea of integration has been explored throughout the history of education. As early as $300 \mathrm{BC}$, Socrates first theorized that integrating contentquestioning and learning-by-doing techniques can promote engagement and self- 
generated understanding in students (Curren, 2010). Accordingly, integrative education can "allow a person to form sound judgment of an investigation and to do this in all the domains of knowledge” (Curren, 2010, p. 551). Other Greek philosophers, such as Plato and Aristotle, suggested that knowledge is developed through the integration of observation and experiential learning (Neiman, 1991). Early philosophers inspired generations of educational reformers, such as Dewey, Kilpatrick, Piaget, Alberty, Hopkins, and Vygotsky, who built upon these concepts, forming the foundation of progressivist philosophy and constructivist educational theory (Beane, 1996; Murphy, 1997). John Dewey, the Father of Progressivism, maintained that education must be continuous and experiential through everyday interaction with the world. Progressivism, then, as an educational philosophy, repudiated the dualistic system of a separate academic education for an elite few and narrow vocational training for the majority (Hayes, 2011; Beane, 1997; Johnson, Dupuis, Musial, \& Hall, 1994). As such, Dewey advocated centering the curriculum on occupations to promote a meaningful, active learning environment (Dewey, 1916). Nevertheless, American education, in practice, has exalted passive learning in a separate subject curricular design that is steeped in tradition and rooted in age-old conflicting philosophical views of education.

"Why is it, in spite of the fact that teaching by pouring in, learning by a passive absorption, are universally condemned, that they are still so entrenched in practice? That education is not an affair of 'telling' and being told, but an active and constructive process, is a principle almost as generally violated in practice as conceded in theory." (Dewey, 1916, p. 38).

Thus, for over a century a debate has persisted between supporters of the concept of passive learning organized by disciplines and/or subjects, and experiential and social 
learning organized around themes, problems, and/or content (Beane, 1975.; Gehrke, 2006).

Historical development. Curriculum, as a field of study and practice, emerged in the late 1800s through the discussions and professional knowledge of scholars and practitioners who explored "the nature of knowledge, the nature of the knowledge process, and procedures for introducing new curriculum insights into practice” (Bellack, 1969, p. 284). Coinciding with the rise of the curriculum field was the idea of integration which first appeared in 1855 in the psychology books of Herbert Spencer and William James, as well as, in Alexis Bertrand's theory of integrated instruction published in Paris in 1898 (Klein, 2005; Wraga, 1997). In modern history, integration is rooted in the Herbartian Movement of the 1890's (Beane, 1997). The term 'integration of studies' originated in the writings of Johan Friedrich Herbart, a German philosopher and educator. Herbart and his followers, Hebartians, maintained that the core of education was to preserve the moral character and ethical principles of students through a five stage integrative process: Acceptance of new learning; introduction of socially relevant material; correlation of new material to pre-existing experience; establishment of guiding principles; and application through experience (Beane, 1997; Blyth, 1981). Based in a systematic psychology of learning, Herbartism promoted connections across related subjects, emphasizing the connection of the whole in understanding the parts (Klein, 2006). This philosophy was in direct contrast to Essentialist educational philosophy which emerged in the late 1920s to protest the disregard of traditional learning inherent in Herbartism. William Bagley, founder and leader of essentialist theory, claimed that the curriculum had become weak and ineffectual (Null, 2007). 
Essentialist educational theory disapproved of vocational courses and watered down content, calling for a return of mental discipline activities such as memorization and drill to instill the essentials of knowledge in students. Strict classroom discipline and a teacher-centered environment; focus on reading, writing, spelling, and mathematics; and high achievement standards typified the essentialist classroom (Albear, 2007). At the beginning of the $20^{\text {th }}$ century, three social movements influenced epistemological change in the concept of integration: (a) Interest in the social and psychological behavior of humans; (b) studies in child growth and development; and (c) resurgence of democratic ideals and citizenry (Schumacher, 1992). Integration assumed an organismic connotation through the work of Gestault psychologists, who intimated that humans are inherently motivated to seek patterns and organization, with learning becoming a personal, unifying process. That is, the relationship between parts afforded the crux of understanding for learning as a whole (Gowin, 1959; Levit, 1959). From this Gestault understanding of integration, a question emerged regarding what constitutes the best curricular organization for students to gain both personal and social integration.

Two perspectives on implementing an integrative curriculum, student-centered approaches and the social approach, arose from this question. Two notable studentcentered responses, the experience curriculum and the activity curriculum, emphasize the personal nature of learning based on student interests and ideas. The experience curriculum was developed through the works and writings of Thomas Hopkins (18891982) who advocated a curriculum designed around life experiences, cooperatively planned by students and teachers (Beane, 1997). The activity curriculum of William Kilpatrick (1871-1965) was rooted in the notion that students are active participants in 
learning and in determining learning objectives, learning activities, and evaluation procedures (Marlow, 1996). Kilpatrick popularized activity theory through his article, The Project Method (Kilpatrick, 1918), which outlined this method as an educational problem-solving process. Paramount in the project method, then, was the idea that over time students apply knowledge and skills to create a product, thereby fostering independent thinking and self-efficacy (Roberts \& Harlin, 2007; Knoll, 1997).

A second perspective, the social approach heralded by John Dewey (1882-1953) and the emerging progressive education movement, focused on the democratic nature of the curriculum for common good of all citizens (Cremin, 1959). The core of progressive education philosophy is a holistic curriculum organized to meet the social, emotional, psychological, and biological needs of students (Levit, 1959). Dewey and his followers were inspired by the work of the German philosopher Friedrich Froebel (1782-1852) and Swiss educator Johann Pestalozzi (1746-1827) who pioneered the idea of educating the whole child through learning that extended beyond the subject matter to center on the student (Reese, 2001). Accordingly, progressivist educators opposed the cultural uniformity of common schooling that endorsed separate academic and vocational curricula. Moreover, the social approach questioned a wholly child-centered perspective, indicating that for a curriculum to be truly integrative it must address the individual process of integration, as well as the social process of integration (Beane, 1997).

Building upon these ideas, the 30-year period between 1930 and 1960 represents an intense period of curriculum change in secondary high schools as educators attempted to reconstruct the curriculum on a broader social basis (Congleton, 1964). During this 
time, the concept of curriculum integration became a basic tenet of progressive curriculum theory and practice. One of the most significant examples supporting an integrative education from this era came from the Eight-Year Study which was conducted over a period of ten years beginning in 1930 by the Commission on the Relation of School and College of the Progressive Education Association. The Commission deemed that education had become lackluster with a lifeless curriculum, leaving students uninspired as learners and as citizens. In an effort to determine the impact of integrative education on college success, students from the 30 progressive secondary schools were matched with graduates of traditional schools. Results of the Eight Year Study indicate that students who attended progressive secondary schools "show more leadership, think more clearly, have a better understanding of democracy, take a keener interest in good books, music and art and get slightly better grades in college than those from traditional schools” (What Did The Eight, 1942, p. 1).

Initiated by the Eight Year Study, the term integrated curriculum also appeared in conjunction with the core curriculum movement in the 1930s and problem-centered core curricula in the 1940s and 1950s (Klein, 2006; Halbach, 2000). The core curriculum movement stressed a curriculum centered on the social needs of society and democratic citizenship with activities planned cooperatively by students and teachers (Wraga, 1993). The content of the core curriculum was not contained in subject-centered silos, but in the broad social issues common to all students (Johnson et al., 1994). Toepfer (1997) presented the following quote from Faunce and Bossing’s 1951 book, Developing the Core Curriculum, in which they identified key characteristics of core courses: 
"We have listed four characteristics of core courses that distinguish them from conventional subject-matter courses: (1) their freedom from subject-matter patterns and their emphasis upon vital problem situations; (2) their emphasis upon group problem-solving; (3) their use of a long block of time; and (4) their emphasis on guidance by the classroom teacher" (Toepfer, 1997, p. 169).

The core curriculum purported the elimination of barriers between subjects and units of time. It also differed from the subject, activity, and experience curriculums in that it emphasized not only an education centered on the individual, but also one rooted in social values (Phillips, 1964; Toepfer, 1997; Lawhead, 1960). The problem-centered core curriculum was an assimilation of the experiential and core approaches; thus calling for curricula themed around problems in society and in human relationships with an emphasis on experiential and collaborative solutions (Short, 1986; Beane, 1997; Lawhead, 1960).

Progressivism and integrative approaches to curriculum were besieged in the 1950s and 1960s by critics who claimed a downfall of intellectualism in schools was due in part to the dilution of the subject-centered approach. Other developments, including the National Science Foundation Cold War projects of the 1960s and the back-to-basics movement beginning in the 1970s thwarted integration in secondary schools (Bellack, 1969; Congleton, 1964; Wraga, 1997), thereby resulting in a resurgence of essentialist educational philosophy (Albear, 2007). As a result, the development of integrative approaches came to a stand-still as the curriculum field turned away from integrative design to the politics of national standards and testing, thereby stimulating a renewed interest in separate subject curricular design (Beane, 1997). 
During the mid- $20^{\text {th }}$ century curriculum integration theory and practice largely disappeared from secondary educational reform language. Yet, as a concept, it was nurtured by a small cohort of integrative proponents who maintained that the traditional separate-subject curriculum was failing the middle student (Beane, 1997). With a renewed interest in the early 1980's, spearheaded by the report entitled A Nation at Risk (National Commission on Excellence in Education, 1983) that focused public attention on educational reform, curriculum integration emerged again as a potential method for increasing academic rigor in mathematics and language arts (Anderson et al., 1985; Council on Advancing Adolescent Literacy, 2009; National Council of Teachers of Mathematics, 1989; Conference Board of the Mathematical Sciences, 1983) and for preparing the $21^{\text {st }}$ century workforce (Beane, 1997; Caine \& Caine, 1991; Drake, 1991; Drake, 1993; Grubb, 1995a; Fogerty, 1991b; Jacobs; 1989; Vars, 1993; Vars, 1997). With the onset of common schooling, initial integrative discussions focused on the role of education as an agent in moral education, and through progressivist theory, eventually grew in meaning to encompass curriculum organization as a social construct and viable alternative to the subject-centered design (Wraga, 1997). Regrettably, although the last two decades of the $20^{\text {th }}$ century evidenced a revival of interest in curriculum integration, those decades were also characterized by legislation supporting back-to-basics and standards-based reform (Vars \& Beane, 2000). Hence, even as curriculum integration theory and practice began to reshape and revitalize education, the movement was quickly stymied by a focus on accountability and high-stakes testing, and an emphasis on separate-subject education as the force behind student achievement (Lee and Ready, 2009). 
Reform legislation. In an effort to address the perceived failings of the U.S. educational system, education legislation during the latter half of the $20^{\text {th }}$ century saw a resurgence of integrative language as part of school reforms in vocational and academic education.

Vocational legislation. Federal funding for secondary vocational education was first legislated by the Smith-Hughes Act of 1917 (Wonacott, 2003) which, unwittingly, prepared the way for an instructionally segregated vocational system through various Act requirements: (a) Separate State Board of Vocational Education; (b) separation of funds; (c) segregation of vocational education students; and (d) segregation of the curriculum. In an effort to maintain funding compliance, the Act required the creation of State Boards of Vocational Education; thus, already established state Departments of Education and new State Boards of Vocational Education worked at cross purposes. The Act also separated the financial operations of vocational and academic education by limiting funds mandating that only vocational teachers could be paid from federal funds. However, limiting the academic instruction of vocational education students was the pivotal delineating component of the Act. Accordingly, vocational education students were required to take vocational and related courses $75 \%$ of the school day, whereas academic content was restricted to $25 \%$ of the school day. Vocational education was also further segregated into program areas such as agriculture, industrial, and home economics, thereby resulting in separate teacher education programs; teacher organizations and certifications; and student organizations. Moreover, the basic tenets of federal vocational education remained steadfast through 1960, evolving into a decentralized system which fostered the idea of vocational education as separate from an 
academic education (Hayward \& Benson, 1993). These policies and practices created a niche for vocational education as appropriate for non-college bound students interested in narrow, job specific training (Lynch, 2000; Wonacott, 2003).

The Vocational Act of 1963 was the first legislation in half a century to include occupational cluster language for the broadening of the curriculum; however, educators, administrators, and leaders, entrenched in tradition, failed to implement the necessary programmatic changes. Ultimately, the Act only reinforced the separatist curricular stance and a stay-the-course mindset through expansion of programs and services to include students with disabilities, English speakers of other languages, and students training in non-traditional occupations (Lynch, 2000; Hayward \& Benson, 1993). In 1984 Congress passed the Carl D. Perkins Vocational Education and Applied Technology Act, a precursor to today’s Perkins legislation, which emphasized program improvement and expanded services for students with special needs. Perkins II (1990) shifted the focus from special populations to all students and included, for the first time, language supporting the development and integration of student academic and jobrelated skills (Lynch, 2000). This represented a radical shift placing the integration of academic and occupational education squarely at the core of education reform (Threeton, 2007). The focus of Perkins II, then, was to build workforce preparation through updated programs that included the integration of academic and vocational education; partnerships between education and American businesses; and connections between school and work (Lynch, 2000; Finch, 1999; Gordon, 2006). The Tech Prep Education Act, a component of Perkins II, which provided funding for the development of $2+2$ coordinated programs between secondary and post-secondary institutions, also 
supported the integration of academic and vocational programs (Lynch, 2000).

Furthermore, the School-to-Work Opportunities Act of 1994 (STWOA), jointly administered by the Departments of Labor and Education, also placed an emphasis on career planning; the integration of academic and occupational learning; and work-based learning and experience for high-skill, high-wage jobs (Borman, 1996). Subsequent Acts (Perkins III; Perkins IV) strengthened the integration between academic and vocational education and incorporated school reform, student performance, and accountability language (Gordon, 2006).

Academic legislation. Despite vocational education legislation and the cry from American business leaders for integrative curricular design at the secondary level, an emergent reform philosophy post-A Nation at Risk eulogized a universal education as the most direct way to increase academic rigor and improve student outcomes. Commonly termed the standards movement and/or back-to-basics in education, this movement touted the merits of more academic courses and the constraint of student elective choice (Lee \& Ready, 2009). In response to the demands for increased academic rigor, the mathematics community developed national standards designed to guide reform efforts in restructuring the content, teaching, and assessment of mathematics education to reflect mathematical understanding through various interrelated experiences (National Council of Teachers of Mathematics, 2000). Similarly, language and literacy educators advocated a set of teaching methodologies known collectively as whole language in which reading, listening, speaking, and writing are linked in meaningful contexts and for relevant purposes (McKenna, Robinson, \& Miller, 1990). The emphasis on increased academics was catalyzed in the 1990's by 
federal and state legislation establishing standards for minimum competency in mathematics and language arts with high-stakes standardized testing as the measure of success.

The onset of the Bush administration at the turn of the century saw the back-tobasics movement gain momentum and morphing into the No Child Left Behind (NCLB) Act of 2001, a reauthorization of the Elementary and Secondary Education Act (ESEA). NCLB placed greater emphasis on accountability through federal government involvement and control in education (Hull, 2003). That is, the Act required that students meet mandated proficiency benchmarks, allocating resources to schools that meet benchmarks and implementing sanctions implemented against schools that do not (U.S. Department of Education, 2011). With a clear focus on academic achievement, NCLB reinforced the compartmentalized focus on academic at the expense of CTE, thus creating additional roadblocks for curriculum integration.

Summary. Long endorsed by educational philosophers, scholars, reformers, and American business leaders, curriculum integration was awarded credence and funding through academic and vocational reform legislation in the early 1990s. This legislation, then, set the stage for renewed focus and discussion on curriculum integration and a decade of literature on integration theory, research, and practice. Between 1987 and 1992, a comprehensive review of integration literature yielded over 100 published articles, research studies, books, and informational briefs (Stasz et al., 1994). In another review of literature during the decade of the 1990s, Dare (2000) noted 150 publications and 90 doctoral dissertations relating to applied academics. Similarly, Vars (1993) identified more than 100 studies examining the effects of interdisciplinary and team 
teaching on students, whereas Plihal, Johnson, Bentley, Morgaine, \& Liang (1992) categorized over 140 integrated studies according to vocational program area and type of integrative model. According to Plihal et al. (1992) the most frequently reported CTE program areas for integration were agriculture, business, home economics, and industrial education and the most frequently reported areas for academic education were English, science and mathematics. Berlin (1991) in a review of literature on mathematics and science integration between 1901 and 1991 yielded 555 documents. A second similar review identified 402 science and mathematics integration writings from the second half of 1991 through 2001 (Berlin \& Lee, 2005).

\section{Curriculum Integration: Deconstructing the Basics}

To fully understand the impact of education reforms on the prospects of curriculum integration, it is necessary to deconstruct the basics of this curricular strategy. Curriculum integration has been examined and diagnosed from multiple perspectives. Proponents and critics alike base their arguments on fundamental beliefs entrenched in both theoretical frameworks and practical application. But, what are the basic conceptual foundations of curriculum integration? What follows is a review of its essential meaning, characteristics, and components.

Meaning. Given the breadth of literature on CTE and academic integration, it is no surprise that the term typifies a multiplicity of meanings. Accordingly, educational scholars and researchers have presented diverse definitions, inferred multiple meanings, and created a host of terminologies for curriculum integration; thereby making it is difficult to arrive at one characterization that supports its purpose in all contexts (Etim, 2005; Vars, 1997). At its most basic, the term integration is "an act or instance of 
combining into an integral whole” (Dictionary.com, n.d.). McBrien and Brandt (1997, p.55) define integration as "a philosophy of teaching in which content is drawn from several subject areas to focus on a particular topic or theme”. Moreover, integration refers to the process of connecting the parts of an educational experience to create a complete or unifying curriculum (Plihal et al., 1992). According to Beane (1995), curriculum integration emphasizes linkages or relationships viewed through a multiple perspective lens, one that encourages inquiry in a contextual manner. Additionally, integration is a process for organizing common learning or life skills to help students build connections among topics (Beane, 1995). Likewise, Grubb (1995b) indicates that integration can require the curriculum to surpass content prescribed by teachers and textbooks to content determined by student interest for the fusion of education and occupations. In contrast, Fogerty (1991b) defines integration as the connection of skills, themes, concepts, and topics across disciplines to enhance learning from one subject to another. Roberts and Kellough (1996, p.3) refer to integrated curriculum as "a way of teaching and a way of planning and organizing the instructional program so the discrete disciplines of subject matter are interrelated”. In accordance, Maurer (1994) suggests integration is the restructuring of content from separate disciplines to match or correlate. Similarly, Jacobs (1989) identifies integration as a "knowledge view and curriculum approach that consciously applies methodology and language from more than one discipline to examine a central theme, issue, problem, topic, or experience” (Jacobs, 1989, p. 8). According to Walker (1995, p. 2) in a quote by Shoemaker, the author merges several ideas to create an eclectic definition: "Integrative education cuts across subject-matter lines, bringing together various aspects of the curriculum into meaningful 
association to focus upon broad areas of study." Thus, integrative learning replicates the mutually dependent real world by involving the student's mind, body, and senses for the unification of knowledge and "provides a greater understanding than that which could be obtained by examining the parts separately" (Walker, 1995, p.2). Others also refer to integration as the application of important concepts across disciplines through interdisciplinary connections, but only when those connections are readily apparent and tied to a theme (Kovalik \& Olsen, 1993; Post, Humphreys, Ellis, \& Buggey, 1997; Maurer, 1994; Roberts \& Kellough, 1996; Tchudi \& Lafer, 1996), or connected to student interests (Stevenson \& Carr, 1993).

In addition to the different connotations for integration, the term curriculum integration is used interchangeably with other synonyms. Stevenson and Carr (1993) use the term integrated studies, whereas Maurer (1994) prefers correlated. Vars (1997) uses the terms correlation, fusion, and core curriculum. Other generic terms include integrated learning, integrative, interdisciplinary, multidisciplinary, pluridisciplinary, cross-disciplinary, cross correlation, interdisciplinary thematic unit (ITU), integrated thematic instruction (ITI), interdisciplinary team teaching; multi-subject learning, holistic education, core learning, block learning, common curriculum, common learning, balanced curriculum, problem-centered core, unstructured core, whole topic, unified learning, and applied academics (Beane, 1997; Drake, 2007; Fogerty, 1991b; Halbach, 2000; Klein, 2005; Klein, 2006; Matheson \& Freeman, 1997; Plihal et al., 1992; Pritz, 1989; Roehler, Fear, \& Herrmann, 1998; Roberts \& Kellough, 1996; Stevenson \& Carr, 1993; Vars, 1997). 
Klein (1990) attempts to classify the myriad of meanings into some semblance of order, suggesting that the term can be defined by its practical applications; by the motivation behind integrative efforts; by the role the disciplines play in integrative efforts; and by terminology that distinguishes its hierarchal nature (Grady, 1996). According to Klein (1990), some synonyms are reflective of the activities that characterize integrative learning as follows: (a) Borrowing of analytical tools from one discipline for use in another discipline (i.e. disciplinary models, methods, and strategies), termed pseudo interdisciplinary, auxiliary interdisciplinarity, legal interdisciplinarity, linear interdisciplinarity, and method interdisciplinarity; (b) problem solving that does not seek to unify knowledge (i.e. a project for projects sake), termed composite interdisciplinarity, restrictive interdisciplinarity, and problem interdisciplinarity; (c) coordination between subjects and/or methods of instruction to create an overlapping course (i.e. biophysics), termed supplementary interdisciplinarity and unifying interdisciplinarity; and (d) co-mingling of two related disciplines to create a new discipline (i.e. general systems, sociobiology, and phenomenology), termed border interdisciplinarity, hybrid interdisciplinarity, and structural interdisciplinarity.

Mathematics. Integration in mathematics can also have multiple associations, depending upon personal or organizational interpretations. For example, mathematics integration may refer to concept connections among single discipline subjects (arithmetic, algebra, geometry, calculus, etc.) or across two or more disciplines (such as mathematics and language arts; mathematics and science). Inherent in the definition of CTE and mathematics integration is the understanding of mathematical concepts rooted in occupational content (Bottoms \& Sharpe, 1996; Grubb, 1997; Grubb, 1995b; 
Hernandez \& Brendefur, 2003; Pearson, 1989). Moreover, Roebuck and Warden (1998) suggest the basic concept skills of information gathering and observation; counting and measuring; interpretation through the use of visuals; and inference, prediction, and estimation are common grounds for true mathematics integration across disciplines. The literature reveals terms such as unified, coordinated, correlated, interrelated, crossdisciplinary, blended, and linked learning as synonyms for the integration of mathematics into other subjects and/or disciplines (Lederman \& Niess, 1998).

Reading/Language arts. Integration from a language arts perspective is defined as a whole process taught within meaningful and functional contexts that link reading with listening, speaking, and writing; that is, within discipline integration. This integration, called whole language instruction or emergent literacy, focuses on providing a contextually-rich environment that emphasizes comprehension skills. For example, reading may be incorporated into other language arts subjects with emphasis on relevancy (McKenna, Robinson \& Miller, 1990; Moorman, Blanton, \& McLaughlin, 1994; Roehler, Fear \& Herrmann, 1998). Inherent in language arts and CTE integration is the idea of reinforcing or teaching reading, writing, comprehension, presentation, and speaking skills in a contextual way through CTE course content (Goodman, K., 1989a; Goodman, K., 1989b; Goodman, Y., 1989; Penn, 1992). Roehler, Fear \& Hermann (1998) suggest that language arts subject integration is represented by names such as holistic teaching, coherent curriculum, aligned curriculum, language across the curriculum, language experience, emergent literacy, multicultural education, reading and writing in content areas, and whole language. 
Disciplinarity. As a result of its ill-defined nature, multiple perspectives exist on the 'real' meaning of integration. To this end, some scholars maintain that the integration is discipline-free, student-driven, and socially relevant (Beane, 1997; Dewey, 1916; Hopkins, 1941; Piaget, 1969; Kilpatrick, 1918; Stevenson \& Carr, 1993; Vars, 2001). Beane (n.d.) a leading proponent in discipline-free integration, offers the following definition:

"a curriculum design that promotes personal and social integration through the organization of curriculum around significant problems and issues, collaboratively identified by educators and young people, without regard for subject area lines" (Beane, n.d.).

Discipline-free proponents oppose the fragmentation of curricular content suggesting that traditional disciplinary boundaries limit the scope of education and restrict the assimilation of knowledge (Klein, 1990). Terms such as non-disciplinary, adisciplinary, metadisciplinary, supra-disciplinarity, omnidisciplinary, and trans-specialization, then, are used to describe activities that "subordinate disciplines to a particular issue, problem, or holistic scheme” (Klein, 1990, p. 6). Yet in another example of the multiple representations of the term curriculum integration, other non-discipline proponents suggest that any term using the word 'discipline' (i.e. interdisciplinary, multidisciplinary, and pluridisciplinary) seeks to enhance disciplinary learning for mastery of skill, rather than eliminate disciplinary lines for holistic learning (Beane, 1997; Mathison \& Freeman, 1997; Vars, 1997).

Adversely, some scholars propose integration as a connection or interrelation of knowledge that respects disciplinary boundaries (Badley, 1986; Kovalik \& Olsen, 1993; Loepp, 1999; Maurer, 1994; Post et al.,1997; Tchudi \& Lafer, 1996; Grossman, 
Wineburg, \& Beers, 2000). Typically, these integrative practices are found at the lower end of the integration continuum, such as interdisciplinary or multidisciplinary thematic units. Mathison and Freeman (1997, p. 8) present the following quote by Gosser in which disciplinarity is defined as

"a compartmentalization determined by the need to gain thorough knowledge of the various aspects of each cognitive area: thus, criteria of reflection and study appropriate to each sector are determined, and there is a certain crystallization of the various fields of inquiry, defined by their characteristics of observability, method and application".

Others scholars refer to the concept of integration as a continuum, with discipline-based integration at one end of the spectrum and non-discipline-based integration at the other (Alberty, 1947; Drake, 2007; Faunce \& Bossing, 1958; Fogerty, 1991b; Harden, 2000; Jacobs, 1989; Pritz, 1989; Roberts \& Kellough, 1996; Shoemaker, 1991; Tanner \& Tanner, 1980). According to Jacobs (1989), this arrangement allows administrators to determine the integrative design that best fits school needs.

The term curriculum integration covers a multitude of teaching and learning situations, leading to the conclusion that integration is a nebulous, catch-all with no real parameters. As a result, integration is often seen as a goal rather than a strategy in education. Moreover, ambiguity also occurs in how curriculum integration is referenced by researchers and practitioners in the literature: as an end result or as an approach to instruction. As an end result, integration is viewed as a form of knowledge used to develop the thinking and problem-solving processes required of workers and citizens in the $21^{\text {st }}$ century, whereas, other researchers see integration as a way to teach existing curricular standards (Case, 1991). 
Beane (1997) believes that the greatest confusion occurs through the misuse of the term to represent designs that are more accurately categorized as discipline-based learning. Disciplinarity, then, has significant implications for curricular organization, instruction, and assessment; thus, clarifying the term extends beyond simple semantic concerns (Roebuck \& Warden, 1998).

Characteristics. Certain characteristics, or basic conditions, are essential for a learning environment to exert an integrative influence on students. Integrative learning starts with identifying the psychological and biological differences and needs of students. Diagnosing and treating those needs, then, sets the stage for well-balanced and enriched integrative programs. Accordingly, an experience initiated by the student, culminating in the realization of a student-driven purpose, is more apt to promote integration. An integrative experience should also be self-directed by the student and suited to his/her level of maturity and ability. In addition, the experience should challenge the student to perform at his/her best ability and result in noticeable achievement or success. Socialization and a sense of cooperation also aid the integrative process because of the natural tendency toward camaraderie. Furthermore, experiences that develop values, maintain consistency of action, and inspire creativity also play an important role in integration (Umstattd, 1940).

Using cognitive research, Kovalik and Olsen (1993) identify eight brain-based conditions that help to create an integrative environment: (a) Absence of threat in the classroom; (b) connected, meaningful content; (c) choice as a tool to heighten interest; (d) adequate time to complete work; (e) an enriched, hands-on learning environment; (f) classroom collaboration and teamwork; (g) immediate feedback; and (h) mastery 
learning. Cognitive research indicates that memory retrieval is enhanced in learning environments where these conditions are met (Walker, 1995).

In a different light, Pearson et al. (2010) identify five core principles essential to maintaining successful integrative programs including the development of a community of practice among teachers; initiating integration through the CTE curriculum and not the academic curriculum; realizing that core academic knowledge and skills are vital to workplace success; utilizing natural academic connections in the CTE curriculum; and recognizing the CTE teachers are not academic teachers, but do reinforce academic content.

Components. To move from these broad principles to an understanding of specific integration components, Case (1991) identifies eight components in an effort to clarify its true nature including: Domain, form, dimension, objective, mode, locus, coherence, and degree.

Integrative domain. The broadest component of integration, domain, refers to the environment and context in which integration of action, thought, or influence occur. The domain of integration is determined according to educational goals, content, methods, and procedures. Domains of integration can be also be divided by school, classroom, or program; by teaching and learning methods; and in curricular procedures and practices. Formal and informal integration are also sub-domains of integration. Formal integration refers to planned curriculum or the intended learning experiences, whereas informal integration refers the unplanned experiences both inside and outside the classroom that determine student learning (Case, 1991). 
Integrative form. According to Case (1991), connecting disciplines; skills and processes; school and self; and rules and routines that influence learning, are types of curricular form. Hoachlander (1999) outlines four forms of integration ranging from classroom to school-wide initiatives with each form requiring an increase in the degrees of planning, coordination, and commitment. Course-level integration refers making curricular changes at the classroom level. That is, a teacher agrees to add content from another curricular area to his/her existing course. Cross-curricular form requires a coordinated, or joint, approach with a team of teachers determining integrated content. Requiring more concentrated efforts are programmatic integration organized around career clusters and school wide integration organized around career academies and small learning communities.

Integrative dimension. Dimension refers to the 'when' of integration or the time frame for teaching and the objectives are the 'why' or purpose for integrating and can be subdivided into integration at the present time (horizontal alignment), and integration over time (vertical alignment). In the horizontal alignment of integrative efforts, students learn about similar subjects at the same time (course-level and cross-curricular forms), whereas in vertical alignment of integrative efforts (programmatic and school wide forms) students take courses sequentially over a period of time (Schmidt, Beeken, \& Jennings, 1992). Beane (1997) articulates a multi-faceted, non-disciplinary theory of integration requiring four dimensions: Integration of experiences uses past experiences or 'schemes of meaning' as blueprints for future transfer of knowledge; social integration ties personal and democratic life to school and community through problemcentered curriculum; integration of knowledge refers to holistic learning without regard 
for subject-area lines; and integration as curriculum design refers to the features that distinguish it from other approaches, namely the participation of students in planning curriculum.

Integrative objectives. Much of the literature on curriculum integration also examines it in terms of objectives, or the 'why', with advocates having diverse reasons for supporting this curricular reform. Case (1991) suggests several objectives that underscore the need for integration: Managing the difficult realities of the world; eradicating the rigid, separate subject approach; deference to knowledge as a continuum; encouraging resourceful and effective teaching. Etim (2005) underscores the importance of integration for the purpose of grounding learning in state and national standards; linking learning to real life; emphasizing classroom practices that increase critical thinking and creativity; and developing students as holistic learners with individual needs, interests, and learning styles. Bodily, Ramsey, Stasz, and Eden (1992) stress four purposes for integrative reform: To provide a more coherent curricula; to improve the teaching of all subjects through activity-based pedagogy; to induce teacher collaboration and coordination; and to improve student transition from high school to post-secondary education.

Many of these purposes are confirmed in a review of integrative literature by Stasz et al., 1994): Integration as curricular reform to meet the uncertainty in the future workforce; integration as curricular reform to maintain global competitiveness; integration as a tool for basic skill enhancement; integration as a tool to develop critical thinking skills; integration as a method to improve student engagement and learning; integration as a means to ensure access and equity. For example, the objectives related 
to meeting the uncertainty in the future workforce and ensuring global competitiveness stem from the rise of the global economy and dramatic changes in the nature of work. The changing workplace requires knowledge work tied to information technology and highly educated workers, and is resulting in a steady decline in low-skill and semiskilled jobs with an increase in high skilled jobs requiring intuitive workers (Lewis, T., 1998). Therefore, mental discipline activities such as memorizing facts; listening to lectures; completing worksheets and non-relevant activities; and drilling to instill the essentials of knowledge fail to prepare students for uncertainty of the future workforce in a knowledge-driven era (Bailey, 1992). Also, evidence suggests that America is losing its competitive edge because the workforce is not prepared for the high performance workplace (National Center For Research In Vocational Education, 1989). The high-performance workplace now requires an emphasis on integrated work groups, teamwork, and shared information, as well as active, intellectually engaged workers who are flexible and can construct, adapt, and refocus information on demand (Doolittle \& Camp, 1999; Rojewski, 2002; Trefler, 2005). To this end, the relationship between curricular content, school structure, and jobs of the future suggest that to maintain global competitiveness education and economics must be integrated (Bailey, 1995).

Another objective of integration is as a tool for basic skill enhancement. Employers claim that new job entrants lack certain skills to succeed in the future workforce, including basic skill competency and specific/applied skill training with the ability to use these skills in new, unpredictable ways (Christensen, 2008; Stasz \& Grubb, 1991). The basic skills are those of reading, writing, computation, mathematics, science, and social studies with the ability to learn continuously throughout life. In addition to 
basic skill competency, scholars also indicate the importance of specific skill training through CTE programs and generic or soft skills (Adelman, 1989; Bailey, 1991, Bailey,1992; Bailey, 1995; Carnevale, 1991; SCANS, 1991; Stasz \& Grubb, 1991; Stasz, McArthur, Lewis, \& Ramsey, 1990; Stasz et al., 1994; Stasz, Ramsey, \& Eden, 1995), including problem-solving, communication, teamwork, higher order thinking, and interpersonal skills. Furthermore, human capital is now regarded as a critical skill in the complex workplace. Human capital, also called emotional intelligence, refers to the traits that make us human, such as creativity, imagination, humor, reflection, and communication (Cox \& Alm, 2003; Lewis, T., 1998). That is, for students to function effectively as workers they need the ability to use language well and thoughtfully; have a high capacity for abstract, conceptual thinking and the ability to apply thinking to a problem as well as experiment with solutions; understand scientific and technological ideas and use tools; use imagination; understand how people function in groups; and learn how to learn independently (Grady, 1996; Stasz, 1995). Bennett and McLaughlin (1988) report that there is a contradiction in skills obtained and skills needed on the job and "employers indicate that the skills they value are well-matched to the curriculum designs of innovative efforts to integrate vocational and academic education” (Adelman, 1989, p. 65).

Integration has also been identified as a tool to develop the critical thinking skills essential for citizens and workers in the 21st century. As such, reform initiatives have centered on instruction designed to improve the thinking processes as tied to the psychological and developmental needs of students. Research in developmental and cognitive psychology suggests students learn best when ideas are connected to one 
another (Mason, 1996). According to this brain-based research, multiple complex and concrete experiences are essential for students to engage in meaningful learning. Educators can influence the direction of patterning by presenting information in an integrative context, focusing on the sensory, cultural, and problem experiences connected to the real world. Problem-solving and critical thinking are ways of patterning that coincide with how the brain works and teaching through integration is the most recognized strategy for creating multiple complex experiences that promote critical thinking and problem-solving (Caine \& Caine, 1991; Jensen, 1998).

Integration has also been touted as a method to improve student engagement and learning. Research indicates that student attitude about school in general, and about specific academic subject areas, can begin to deteriorate when developmental and learning needs are not met in the classroom. Classroom experiences that are mentally and physically passive, with no connection between school and life, can contribute to high school dropout (Bodilly, Ramsey, Stasz, \& Eden, 1995). According to a report by the National Center for Educational Statistics (Planty, Provasnik, Hussar, \& Snyder, 2006), 4 out of every 100 students leave high school prior to completing one school year. Student interests, perceptions about school, purpose for achievement (i.e. goals), and the classroom environment, then, interact to promote motivation and ultimately, student engagement and learning (Hidi \& Harackiewicz, 2000; Mason, 1996). Integrative education creates a richer, more coherent curriculum by enhancing academic and applied content in an interest-based, educationally powerful model. A studentcentered focus can provide a sense of direction and motivate students to achieve and to stay in school (Plihal et al., 1992). 
Another objective of integration is as a method to eliminate student tracking for the purpose of access and equity. Comprehensive high schools offer a mix of courses at differing ability levels, from low-level/remedial to high-level/honors programs and attempt to match students to programs that accommodate their strengths and weaknesses. This placement practice, or tracking, refers to the development of a student's program of study as evidenced by judgments about his or her ability, interests, and motivation (RAND, 1992). Given the inequities of a dualistic system of education, integration between academic and CTE is viewed as a way to overcome tracking and to provide unbiased, interest-based curricular pathways for all students (Benson, 1991; Oakes, Selvin, Karoly, \& Guiton, 1992; Schmidt et al., 1992).

Integrative modes Integration modes identify the characteristics of curricular organization in relation to the connectedness with other subjects or disciplines. Integrative modes are presented on a continuum, from the lowest to highest. Inherent in most of the literature, then, is the idea that integration is hierarchal, ranging from least integrative to most integrative (Pritz, 1989). Movement along the continuum is determined by the role of disciplines in curricular organization; the role process has in thinking about the curriculum; and the role students and teachers play in developing and carrying out the curriculum (Kysilka, 1998). The modes also range from specific to generic in design, and run the gamut from single-subject academic or CTE designs to cross-disciplinary academic and CTE designs.

As indicated, educational scholars have identified and proposed numerous ways to organize curriculum, ranging from separate subject to non-subject design, thereby leading to the ambiguous nature of integration. As such, the primary goal of this section 
is not to organize modes of integration by either academic or CTE, but to present a comprehensive 100 year review of the modes and to align them for the purpose clarifying the meaning of integration. As such, the modes are organized into one of three categories as follows: Patterns, models, and classifications. The patterns are broad representations of curricular organization that establish a conceptual foundation for integrating curriculum. The models of integration are more specific, complex representations of integration that exemplify practice-based applications to theory. That is, the patterns are the 'why' of integration and the modes are the 'where' of integration (Plihal et al; Grubb, 1995b). The classifications, then, are attempts to generalize or group integration by certain characteristics.

As the most descriptive organization of curriculum integration, Fogerty's model is used as an alignment tool. Fogerty (1991a) describes the integration continuum in ten ways. The cellular model of integration is a traditional approach to teaching in which separate disciplines are taught by different teachers in different classrooms with relationships between subjects left up to the student for interpretation; the connected model of integration specifies the teachers make deliberate, but rudimentary connections between single disciplinary subjects, (i.e. physics and mathematics); the nested model of integration uses natural connections within a single discipline for additional exploration beyond a concept to application of the concept; the sequenced model of integration is a separate but shared view with the disciplines connecting subjects through common themes or units; the shared model of integration uses overlapping concepts in a crossdisciplinary partnership where teachers plan units together; the webbed model of integration ties a team of cross-discipline teachers to a broad common theme; the 
threaded model of integration weaves big ideas throughout the disciplines by making connections among basic, applied, and social skills in a multi-curricular format; the integrated model rearranges curriculum within the four core areas by developing a blueprint of overlapping concepts that transcend subject areas; the immersed model of integration filters content through the student, bearing in mind his/her interest, skills, and expertise; and the networked model is student-driven and provides multiple perspectives for exploration and deep understanding. Three additional types of integration are added by the researcher to support integration as identified by other theorists as follows: Siloed, merged, and harmonized. Siloed integration refers to subjects brought together in a wide-ranging course with each subject taught in selfcontained units, whereas merged integration unites two separate, but interrelated subjects into a new subject within a single discipline. Harmonized, then, creates synthesis among an entire discipline of knowledge with content taught harmoniously (see Figure 2.2).

Patterns. A comparative matrix of models of integration reported in the literature is presented in Figure 2.2. Alberty (1947), using ideas from the core curriculum movement of the 1930s and 1940s, presents a five core approach to the organization of curriculum. Type I Core adheres to strict subject-centered boundaries and the systematic organization of knowledge, with each subject taught independently of the other. Type II Core incorporates informal correlation to create meaning among subjects. 


\begin{tabular}{|c|c|c|c|c|c|c|c|c|c|c|c|c|c|}
\hline 总 & & 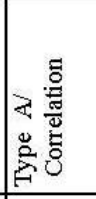 & & & & & & & 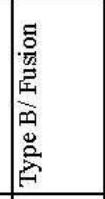 & & & 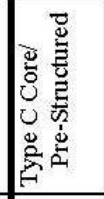 & 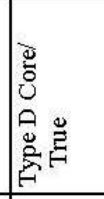 \\
\hline : & & 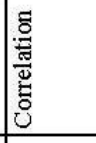 & & & 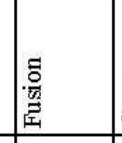 & 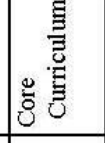 & & & & & & & \\
\hline 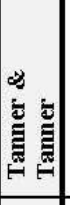 & & 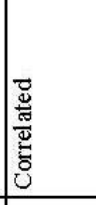 & & 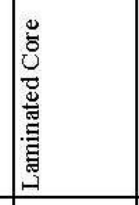 & 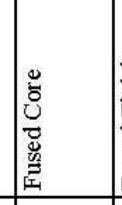 & 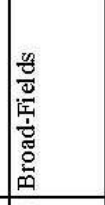 & & & & & & 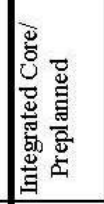 & 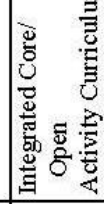 \\
\hline 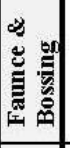 & & 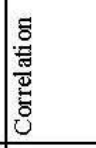 & & & $\mid$ & 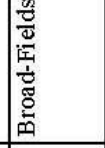 & & & & & & & \\
\hline \begin{tabular}{|l|} 
\\
: \\
\end{tabular} & & & & 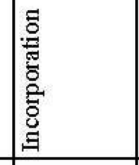 & 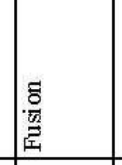 & & & & 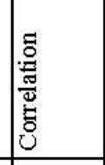 & $\mid$ & & & \\
\hline : & 䓂 & 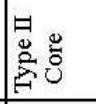 & & & 甚。气 & & 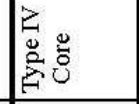 & & & & & 尊 & \\
\hline 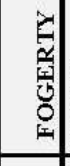 & 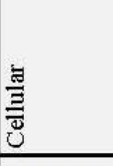 & 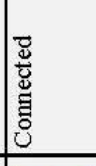 & \begin{tabular}{|l|}
$\frac{\vec{z}}{3}$ \\
$\frac{3}{2}$ \\
\end{tabular} & 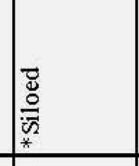 & 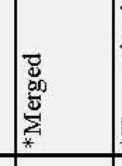 & 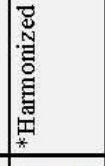 & 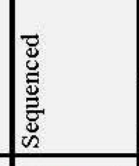 & 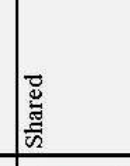 & 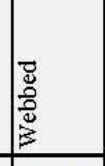 & 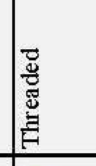 & 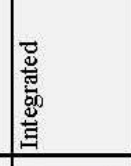 & 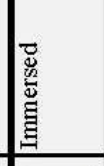 & 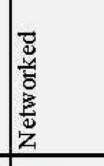 \\
\hline & - & $\begin{array}{ll}0 \\
0 \\
\end{array}$ & (0) & : & ód & 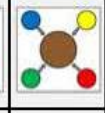 & 8 & 8 & $\because \because: 0$ & $\because$ & 8 & 0 & : \\
\hline 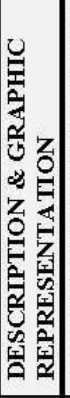 & 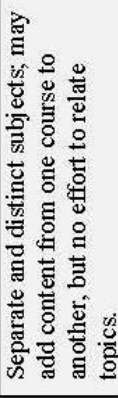 & 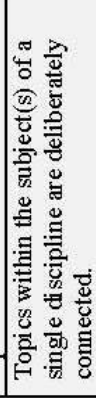 & 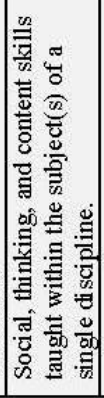 & 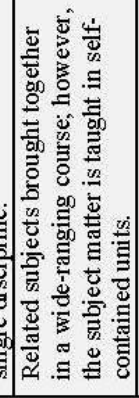 & 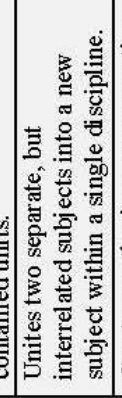 & 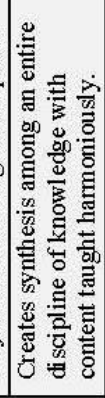 & 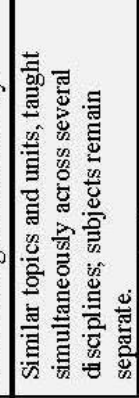 & 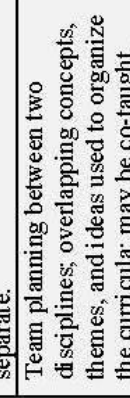 & 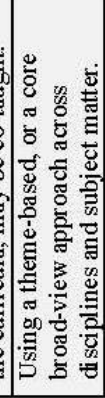 & 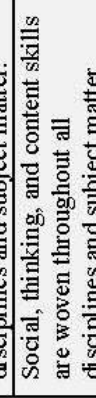 & 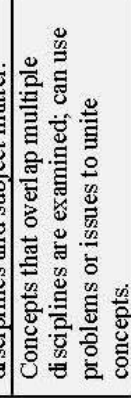 & 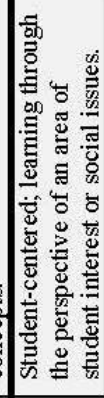 & 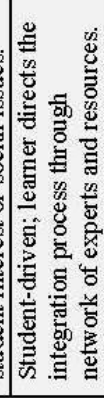 \\
\hline $\mathrm{z}$ & & & 部表: & 言 & & & & & 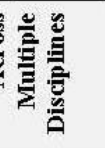 & & & & 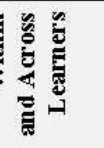 \\
\hline 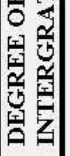 & ) & & & & & & & & & & & $>$ & 苇 \\
\hline
\end{tabular}

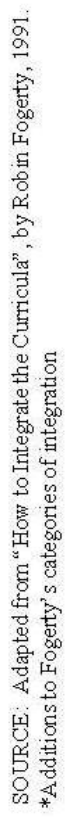

Figure 2.2. The patterns of curriculum integration: A comparative matrix. 
Type III Core fuses separate subjects into a united whole by combining course content. Although Type III Core does depart from the separate subject arrangements represented in Types I and II, it does maintains the concept of subject-driven content. As such, Types I, II, and III are single discipline designs that correspond respectively to the Cellular, Connected, and Merged arrangements of curriculum integration. Type IV Core mirrors Type III in structure; however, unifying content is derived from the common needs, problems, and interests of the student which reflects a multidisciplinary webbed structure. In Type V Core, no curricular structure exists, as content is driven by student needs rather than by subjects or courses (Bullough, 1999); thus, indicating an alignment with Immersed integration. Building on Alberty's five types of curricular organization, Grace Wright (1958), identified four block-time course arrangements. Type A/Correlation maintains separate subject boundaries between block-time courses, but connects them through either planned or unplanned correlation. In a similar separatesubject arrangement, Type $\mathrm{B} /$ Fusion unifies block-time courses around a central theme or unit of work. Type C/Pre-Structured Core organizes block-time courses using predetermined problem areas as influenced by the personal and social needs of students, whereas students and teachers select problems to solve in Type D/True Core (Fetterhoff \& Bossing, 1959; Wright, 1958). Wright's curriculum patterns align respectively with Connected, Webbed, Immersed, and Networked representations of integration.

Faunce and Bossing (1958) present subject-centered patterns of curricular arrangement as follows: Correlation, Fusion, and Broad-Fields. Similar to Type II Core, Correlation connects commonalities among subjects, yet maintains disciplinary boundaries, whereas Fusion, like Type III Core, merges interrelated subjects into a new 
subject, such as the merging of physics and chemistry into physical science. The BroadFields approach correlates to the Harmonized representation of integration because it creates synthesis among an entire discipline(s) of knowledge with content taught harmoniously. Examples include humanities, language arts, and industrial arts courses. Paralleling the arrangements presented by Faunce and Bossing, Vars (1993) offers three ways to interrelate different subject areas: Correlation, Fusion, and Core Curriculum.

In addition to the patterns presented by Faunce/Bossing and Vars, Tanner and Tanner (1980) also incorporate the Laminated Core arrangement, as well as alternatives to the subject-centered curriculum: Integrated Core/Preplanned, Integrated Core/Open, and Activity Curriculum. The Laminated Core brings related subjects together in a broad spectrum course; however, the subject matter is taught in self-contained units. For example, a course in home economics may include separate units on child development, foods, nutrition, and life skills. Thus, the Laminated Core aligns with a Siloed representation of integration. Although organized around key issues and problems, the Integrated Core/Preplanned correlates with Alberty's Type V Core and Wright's Type C/Pre-Structured Core because the teacher determines the sequence and structure of the curriculum. In contrast, the content of the Integrated Core/Open and Activity Curriculum are jointly planned between students and teachers with no formal structure (Plihal et al.; Tanner \& Tanner, 1980).

Badley (1986) identifies four curricular patterns: Incorporation, Fusion, Correlation, and Harmonization. Incorporation and Fusion align, respectively, with the Laminated Core presented by Tanner and Tanner (1980) and Fusion as represented by Faunce \& Bossing (1958) and Vars (1993). Correlation builds connections between 
separately taught subjects through the use of thematic units, indicating a Webbed association, while Harmonization introduces divergent skills, such as social, thinking, and technology, and unites them across disciplines for a Threaded approach to integration.

Models. A comparative matrix of models of integration reported in the literature is presented in Figure 2.3. Models of integration are comprehensive in nature and also place integration on a continuum from lowest/no integration to highest/extreme integration. Fogerty’s (1991a) representation of integration, although used as an alignment tool in this manuscript, is also categorized as an integrative model. Jacobs (1989) also uses the continuum metaphor for designing integrated curriculum in a six options model. Option one, Discipline-Based Content design, makes no attempt at integration; whereas the second, Parallel Discipline design alters only the timeline of lessons so they correspond with lessons in another discipline. Complementary Discipline Units, the third option, bring together related disciplines in the form of a thematic unit. The fourth, Interdisciplinary Units go a step further, bringing together all the disciplines to deliver a team-based, time-sensitive integrative unit. The Integrated Day, option five, focuses on the needs and problems of students and the curriculum is aligned to student questions and interests. The last option, and most extreme, is the Complete Program in which students create curriculum as it represents their lives. Jacob’s representations of integration align respectively with Cellular, Sequenced, Webbed, Integrated, Immersed, and Networked representations of integration. 


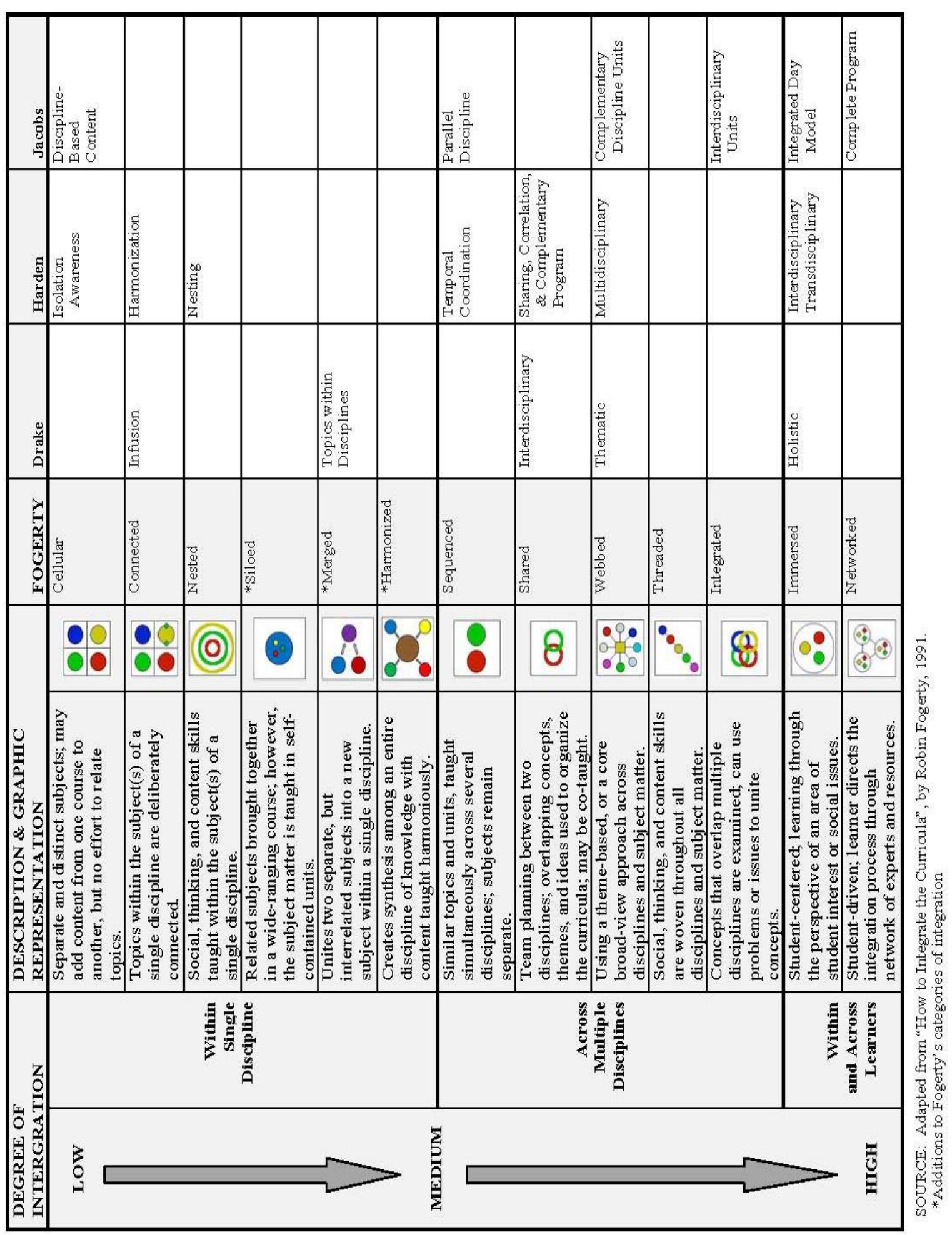

Figure 2.3. The models of curriculum integration: A comparative matrix. 
Harden (2000) uses components of both the Fogerty (1991a) and Jacobs models (1989), describing the integration scale as an 11 step ladder as follows: Isolation; Awareness; Harmonization; Nesting; Temporal Coordination; Sharing; Correlation; Complementary; Multidisciplinary, Interdisciplinary, and Transdisciplinary. Drake (2007) presents integration in a four-part model with Fusion representing low-level integration between subjects; Multidisciplinary defining mid-level, theme-based connections within disciplines; Interdisciplinary describing mid-level, theme-based connections across disciplines; and Transdisciplinary representing extreme integration in a discipline-free environment. However, fusion as defined by Drake, builds informal links among subjects; thereby representing a lesser degree of integration than fusion as defined by other scholars (Faunce \& Bossing, 1958; Tanner \& Tanner, 1980; Vars, 1997).

Classifications. A comparative matrix of models of integration reported in the literature is presented in Figure 2.4. Other approaches to integration are presented in less specific terms, and are fundamentally, broad classifications of integration as categorized by other scholars. Gehrke (2006) identifies two main classifications: Correlated/Fused and Core Curricula/Unified Studies. The Correlated/Fused faction approaches align with all single discipline and across discipline designs. The Core Curricula/Unified Studies, on the other hand, relate to non-disciplinary, student-centered designs that focus on the personal, social, and democratic process of education, including Immersed and Networked approaches to integration. 


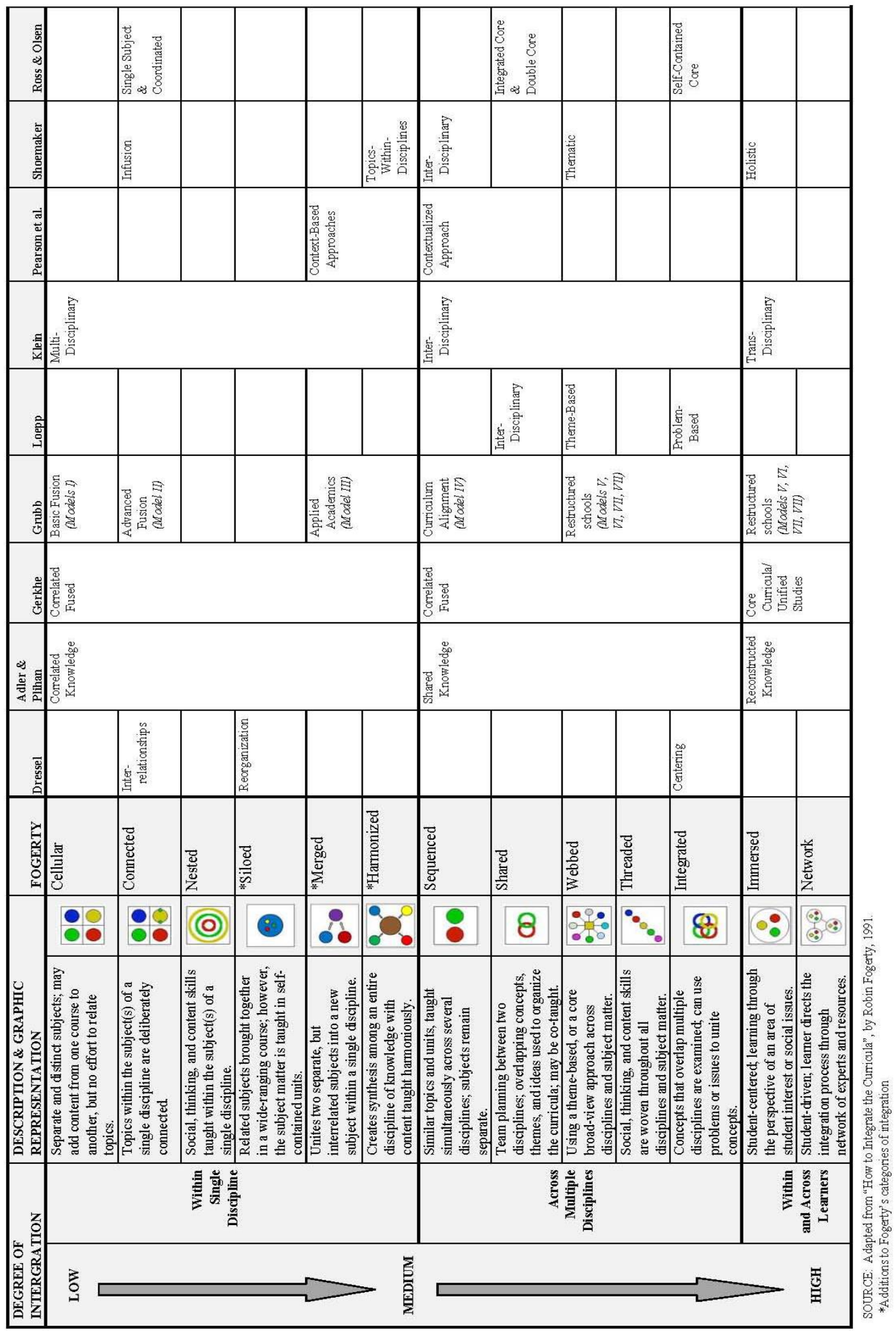

Figure 2.4. The classifications of curriculum integration: A comparative matrix. 
Dressel (1958) categorizes integrative efforts as those developing interrelationships among existing courses (Interrelationships); those involving reorganization of content into more general courses (Reorganization); and those involving the centering of content about vital problems or society or of the students (Centering). Dressel’s classifications align with Connected, Siloed, and Integrated, respectively. Klein (2006), on the other hand, organizes integrative approaches as multidisciplinary, interdisciplinary, and transdisciplinary. Multidisciplinary approaches represent single discipline designs at the lower end of the integration continuum, such as Connected, Parallel, and Awareness, whereas Interdisciplinary approaches typify across discipline models at the midpoint of the spectrum, such as Sequenced, Shared, and Webbed. Klein refers to classifications at the extreme end of the integration continuum as Transdisciplinary; thereby aligning with Immersed and Networked representations of integration (Plihal et al.). Shoemaker (1991), alternately, uses the terms Infusion for Connected designs; Topics-Within-Disciplines for Harmonized designs; Interdisciplinary for Sequenced designs; Thematic for Webbed designs; and Holistic for Immersed designs.

Adler and Flihan (1997) refer to the interdisciplinary continuum as being constructed of three ways of knowing that embody stages of disciplinary blending as follows: Correlated Knowledge; Shared Knowledge, and Reconstructed Knowledge. Correlated Knowledge retains disciplinary boundaries, incorporating broad-based connections between subjects (single discipline approaches). Shared Knowledge, the second stage of disciplinary blending, views knowledge as apportioned between disciplines through overlapping concepts and patterns (across discipline approaches), 
whereas stage three, Reconstructed Knowledge, eliminates disciplinary boundaries (within and across learners).

Loepp (1999), in a deviation from the hierarchal representation of integration, categorizes integration as Interdisciplinary, Problem-Based, and Theme-Based. Interdisciplinary approaches group traditional subjects into blocks of time, assigning a given number of students to a team of teachers. Problem-based models incorporate issues and concerns across disciplines and theme-based models utilize common units of study. However, Loepp does note these representations do not represent a complete classification of integration. In another non-linear organization, Pearson et al., (2010) propose two overarching classifications of curriculum integration: Context-Based approaches and Contextualized approaches. A Context-Based approach begins with the identification of academic content and embeds this content into an applied setting, such as experiential learning or through the completion of a project. The authors define applied academics as a context-based or programmatic approach to curriculum integration. For this purpose, the researcher aligns Context-Based approaches with single discipline Merged or Harmonized designs of integration. In contrast, a Contextualized approach begins with the CTE curriculum and the identification of naturally occurring academic content; thus, through authentic applications of CTE, academic content is enhanced to support the understanding of both. Contextualized teaching and learning (CTL), then, is a process-driven approach that provides rigor through the combining of CTE and academics, and relevance through application of real-world problems; thus, Contextualized approaches are correlated to the across discipline designs of Sequenced and Shared. 
In yet another approach, Ross and Olsen classify integration according to the role of the teacher. The Single Subject approach course is taught by one teacher through meaningful, real life applications, whereas the Coordinated approach a single subject is co-taught. With the Integrated Core one teacher remains with students for two or three periods and connects one subject to another through a common core. For example, a teacher may present language arts skills in the context of a science core. The Integrated Double Core classification involves two teachers instructing the same students within two integrated cores; thus, one may teach math skills in the context of science and the other language arts skills within a social studies context. The Self-Contained Core calls for one teacher with multiple subject area certifications to instruct a group of students in an all day timeframe through one or two meaningful contexts (Jenks, 1998). The Ross and Olsen approaches to integration correspond with Connected (Single Subject and Coordinated), Shared (Integrated Core and Double Core), and Integrated.

Practical applications. Grubb, Davis, Lum, Plihal, and Morgaine (1991) classify integration in terms of the degree of curricular change between CTE and academic courses. These practical applications are the vehicle by which academic and CTE integration occur at the school level. As such, the authors identify eight practices for integration. Model I/Basic Fusion simply adds academic content to CTE courses, with no collaboration between academic and vocational teachers. Moreover, academic course content remains untouched, whereas CTE course content is modified to add remedial academic skills. Model II/Advanced Fusion links academic and CTE teachers to enhance academic competencies in CTE programs. Again, academic courses are left intact and academic skills are incorporated through the CTE courses; however, academic 
teachers are responsible for initiating integration and may do so by lesson development. The CTE/FCAT Connection intervention represents Model II integration. Making academic courses more occupationally relevant, Model III/Applied Academics, allows for the incorporation of CTE content into academic course content; however the CTE course curricula is left intact (i.e. no changes). Moreover, the integration is the responsibility of the academic teacher, not the CTE teacher; thus, Model III/Applied Academics does not promote collaboration between academic and CTE teachers. Examples include courses such as applied mathematics and applied communications. Models I, II, and III represent integrative approaches at the low-end of the continuum or within a single discipline. Model IV/Curriculum Alignment correlates standards and course competencies for select CTE and academic courses; thus, content of both academic and CTE courses are coordinated; thus, Model IV/Curriculum Alignment calls for academic and CTE teachers, working together, to modify the content of both courses, thereby incorporating linkages across disciplines. Model V/Senior Project, develops student skills in responsibility, problem-solving, and communication via a culminating project. Model VI/Career Academy is a school-within-a-school classification that combines high-level courses and a concentrated program of study focusing on a career area. In Model VII/Magnet School, the school program of study is organized around an occupational area, with students enrolled in courses related to that area. Alternately, Model VIII/Career Pathways incorporates occupational/career clusters into the comprehensive high school. Models V, VI, VII, \& VIII are coined, restructured schools and typify integration that requires whole school reform (Schmidt et al., 1992; Wasike, 
1995). As such, these approaches represent both across discipline and within and across learner designs.

Integrative locus. Efforts to integrate the curriculum can also be impacted by the locus, or level of decision making. Federal and state loci emphasize program development, measurement, and evaluation, whereas district and school loci involve program planning and structural changes in scheduling, course delivery, and teacher deployment. At the classroom level, individual teachers have the responsibility for creating and teaching integrative units of study. As such, decision-making must be vertical in nature, incorporating teachers and staff (Case, 1991).

Integrative coherence. Educational coherence indicates the educational significance of integrative activities. Although the opportunity to identify common features or underlying principles among curricular elements is always present, the connection may be insignificant. That is, integrative coherence requires more than merely uniting two or more curricular elements (Case, 1991). Noskin (1995) suggests that certain characteristics contribute to a coherent integrative curriculum. Accordingly, a coherent curriculum must be holistic providing unity between school and real life knowledge. A coherent curriculum must also provide relevance to students' lives through consideration of their needs, problems, and interests, as well as respect student diversity and centralize cultural experiences as a bridge from current understanding to future learning. Finally, in order for a curriculum to be coherent, it must empower teachers and students to reconstruct knowledge. Students must have the freedom to question knowledge through research and experiential learning in order to solve 
problems. Empowered teachers, then, play the role of facilitative educator and nurture this self-directed learning (Noskin, 1995).

Integrative degree. The degree of integration indicates the extent of integration from low-level/no integration to high-level/extreme integration. Some integrative models such as those offered by Fogerty (1991a), Drake (1991), and Jacobs (1989) suggest that integration is a continuum and that the more connections between subjects indicate a higher level of integration. Others see integration as more complex than a simple linear continuum, suggesting that the method of integration is indicative of the context in which it is used, rather than a perceived level. Accordingly, this oversimplification can negate the distinctive requirements of the various areas of knowledge and what facets of disciplines can appropriately be connected (Case, 1991; Venville et al., 2002).

Perspectives on integrative components. The theoretical patterns, modes, and practical applications for the organization of curriculum have many commonalities among them. Most notably is the reference to a continuum of integration, from low to high (see Figure 2.5).

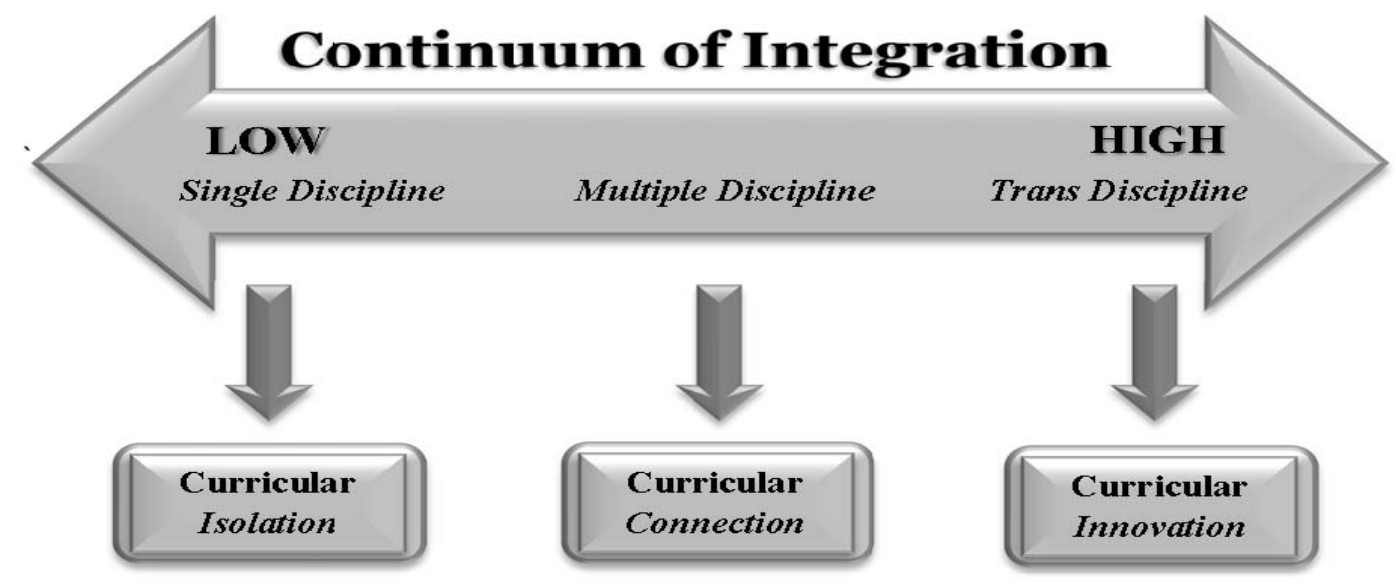

Figure 2.5. The continuum of curriculum integration. 
Advantages and disadvantages of each model are also reflective of the degree of integration. Low integrative models are easy to implement and can allow for simulation of ideas within a discipline, but encourage minimal student transfer of knowledge and foster no connections between disciplines. As a result, students may be confused and lose sight of the main concepts of the activity. Located at the mid-point of the continuum across discipline models encourage the transfer of learning from two or more disciplines through planned teacher collaboration and the development of thematic units; thus, fostering student engagement and motivation as students see connections among disciplines. However, across discipline integration does require extensive, ongoing collaboration, time, commitment, flexibility, and compromise so that themes are thoughtfully selected with rigorous and relevant content. Across and within learner models, or high integrative models, are more difficult to implement, but promote interconnectedness among disciplines and a student-centered environment where learners are stimulated by new information, skills, or concepts. However, these discipline-free models can narrow the curricular focus, if not implemented properly, and the student can be spread too thin and their efforts become ineffective (Fogerty, 1991b; Kysilka, 1998; Merickel, 2003). Given the complexity of integration and its multifaceted components, district-wide integrative efforts are difficult to plan, create, implement, and sustain.

\section{Curriculum Integration: Implications for Practice}

Benefits. Numerous positive changes are associated with the implementation of integrated CTE and academic programs: Integration allows for the inclusion of academic content into CTE courses; the inclusion of CTE content into academic courses; and the 
alignment of curricular content between academic and CTE courses (Grubb et al., 1991;

Grubb, 1995b; Stasz \& Grubb, 1991; Stasz et al., 1994). Scholars also indicate increased collaboration between academic and CTE teachers through team planning, curriculum development, team teaching; thereby reducing teacher isolation and increasing creativity (Bodilly, Ramsey, Stasz, \& Eden, 1995; Jacobs, 1989; Grubb et al., 1991; Stasz et al., 1994). Integrative programs also promote a shift from memorizing facts and procedures to more relevant, contextual, hands on approaches to learning (Jacobs, 1989; Prescott, 1996; Stasz et al., 1990; Stasz et al., 1995). According to Roberson, Flowers, and Moore (2000), several authors indicate that students are better prepared for the workforce as integration promotes project learning, problem-solving skills, and teamwork; that academic skills are strengthened because more high-level academic skills are included in an integrated curriculum; and that student performance on CTE and academic competencies is improved because students learn content simultaneously.

Other positive outcomes of CTE and academic integration include the desegregation and/or equality of academic and CTE students (Andrew \& Grubb, 1995; Benson, 1991; Grubb et al., 1991; Mills, 1997; Oakes et al., 1992; Rumberger \& Palardy, 2005); the creation of new organizational structures, such as career academies and career high schools, that facilitate higher-levels of integration (Bodilly et al., 1993; Grubb, et al.,1991; Heebner, 1995; Katz, Jackson, Reeves, \& Benson, 1995); strengthened guidance and counseling systems (Bodilly et al., 1993; Feller \& Daly, 1992; Grubb, 1995c); enhanced career pathways, career cluster, and post-secondary opportunities (Grubb, 1995b; Hull, 2005; Lekes et al., 2007; Maxwell, 2001); and 
increased motivation and student engagement (Bodily et al., 1992; Plank, DeLuca, \& Estacion, 2005; Lipka, 1997; Stem, Dayton, Paik, \& Weisburgq, 1989; Venville et al., 2002).

Proponents of CTE and academic curriculum integration indicate several psychological, sociological, and philosophical advantages to students in integrated learning environments. Integrative learning that focuses on the psychological needs of students, such as problems, concerns, interests, and aspirations, creates motivation and retention of learning (Faunce \& Bossing, 1958). Moreover, as integration is developmentally appropriate and responsive to the needs of students, student learning and achievement are greatly enhanced as students become actively engaged in the learning process (Dewey, 1916; Vars, 1997). Because integrative curriculum is more compatible with the way the brain works, it also fosters development of higher-order thinking skills as students become the focus of learning (Caine \& Caine, 1991). In another advantage, integration supports the sociological needs of students by preparing them for life in our society helping students make connections between school and life, with an opportunity to make interest-based learning choices (Vars, 2001; Rojewski, 2002). Through a coherent core of essential common learning, deemed necessary for all citizens in a democracy, integration can also provide a philosophical advantage to students using a meaningful framework to examine values (Beane, 1995; Beane, 1997; Vars, 1993).

According to Wasike (1995), several scholars also indicate that teachers can benefit from CTE and academic integrative learning environments. Through work with a cohort of students sharing similar career interests, teachers have the opportunity to 
develop holistic instructional plans that connect CTE and academic content. Integrative environments, then, can improve job satisfaction and self-efficacy through the establishment of strong collegial relationships and subject-area understanding, both within and across disciplines (Arhar, 1997).

Barriers. Although the literature indicates many positive outcomes and advantages to integrating CTE and academic curriculum, there are also challenges that can thwart these efforts. According to Drake (2007), several beliefs can limit integrative education. One such widely held belief is that basic academic skills cannot be covered in integrative programs. This belief stems from the idea that content is the most important aspect of education and that educators do not know enough to teach an integrated curriculum. Also, testing mandates have fostered the notion that academic knowledge belongs in isolated disciplines and, as such, are a 'force fit' in integrated environments. The conviction that integration is superficial, or lacking scope and sequence, can also undermine the development of integrative programs. Furthermore, teachers, who believe in the role of the student as a passive learner and in integration as a strategy for only the academically gifted, may be unwilling to experiment with new teaching and learning strategies.

In addition to stereotypical beliefs regarding integrative education, the literature also reveals systemic barriers as follows:

District and school leadership. Developing, implementing, and sustaining successful curriculum integration efforts require strong leadership, commitment, and planning at both the district and school leaders (Johnson, Charner, \& White, 2003). Successful curriculum integration is contingent on innovative administrators who are 
willing to consider new staffing and scheduling arrangements and who show commitment by allocation of resources (Johnson et al., 2003; Raby, 1995; Walker, 1995). Moreover, integration requires both a commitment to financial investments and human capital to cover the cost of curriculum development, staff, training, and equipment. When leadership and financial support from district and school administrators are absent, teachers are not given the planning time or the incentives required to facilitate the exchange of ideas necessary for developing integrative programs (Jacobs, 1989; Schmidt et al., 1992; Roberson, Flowers, \& Moore, 2000). Compartmentalized subjects and distinct class periods can also act as barriers to integration; thus, leaders must embrace flexible scheduling, such as block-time and alternate day arrangements, and unique teaching scenarios, such as co-teaching, team teaching, and online teaching (Raby, 1995).

Subject-centered approach. Beane (1995, p.617) suggests that disciplines of knowledge are not the real enemy of integration as "those on the front edge of a discipline know that disciplinary boundaries are fluid and often connect with other disciplines to create interdisciplinary fields and projects”. That is, the primary obstacle faced in curriculum reform is the institutionally-based representations of the disciplines of knowledge, the separate subjects. The separate subjects are "territories carved out" (Beane, 1995, p.618) by educators as a form of encapsulation, or narrowing of learning, for economic, social, or academic purposes, rather than for knowledge itself. Subject areas, according to Beane (1995, p. 617), "are a more severe case of the hardening of the categories than the disciplines they represent”. The pervasiveness of the separate subjects approach is rooted in classical humanist view which sees the world as divided 
into counterparts; thus, following this view, alternative views of teaching and learning are usurped by the subject-area teaching and learning (Tyack \& Tobin, 1994).

Defining integration. The literature on integration is plagued with vague definitions, esoteric differences among curricular designations, and an absence of common vocabulary (Adler \& Flihan, 1997). That is, the term integration means almost anything, as long as there is a linkage between previously isolated content areas (Kysilka, 1998). Hopkins, as cited by Morse (1958, p.144) in the book Integration of Educational Experiences, expresses this idea:

"With increasing frequency and with expanding meaning, the noun integration, or one of its grammatical associates, has been used to designate educational goals, processes, and outcomes. It has been used to describe the individual as a whole, some aspect of his behavior, the entire school curriculum, the working relations between teachers and pupils, the administrative organization, the relation of school to other social agencies or the community as a whole, the functions of the school in a democracy, how learning takes place, and in many other ways too numerous to mention".

As a community of educators, clarification of the meaning of integration is paramount in implementing integrative programs. Without an agreed upon use of language, communication becomes disjointed and confused, resulting in negative implications for integrative teaching and learning (Venville et al., 2002).

Structure of schools. The traditional school structure with its standardized organizational practices can prohibit curriculum integration. Tyack and Tobin (1994, p. 454) refer to this enduring structure as 'the grammar of schooling' defining it as the "regular structures and rules that organize the work of instruction”. Given its longevity, this institutional framework is difficult to overcome as multiple factors contribute to its persistence, including social and political influences on schooling; the time honored 
relationship between teachers and students; parental pressure for an academic focus and higher education; increasing graduation requirements; over-crowded curriculum; discipline-based teacher qualifications; traditional assessment structures; and departmentalized school policies and procedures (Tyack \& Tobin, 1994; Venville et al., 2002).

Role of the teacher. Research also reveals that personal teaching styles, as well as educational and professional experiences may impede changes in instructional strategy (Martin, 2011); thus, educators not exposed to integration in their own schooling are more likely to reject new teaching methods for the safety of pre-prepared materials (Barefield, 2005). Zirke (2004) indicates that teacher education programs emphasize knowledge in specific content areas, thereby preparing educators to present curriculum in an isolated context. Teacher content knowledge is an important factor in developing integrative programs; however, "when teachers do not have the prerequisite background needed to integrate the curriculum, there is a considerable problem with regard to the development of student knowledge” (Harrell, 2010, p.150). Moreover, teacher theoretical rationales and subject-area territoriality can effectively block development of integrated curriculum. Jacobs (1989) suggests this 'polarity problem' occurs because, traditionally, the disciplines of knowledge operate in a 'them and us' structure, rather than in a collaborative 'we' formation. To that end, gaining consensus on what subject-area content to merge and/or delete can threaten the professional identity of teachers (Applebee, Adler, \& Flihan, 2007; Beane, 1995; Goode, 1998; Schmidt, Finch, \& Faulkner, 1995). 
Furthermore, in an educational environment that espouses separatism, some educators see integration as diluting the academic curriculum (Venille, Wallace, Rennie, \& Malone, 2002; Zirkle, 2004). Jacobs (1989) indicates that an integrative design lacking in scope and sequence can foster this problem as integrated instruction becomes a mere sampling of content from each discipline. Patrick and Remy as cited by Wraga (1993, p. 213) suggest that interdisciplinarity often "fails to provide appropriate conceptual and factual foundations for studies of problems, issues, and values” and that "students in poorly organized interdisciplinary courses often flounder". Other disadvantages of integration related to changing educator responsibilities include working with multiple groups of students; adding content responsibilities; dealing with at-risk students or low achievers; and an overwhelming amount of time and energy (Stasz et al., 1994; Vasquez-Mireles, \& West, 2007; Wraga, 1993).

Scientifically-based research. Federal funding is increasingly tied to scientifically-based research; however, the majority of CTE studies are still descriptive or qualitative in nature. As such, there is little empirical research to substantiate that greater learning occurs in high quality integrated classrooms versus high-quality discipline-based classrooms (Grossman et al., 2000). Historically, research in education has not been scientific in nature as the framework for studies cannot be replicated or generalized (Lambeth, Joerger, \& Elliott, 2009). In fact, "the existing literature on this topic is almost entirely comprised of idealized descriptions of programs and how to put them in place, and almost entirely devoid of descriptions of what actually happens when theory meets practice” (Grossman, et al., 2000, p. 9). In an examination of articles from the Journal of Career and Technical Education Research, Gemici and Rojewski (2007) 
indicate that of the 64 articles reviewed between 2001 and 2005, only four use experimental research designs. Scholars indicate the inability to isolate integrated teaching from other closely related variables and an unclear working definition of the term integration as contributing factors to the student achievement research void. Paramount in the literature, then, are the holistic benefits of integration, such as motivation, attitude, cooperation, and the transfer or application of knowledge (Venville et al). As a result, scientifically-based research linking integration practices to student achievement as measured by high-stakes testing remains scarce and, for the most part, inconclusive (Beane, 1997; St. Clair \& Hough, 1992; Stasz et al., 1994).

High-stakes testing. High-stakes testing mandates also undermines integrative teaching as it "narrows curriculum, limits the ability of teachers to meet the sociocultural need of their students, and corrupts systems of educational measurement” (Au, 2007, p. 259). Moreover, in a high-stakes environment that tests factual information, districts and schools are reluctant to engage in the curriculum restructuring required of integrative programs, instead utilizing teach-to-the-test strategies (Kysilka, 1998). Au (2007) in a meta-analysis to determine the impact of high-stakes testing on curriculum, found that of the 49 studies analyzed, $83 \%$ reported changing the content of the curriculum to align to the test. And of these, $69 \%$ narrowed the curriculum to tested content. Moreover, $69 \%$ of the studies indicated that the form of curricular knowledge also changed as a result of high-stakes testing, with $49 \%$ indicating a fragmentation effect. The partitioning of the curriculum into testable pieces, then, reduces the opportunity to integrate with other subjects or disciplines. A final significant finding was an increase in a teacher-centered pedagogy as a result of the high-stakes setting. 
"The most prominent theme pairing suggests that there is a relationship between the narrowing of curriculum and an increase in teacher-centered instruction as teachers respond to pressures created by high-stakes testing environments” (Au, 2007, p. 263). Other studies have shown that most state tests do not measure the higher order thinking, problem-solving, and creativity needed for students to succeed in the $21^{\text {st }}$ century (Resnick \& Berger, 2010). More specifically, standardized tests view academic areas, such as mathematics and literacy, as isolated components rather than an integrated whole. According to Stowell and McDaniel (1997), to test for alignment, six of the most widely used standardized tests were compared to the curriculum standards identified by the National Council of Teachers of Mathematics. The results indicate that these tests do not assess the range of mathematics content; do not reveal student processes; and continue to emphasize procedures over content. Furthermore, "multiple choice tests do not capture the relationships among ideas and how students are thinking about a particular subject” (Stowell \& McDaniel, p. 140). And, according to Orlich (2004), numerous studies also question the reliability of high-stakes test gains; conclude that high-stakes tests have little impact on student achievement; contribute to low student performance, and intensify dropout rates; maintain that unrealistically large AYP targets may result in more failing schools than non-failing schools; and caution that discrepancy in selection and analysis of test data minimizes the conclusions and the impact on student performance. Guisbond \& Neill (2004, p.12), emphasize that “at NCLB’s destructive core is a link between standardized testing and heavy sanctions through the rigid and unrealistic ‘adequate yearly progress' (AYP) formula.....that is not grounded in any proven theory of school improvement”. Given that high-stakes testing has both 
direct and indirect consequences on CTE, it is imperative to understand the programmatic implications; however, in a reoccurring theme, little research exists on the relationship between high-stakes testing and CTE (Austin \& Mahlman, 2002).

Back-to-basics pedagogy. As a result of academic legislative mandates and separate-subject curricular design, schools vehemently support integrative connections between academic courses and negate the integration potential of CTE and academics. That is, back-to-basics integration has emphasized a within-discipline design between mathematics subjects or the language arts subjects, rather than connecting CTE and academic education. Yet, given this emphasis, academic integrative efforts have been limited in size and scope. In mathematics, the sequential nature of courses, conceptual and epistemological differences, and teaching practices such as segmenting courses into smaller components, have limited the opportunity for the development of withindiscipline mathematics and/or science integration units (Corcoran \& Silander, 2009; Czerniak, et al., 1999). Similarly, in language arts, sequential teaching materials categorized by skill, have also limited the capacity for integration (Roehler, Fear \& Hermann, 1998). Given the fact that subject-area integration has not been well-defined, McKenna, Robinson, \& Miller (1990) found that language arts teachers spent less than $5 \%$ of class time integrating skills, and content remained segmented into reading, writing, spelling, and grammar components (McKenna, Robinson, \& Miller, 1990; Schmidt et al., 1985).

Other barriers. Critics of integration claim that there is little evidence that an integrated curriculum is any more effective than a well-prepared traditional curriculum. And, scholars suggest a number of claims about integrated curriculum versus a high- 
quality traditional curriculum are not substantiated by research: (a) Integration addresses more real world issues; (b) integration promotes more independent learning; (c) integration offers more opportunities for problem-solving and in-depth learning; (d) integration allows students to more effectively benefit from prior knowledge and encourages more transfer of learning; (e) integration provides more opportunity for teachers to be facilitators of student learning; (f) integration more effectively promotes student achievement; (g) integration promotes personal development and encourages social and democratic responsibility; (h) integration allows for more differentiated learning among learner ability levels; and (i) integration revitalizes career teachers with new teaching and learning experiences (Czerniak, et al., 1999).

\section{Curriculum Integration: Promising Practices}

In the second decade of the $21^{\text {st }}$ century, student academic achievement continues to 'flat line' in an educational environment littered with failed single discipline reform initiatives and a one-size-fits-all, assembly line curricula. Merely adding academic courses and demanding performance by implementing accountability rewards and sanctions may not significantly improve student achievement (Silverberg et al, 2004). Similarly, a workforce education devoid of academic rigor cannot meet the demands of a $21^{\text {st }}$ century economy. However, research suggests that "almost without exception, students in any type of combined curriculum do as well as, and often better than, students in a conventional departmentalized program” (Vars, 1997, p.181). As such, an effective mixture of both academic and CTE coursework may provide the impetus for improved student outcomes through both rigorous and relevant content and a 
workforce prepared for the challenges in an uncertain economy (Castellano, et al., 2003;

Rojewski, 2002; Silverberg et al., 2004).

National Council of Teachers of Mathematics (NCTM). Leading the standards charge and a new vision for teaching and learning in the late 1980's and 1990's, the National Council of Teachers of Mathematics (NCTM) released a series of three publications that represent a historic first attempt by a professional organization to develop precise goals for educational leaders, teachers, and policymakers: The Curriculum and Evaluation Standards for School Mathematics in 1989; the Professional Teaching Standards for School Mathematics in 1991, and the Assessment Standards for School Mathematics in 1995. The NCTM publications acknowledged the importance of mathematical literacy in the $21^{\text {st }}$ century and articulated five general mathematical goals for all students: (a) That they learn to value mathematics; (b) that they become confident in their ability to do mathematics; (c) that they become mathematical problem solvers; (d) that they learn to communicate mathematically; and (e) that they learn to reason mathematically. NCTM maintained that all stakeholders must work together to create mathematics classrooms where students learn important mathematical ideas in the context of authentic problems and situations and in environments that are equitable, challenging, supportive, and technologically equipped for the $21^{\text {st }}$ century (National Council of Teachers of Mathematics, 1989). Mathematics in Context, a middle school mathematics curriculum for grades 5 through 8, was developed to align with the Curriculum and Evaluation Standards for School Mathematics, brain-based research on the problem-oriented approach to teaching mathematics, and the Dutch Realistic Education Mathematics approach. The 
Mathematics in Context curriculum emphasized connections among mathematical topics (i.e. algebra and geometry) and problem situations that give rise to mathematics (Educational Development Center, 2001; Romberg, 2001). According to Romberg (2001), in several cases, teaching the Mathematics in Context curriculum to middle school students increased student performance; however, the Institute of Education Sciences report (2008) revealed that, in 27 studies on Mathematics in Context between 1997 and 2007, no conclusions could be drawn about the effectiveness or ineffectiveness of the intervention.

CTE integrative practices. Research indicates that every high school student takes at least one CTE course (Silverberg et al, 2004); thus, CTE is positioned to play a role in whole school reform. Moreover, according to Drake (2000) teachers indicate that the use of integrative approaches in teaching and learning can respect the accountability movement. By becoming familiar with discipline-based standards, teachers are able to connect the common learning across subject areas (Drake, 2000).

Given this, there is still little empirical evidence to support the notion that CTE can contribute to improved academic outcomes. And, the implications are that CTE could be in grave danger of losing all credibility, resulting in its untimely death (Sinan \& Rojewski, 2007). Castellano et al. (2003) indicate the need to substantiate the link between CTE course taking and student achievement on high-stakes tests. And, NCLB mandates for accountability and student achievement "have necessitated a search for ways to integrate CTE into broader school reform that have improved student achievement as their goal” (Castellano, Stringfield, \& Stone, 2003, p.233). To compound the issue, since the inception of NCLB, scientifically-based research (SBR) 
has become even more important as its principles have been adopted as the standard in the 2006 reauthorization of Carl Perkins Legislation (Sinan \& Rojewski, 2007).

Accordingly,

"the Department of Education is exerting considerable pressure on all sectors of education, including CTE, to propose research designs that follow the provisions of scientifically-based research. A primary driver for the federal position is based on a perceived need to answer questions related to student achievement and program improvement to raise the efficacy of current and future interventions” (Sinan \& Rojewski, p.144).

As federal and state funding is now tied to SBR, CTE researchers and educators must embrace these principles in research efforts to validate CTE as a partner in whole school reform. Despite the vital signs to date, research using SBR standards indicates that integrating CTE and academics can improve student performance.

National Research Center for Career and Technical Education (NRCCTE). A series of reports from a longitudinal study funded through the National Research Center for Career and Technical Education (NRCCTE) follow SBR guidelines and reinforce the theory that relevant CTE curricula, when coupled with rigorous academic elements, such as mathematics and reading, have a positive impact on student achievement (Harris \& Wakelyn, 2007).

NRCCTE: Math-in-CTE. This study sampled over 3,000 students and 131 CTE and mathematics teachers in 12 different states (Stone, Alfeld, Pearson, Lewis, \& Jensen, 2006). Together, CTE and mathematics teachers developed real-world lessons tied to specific CTE courses. During a one-year period, the CTE teachers taught mathematics-enhanced lessons to the experimental group an average of $10 \%$ of the class time. Results showed that the experimental group scored, on average, 21 points higher 
on the TerraNova and ACCUPLACER mathematics ability assessments than students in the control group (Stone, et al., 2006). According to Harris and Wakelyn (2007), students who learn mathematics in the context of solving problems, rather than merely as abstract conceptions, are engaged in learning. Similarly, another study also confirmed that CTE course work can improve reading proficiency (Vaites, 2003).

NRCCTE: Whole-School Reform. The fourth report released from the NRCCTE longitudinal study analyzed student achievement and progress in schools with experimental language arts-enhanced and science-enhanced CTE curricula (Castellano, Stone, Stringfield, Farley, \& Wayman, 2004). Results indicate that CTE students exposed to enhanced reading and writing lessons had greater academic outcomes than students in the control group. In addition, students who academically lagged behind the control group in the early high school years closed this gap during the later high school years. Science results were more mixed, but more often than not, favored students from the study schools (Castellano, et al., 2004). These findings are in concert with other reports from this longitudinal study, which provide evidence that CTE can be offered effectively without forfeiting the integrity of core academic subjects (Castellano, Stone,et al, 2004.).

NRCCTE: Authentic Literacy in CTE. NRCCTE conducted a half-year pilot study in the spring of 2009 to determine the impact of disciplinary literacy strategies on the reading comprehension and vocabulary development of students enrolled in CTE courses. Students in the experimental group (content-area reading strategies) had statistically higher scores on Gates-MacGinitie Reading Test (GMRT) than students in the control group (reading as usual). The pilot test results led a full school-year test of 
the two content-area reading interventions with 116 teachers randomly assigned to one of the content-area approaches or the control group. Teachers in each of the two experimental groups received training in implementing the assigned reading strategy. Students in both experimental groups scored 9\% higher on the GMRT post-test than those in the control group. Moreover, students of teachers who participated in both the pilot study and the full-year study, scored 7\% higher than students of experimental teachers who participated in only the full-year study and $17 \%$ higher than the control group. That is, experience with the content-based intervention produced stronger student outcomes (National Research Center for Career and Technical Education, 2011; Pearson et al., 2010).

High Schools That Work (HSTW). The High Schools That Work (HSTW) was established in 1987 by the Southern Regional Education Board (SREB) State Vocational Education Consortium, a partnership of SREB. HSTW initiative requires participating schools to use six clusters of practices as follow: A program of study combining rigorous academics and relevant CTE coursework; an instructional methodology that actively engages students; CTE and academic integration; career and guidance counseling; and work-based learning. Twelfth grade students in schools utilizing these practices during a two-year period between 1996-1998 showed statistically significant increases in student achievement (Kaufman, Bradby, \& Teitelbaum, 2000; Marsella, 2010; Turnipseed, 2008).

Local practices. Locally developed integration efforts also support the notion that CTE can improve student achievement. In a study by Anderle (2008), increased standardized test scores resulted from integrating academics into CTE courses using a 
career academy model in a California charter school. According to Anderle, school Academic Performance Indicators (API) on the California Achievement Test went up 50 points in the 2006-2007 school year from the previous year. In another study by Foster (1997), integrating vocational content and methodologies into science courses helped students consistently score higher on the NAEP. Hartzler (2000) conducted a metaanalysis of 30 studies on integrated curriculum programs and their effects on student achievement and found that students in integrated programs "consistently outperformed students in traditional classes on national standardized tests, on statewide testing programs, and on program-developed assessments." (Hartzler, 2000, p. 156).

A study conducted by the Chesapeake Public School District in Chesapeake, VA, trained teachers to integrate the Virginia Standards of Learning (SOL) into a tech prep program and CTE courses. Statistics confirm that the academic achievement of CTE students improved from the 1999-2000 school year to 2001-2002 school year as a result of the integrated lessons. The language arts passing rate on the SOL end-of-course tests for CTE students increased from 67.77 to 73.83 and the mathematics passing rate increased from $47.37 \%$ to $67.07 \%$ (Reese, 2003).

A recent dissertation (Aguilera, 2011) analyzes the achievement outcomes of $9^{\text {th }}$, $10^{\text {th }}$ and $11^{\text {th }}$ grade students in a mathematics-enhanced business computer technology education course. The results indicate that $10^{\text {th }}$ and $11^{\text {th }}$ grade students in the experimental group outperformed $10^{\text {th }}$ and $11^{\text {th }}$ grade students in the control group on the Texas Assessment of Knowledge and Skills (TAKS) in all ten mathematics objectives as follows: Objective 1/functional relationships; Objective 2/properties and attributes; Objective 3/linear functions; Objective 4/linear equations and inequalities; Objective 
5/quadratic and other nonlinear functions; Objective 6/geometric relationships and spatial reasoning; Objective 7/2D and 3D representations; Objective 8/measurement; Objective 9/percent, proportions, probability, and statistics; Objective 10/mathematical

processes and tools. Ninth grade students in the experimental group outperformed $9^{\text {th }}$ grade students in the control group on all but Objective 5/quadratic and other nonlinear functions and Objective 6/geometric relationships and spatial reasoning.

\section{Conceptual Framework}

The conceptual framework for this study was tied to constructivist educational theory and contextual teaching and learning (CTL).

Background. Since its inception, the learning theory supporting vocational education has been behaviorism. This competency-based approach, where learning outcomes are clearly defined and students are assessed by whether they can demonstrate those outcomes, allowed behaviorism to prevail throughout the latter part of the 1900s. Industrial age vocational education, then, emphasized job-specific skills to the exclusion of theoretical content and utilized a competency-based education and training (CBET) approach to learning in which connections are formed between stimuli and responses via the application of rewards. A fundamental principle of CBET is the application of knowledge in the performance of workplace tasks. That is, learning outcomes are clearly defined, and learners are assessed by whether they can demonstrate those outcomes (Bowden, 2000). Back-to-basics also utilizes a competency-based approach to teaching and learning through the memorization and reproduction of the same content through various drills, exercises, and tests (Newmann, Bryk, \& Nagaoka, 2001). 
The rapidly changing world of work and ensuing knowledge-era have fueled a cry for a new theoretical framework in CTE: One that unites theory and practice in a holistic, new worldview for the construction of knowledge, rather than perpetuating the $18^{\text {th }}$ century dualism between thinking and doing (Johnson, 2002).

Constructivist educational theory. Constructivism, as a theory of teaching and learning, has roots in the philosophy of pragmatism and the progressive movement (Dewey, 1916); cognitive psychology and affective development (Piaget; Bruner, 1960); sociology (Vygotsky, 1978; Bruner, 1971); and modern neuroscience on brain-based learning (Caine \& Caine, 1991). Caine and Caine in their landmark research on the brain and learning advise that the traditional, industrial model of education fails to teach to the way the brain learns. According to the authors, the brain seeks patterns of organization in which to correlate new information.

"Among the features of brain-based learning are active uncertainty or the tolerance for ambiguity; problem-solving; questioning; and patterning by drawing relationships through the use of metaphor, similes, and demonstrations. Students are given many choices for activities and projects. Teaching methods are complex, life-like, and integrated, using music and natural environments...It involves the entire learner in a challenging learning process that simultaneously engages the intellect, creativity, emotions, and physiology" (Caine \& Caine, 1991, p. 17).

For many curricular theorists, this evidence underscores the need to revisit an integrative curriculum organized around themes, units, and projects. Constructivist teaching and learning correlates to the way the brain works by grounding new learning in past experiences and meaningful contexts, rather than in fragmented parts (Beane, 1997).

Learning from the constructivist perspective, then, is a self-regulatory process of creating new understandings reconciled with prior knowledge and experiences. 
Furthermore, constructivist learning calls for active participation in problem-solving and critical thinking in an authentic environment that involves social negotiation and mediation (Brown, 1998). Central to constructivist educational theory is that human learning is constructed and that learners build new knowledge upon the foundation of previous learning (Fosnot \& Perry, 2005). Learners in a constructivist environment actively assemble their own knowledge and meaning from experiences in order to apply new learning to relevant, real-world issues. This cognitive approach to learning assumes that the mind naturally seeks meaning in relation to the learner's current environment and it does so by searching for relationships that make sense and appear useful (Fosnot \& Perry, 2005). Jerome Bruner, as quoted by Smith (2002), states that "to instruct someone is not a matter of getting him to commit results to mind. Rather, it is to teach him to participate in the process that makes possible the establishment of knowledge. Knowing is a process not a product” (Smith, 2002, para. 12).

Contextual teaching and learning (CTL). CTL is a constructivist educational practice, evolving from a grass roots movement in the early 1990's in response to the well-noted deficiencies of the industrial age educational system. A derivative of the Latin word, contexere, context is defined as the "interrelated conditions in which something exists or occurs" (context, n.d.). CTL is a system of instruction that generates meaning for students by linking academic content to everyday context in a braincompatible manner. By connecting new information to existing contexts (i.e., culture, neighborhoods, family, schools, community), CTL is in concert with how the brain functions; the psychology of learning; and the three scientific principles: interdependence, differentiation, and self-organization (Johnson, 2002). Through 
neuroscience we know that the outside environment plays a pivotal role in brain structure and in the development of pathways, or connections, to create meaning and, ultimately, the transfer of information. In psychological terms, "the search for meaning and regularity begins a birth. There is a constant search for cues for significance that need nurturing” (Bruner, 1960, p. 159). Meaning, then, is central to learning and retention in the constructivist framework and contextual teaching and learning strategies. For instructional processes to be CTL, learning must be extended across disciplines so that students gain a real-life perspective. As a result, students see how the knowledge and skills relate to life either now or in the future. Real-world situations and problems rarely represent only one discipline. The intent of CTL is also for the level of learning to rise so the students can better understand life situations, identify and effectively solve problems, make wise decisions, and think creatively. The learning goals may be based on (1) state, local, and/or professional association content standards from the involved disciplines; (2) essential work skills and other family, employability, and process competencies; and (3) higher-order thinking skills such as problem-solving, critical thinking, and decision making.

Some approaches to implementing CTL are problem-based learning, projectbased learning, cooperative learning, service learning, and work-based learning. Problem-based learning is a CTL strategy for curriculum development and can be defined as "an inquiry process that resolves questions, curiosities, doubts, and uncertainties about complex phenomena in life” (Barell, 2007, p. 3), thereby affording students the experience of examining complex problems from multiple perspectives. Problem-based learning can promote integration among disciplines as questions and 
issues rarely encompass only one subject area. For problems to be considered an instance of problem-based learning, they must be central to the curriculum, focus on questions or problems related to the principles of a discipline(s), involve constructive inquiry, provide for student autonomy, embody realistic characteristics, and result in a cognitive outcome (Bender, 2012; Thomas, 2000). Another approach to CTL, projectbased learning, also involves student in a problem-solving process, but results in either a tangible product. The principles associated with project-based learning development are as follows: (a) an anchor/hook to generate interest and set the stage; (b) collaborative teamwork elements; (c) open-ended driving questions, issues, or uncertainties; (d) a process for investigation or research; (e) essential, need-to-know content and skills; (f) inquiry and innovation; (g) opportunities for reflection; (h) a publicly presented physical product; and (i) a process for feedback and revision (Markham et al., 2003).

CTE/FCAT Connection Model. The CTE/FCAT Connection intervention was a curriculum integration model grounded in constructivist educational theory and contextual teaching and learning (CTL) that utilized problem-based, project-based, cooperative, and work-based strategies. The intervention was a series of academicenhanced CTE lessons that tied medium and highly tested FCAT SSS to the content of 13 introductory CTE courses (see Table 1.1). Figure 2.6 is a graphic representation of the CTE/FCAT Connection components.

Objectives. The objectives of the intervention were: (a) To link the frameworks of 13 introductory CTE courses to medium and highly tested FCAT SSS and essential work skills; (b) to identify a team of volunteer CTE and academic teachers to participate in integrated unit development and implementation; (c) to provide extensive professional 


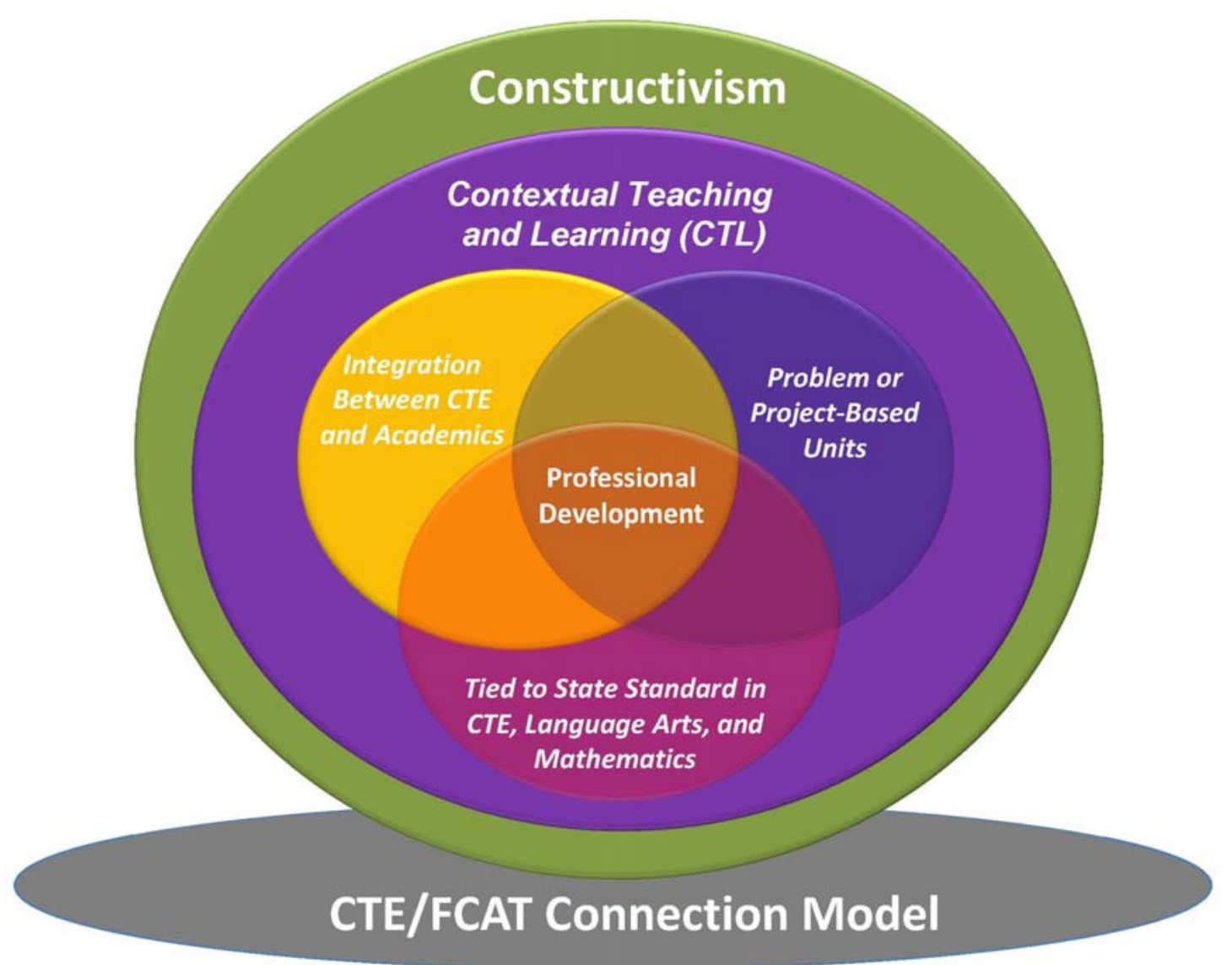

Figure 2.6. CTE/FCAT Connection graphic organizer.

development in CTL for volunteer CTE and academic teachers; (d) to develop rigorous and relevant, contextual-based academic-enhanced lessons in the 13 identified CTE courses; and (e) to implement the academic-enhanced lessons for 26 weeks.

Crosswalk development. District specialists, using Microsoft Access, created a database to merge the following curriculum components: (a) The CTE Curriculum Matrix for Florida developed by the International Center for Leadership in Education (purchased materials), (b) the Florida FCAT SSS for mathematics and language arts, (c) the Curriculum Survey of Essential Skills developed by the International Center for Leadership in Education (purchased materials), and (d) the Florida DOE Frameworks for the 13 identified CTE courses. The crosswalk connected each CTE performance 
standard to related SSS and essential work skills. More importantly, the database linked CTE course frameworks to the medium and high frequency SSS tested on FCAT and the high essential skills necessary for employment (see Appendix A/Figures A1 \& A2). The full-course crosswalk report of standards for each course is the planning tool teachers used to prioritize and select lesson standards for unit development.

Team building. Developing a team of CTE teachers to support curriculum integration through CTL was critical to unit development. In March 2003, potential teacher volunteers attended a district staff development workshop to learn about FCAT, accountability, high school reform, and the ensuing impacts of new legislation on CTE educational practices. Interested teachers were encouraged to participate in the development of a new curricular initiative, and from that meeting nineteen CTE teacher volunteers (called CTE Lead Teachers) were recruited. Academic teachers, called Core Academic Consultants, were also recruited to serve as academic content experts during integrated unit development. Five integrated units were written for 11 courses for a total of 55 units. Two pairs of courses had similar competencies, thus, one set of five integrated units were written for those courses as follows: Marketing Essentials and Fashion Essentials; and Construction Technology 1 and Building Construction Technology 1 (See Table 1.1). Each integrated unit provided approximately 15 hours of classroom instruction for a total of 75 hours of instruction per CTE course. Each CTE Lead Teacher signed a Lead Teacher Compensation Agreement in acknowledgment of the $\$ 500.00$ per unit compensation to be paid upon final unit approval (See Appendix B/Figure B1). In addition, CTE Lead Teacher signed a Lead Teacher Contractual 
Agreement outlining integrated unit requirements, mandatory professional development dates, and a unit development timeline (see Appendix B/Figure B2).

Professional development. Professional development in CTL strategies was the backbone of CTE/FCAT Connection intervention development. CTE Lead Teachers attended over 60 hours of professional training between summer 2003 and spring 2004. The topics were as follows: (a) Integrated unit building blocks including learning about FCAT and Sunshine State Standards, connecting CTE frameworks to the Sunshine State Standards, incorporating the essential work skills, and using the CTE Curriculum Matrix for Florida developed by the International Center for Leadership in Education (purchased materials) to identify medium and highly tested standards; (b) teaching strategies for language arts and mathematics, as well as the design of CTL units; (c) FCAT testing requirements and guidelines, including development of reading and mathematics response forms and rubrics that mirrored FCAT response forms and rubrics; and (d) implementing rigor and relevance into lessons as determined by the Rigor and Relevance Framework developed by the Center for Leadership in Education. In addition, the district team also provided on-site consultants from the International Center for Leadership in Education for training in rigor and relevance and integrated unit development. All CTE Lead Teachers and Core Academic Consultants attended the Model Schools Conference in the summer of 2003. Throughout the 2003 - 2004 school year, CTE Lead Teachers also attended weekly, 2-hour trainings in reading, writing, and mathematics teaching strategies delivered by the Core Academic Consultants, who then provided assistance and feedback on academic connections with the units. Training topics included reading strategies, reading SSS, writing strategies, 
writing SSS, mathematics strategies, mathematics SSS, teaching writing to students, using Bloom's taxonomy, FCAT writing, FCAT reading, FCAT mathematics, rigor and relevance, and FCAT test formatting. The Core Academic Consultants remained on retainer throughout the 2003-2004 school year. CTE Lead Teachers also received CDs containing all workshop materials and lesson development strategies, as well as sample CTE activities tied to the academic SSS. All workshop content was also available on the District website.

Integrated unit development. CTE Lead Teachers, using the course crosswalk reports and Project Foundations worksheet (See Appendix C/Figure C1) were asked to select CTE performance tasks linked to high and medium frequency SSS and essential work skills and then to identify five broad concepts for development of integrated units. Required unit lessons (called Connections) were as follows: (a) Pre-Reading Connection, (b) Reading Connection, (c) Writing Connection, (d) Mathematics Connection, (e) Science Connection (if applicable) (f) Research Connection, and (g) Presentation Connection. Additional lessons were encouraged, but optional. To maintain lesson formatting and uniformity, CTE Lead Teachers used the Project Connection worksheet (see Appendix C/Figure C2) to display general information about the overall unit such as CTE course title and course number; duration of unit; authors and grade level; unit summary; instructional focus (unit topic and academic strands); and the level of rigor and relevance. Both required and optional lessons were created using a standard template to document Connection standards, teacher instructions, student instructions, assessment information, learning style modifications, time requirements, equipment needed, materials used, resources and a list of attachments (see Appendix 
C/Figure C3). All teacher and student lesson attachments followed on subsequent pages (i.e. readings, web pages, grading forms, rubrics, etc). For verification of teaching standards, the course Crosswalk Report, containing lesson-specific standards (CTE performance tasks, SSS, and essential work skills), was included at the end of each unit.

CTE/FCAT Connection intervention lessons contained academic connections, as well as high order thinking skills, alternatives for various learning styles, and rigorous and relevant content. The Rigor/Relevance Framework was the tool CTE teachers used to analyze the level of difficulty of curricula and instruction and the visual representation of both the cognitive complexity and the application level of the knowledge and skills required by a lesson. The Framework placed activities in one of four quadrants according to cognitive complexity and level of application as follows: Quadrant A - Acquisition; Quadrant B - Application; Quadrant C - Assimilation; Quadrant D - Adaptation (International Center for Leadership in Education, 2013). All integrated units contained at least one Quadrant D activity to meet the rigor requirement and lessons were also sequential, building skills from low to high in complexity and application. In addition, as applicable within lessons, questions were phrased in FCAT format and responses provided in an FCAT framework to provide practice and familiarity for FCAT testing (see Appendix C/Figure C4 and C5).

The CTE/FCAT Connection integrated units also contained problem-solving and project-based elements; cooperative education and work-based elements, as well as critical thinking components emphasizing student research and active learning. For example, in an Early Childhood Education 1 unit, student cooperative teams researched brain development in the critical first years of a child's life and then created 
developmentally appropriate activities for enhancing brain development in young children. These student-developed activities were then implemented in an on-campus preschool class with feedback given by the instructor, student peers, and an outside childcare professional. In an Agriscience Foundations 1 unit, students researched multiple resources to learn the process for developing a business plan and starting an agriscience business. Students researched marketing techniques to determine the most appropriate method for selling a unique agriscience product. The unit outcome was both cognitive, in the form of a presentation, and tangible, in the form of a unique product prototype. In yet another example, Business Computer Programming 1 students researched the use of statistics in sports and then designed, created, and implemented a database program that kept track of scores and team statistics for a high school sports program. Students had to package and present the program to athletic directors from several local high schools. In a Business Systems and Technology unit, student teams used Excel to solve real world problems involving community preparedness and restoration in the event of a natural disaster. The integrity of the academic connections within each unit was verified by the Core Academic Consultants who provided assistance throughout the lesson planning and development process. Similarly, district CTE Curriculum Specialists also provided on-going support and reviewed integrated units for content and CTL components. Integrated units not meeting both academic and content requirements were revised and resubmitted.

The nature of these examples illustrates how the CTE/FCAT Connection intervention fit into the literature on curriculum integration. That is, the intervention fell at the lowest end of integration continuum (See Figure 2.5). This single discipline 
model embedded academic standards into CTE content without modifying an academic course(s). According to Grubb et al (1991) models of integration that simply incorporate academic content into CTE courses characterize basic fusion models, while advanced fusion models require modification of the CTE course by the academic teacher(s). Accordingly, the CTE/FCAT Connection intervention was a blend of basic and advanced fusion (See Figure 2.4).

Implementation. The district CTE department was given approval by the school board and district instructional council to implement the CTE/FCAT Connection intervention in fall of 2004. In a project launch celebration, CTE Lead Teachers were recognized throughout the district as curriculum designers and integrative practitioners. Moreover, in a show of support, the district school board and leaders gave CTE Lead Teachers the flexibility to deviate from sequential curriculum maps and traditional instruction to teach using only the integrated units. All integrated units and instructional resources were uploaded to the district CTE website for ease of access.

CTE Lead Teachers, along with district specialists and Core Academic Advisors, maintained a professional learning community during the implementation period of the CTE/FCAT Connection intervention through attendance in four day-long continuous improvement sessions, as well as in weekly school meetings to discuss teaching strategies; to share successes and challenges; and to make revisions. In these sessions teachers addressed issues associated with teaching the integrated units in a nurturing, collaborative environment. Furthermore, in a peer evaluative and supportive manner, CTE Lead Teachers observed at least two other CTE Lead Teachers teaching the units during the implementation year. In addition, to monitor the teaching of integrated units, 
CTE Lead Teachers agreed to complete online teaching timelines identifying the dates and class periods in which integrated units were taught. District specialists and school administrative staff then visited CTE/FCAT Connection intervention classrooms weekly to observe integrated teaching. Visitations were both announced and unannounced and observations were logged using an online database as a measure of control. During the implementation time period, CTE Lead Teachers also met with district specialists weekly. The 26 week intervention commenced prior to FCAT testing in spring 2005.

The integrated units featured in the CTE/FCAT Connection intervention were rooted in constructivist educational theory and contextual teaching and learning (CTL) strategies, which served as the conceptual framework. This framework was grounded in the idea that rigorous mathematics and reading standards integrated into relevant CTE courses were more likely to result in higher performance on a standardized measure of achievement as compared to non-integrated courses. 


\section{CHAPTER THREE: METHODOLOGY}

The purpose of this study was to determine whether students who participated in CTE courses that integrated core mathematics and reading standards performed better on a test of mathematics and reading skills compared to students who participated in traditional, non-integrated courses. The intervention, titled the CTE/FCAT Connection, was a district-wide integrated curriculum initiative that resulted in the development of over 200 integrated units in 55 CTE courses during a 6 year period. For the purpose of this study, the first round of 13 CTE courses targeted for integrated curriculum development were used as indicated in the conceptual framework (pp. 88) and in Table 1.1. This chapter contains the following sections related to methodology: Research design; population and sampling procedures; instrumentation; and data collection and analysis.

\section{Research Design}

A non-equivalent, quasi-experimental research design was used to investigate the effects of curriculum integration and student performance on a state-standardized test of mathematics and reading skills. The manipulated independent variable, the curriculum integration intervention, was classified as a nominal variable, and the dependent variable, scores on the reading and mathematics skills test, was classified as a continuous variable. Using a between-subject, non-equivalent group design (NEGD) allowed the researcher to non-randomly assign intact classroom sections of students to the treatment and control groups. The study was considered longitudinal in that it took 
place over time (26 weeks) and two measurements (prior achievement scores and posttest scores) were used to compare the treatment group to the control group in an effort to determine the degree of change that occurred as a result of the intervention (Cresswell, 2009; Campbell \& Stanley, 1963; Trochim, 2006).

\section{Population and Sample}

A central Florida school district that serves approximately 20,000 high school students of all abilities and grade levels, with more than $50 \%$ of these students enrolled in CTE courses (National Center for Education Statistics, 2011) was the setting for this study. The student target population included approximately $2,0009^{\text {th }}$ and $10^{\text {th }}$ grade students enrolled in the 13 identified CTE courses. The CTE teachers who taught the 13 identified introductory courses were targeted as potential integrated unit development and intervention candidates. A formal invitation and email memo outlined the purpose and rationale (as identified in the review of literature) for the intervention, and informational meetings discussed the process and time requirements. Nineteen CTE teachers volunteered and, in collaboration with volunteer mathematics and language arts teacher-consultants, created the academic-enhanced CTE lessons. These 19 CTE Lead Teachers represented 9 of the 9 district high schools and had between 5 and 25 years of teaching experience in their respective content areas. Nine of the 19 teachers began their careers in the private sector, then transitioned into teaching. Of those nine, all held occupations related to their current teaching assignment, and became licensed to teach as identified by Florida vocational certification guidelines.

The unit of analysis for the study was the student and a non-probability

convenience sample allowed for the non-random assignment of intact classroom sections 
of students to the treatment or control group. More specifically, students enrolled in one of 13 introductory CTE courses taught by a CTE Lead Teacher (those who developed and taught the integrated units) were assigned to the treatment group. The mathematics treatment group consisted of $3269^{\text {th }}$ and $10^{\text {th }}$ grade students and the reading treatment group consisted of $3299^{\text {th }}$ and $10^{\text {th }}$ grade students. The mathematics and reading control groups, then, represented all other $9^{\text {th }}$ and $10^{\text {th }}$ grade students in non-integrated sections of the 13 identified CTE courses taught by teachers other than the 19 CTE Lead Teachers.

District demographics. With nearly 63,000 students and more than 8,000 employees, the study took place in a school district that was the state's tenth largest (see Figure 3.1).

Demographics and student achievement. The achievement gap in mathematics and reading assessment scores based on gender, race, socio-economic status, and grade transition have long been observed and discussed among educators and researchers. According to The Nation's Report Card, the mathematics average for high school White students is higher than the average scores for Black and Hispanic students, with Hispanic students scoring higher on average than Black students (National Center for Educational Statistics, 2007). This ethnic trend also held true for the identified District (see Table 3.1).

Achievement gaps by gender appear earlier in the U.S. than in most other countries and gaps in both mathematics (favoring males) and reading (favoring females) seem to be larger in later grades $\left(8^{\text {th }}\right.$ and $\left.12^{\text {th }}\right)$ than at earlier grades (National Center for Educational Statistics, 2007). Research also suggests that, on average, schools with 


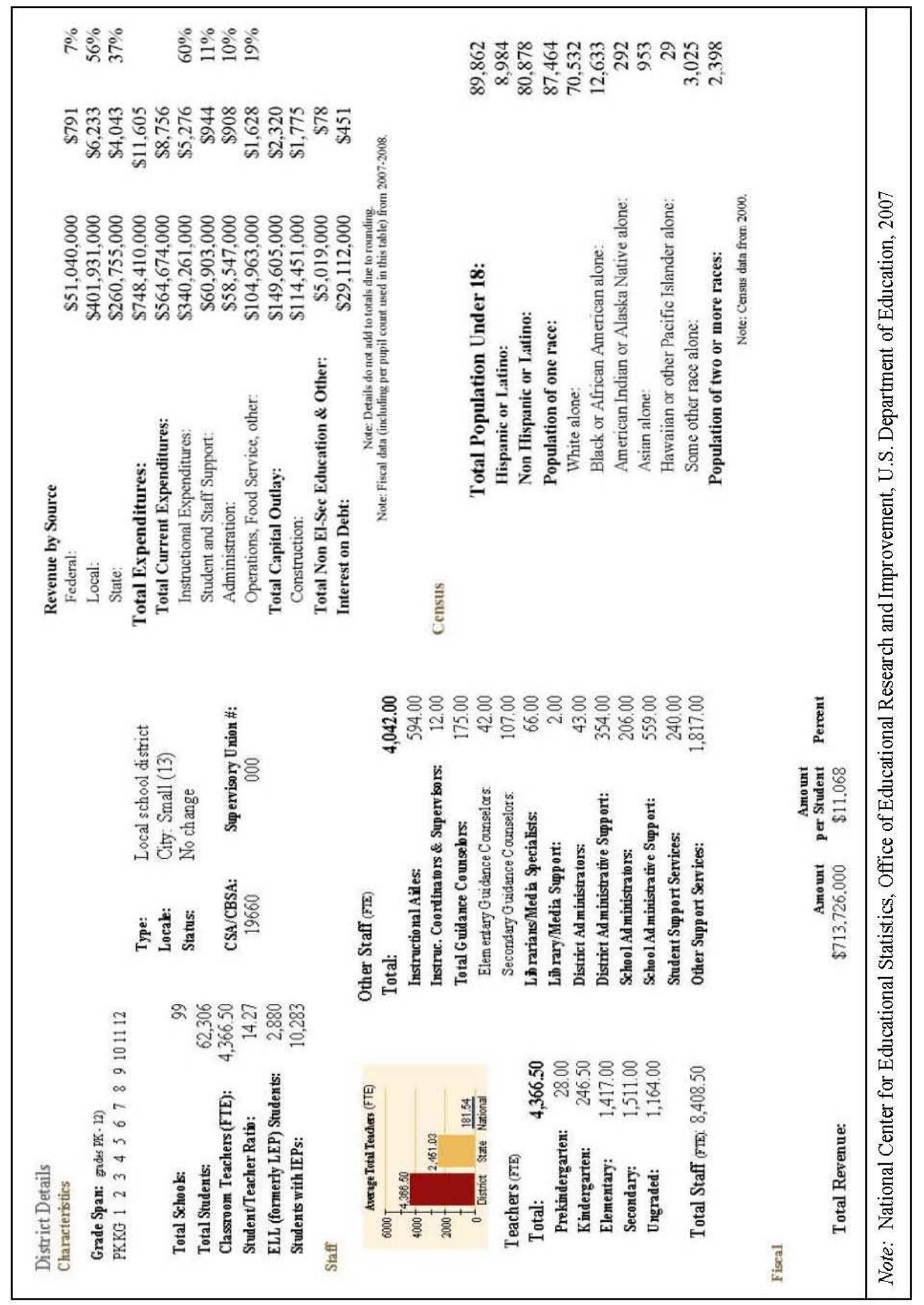

Figure 3.1: District demographic sketch. 
Table 3.1

High School Students by Race Scoring at or Above Grade Level on the 2004 FCAT.

\begin{tabular}{|c|c|c|c|c|}
\hline & \multicolumn{2}{|c|}{$\begin{array}{l}\text { 31\% Scoring at or Above } \\
\text { Grade Level in Reading? }\end{array}$} & \multicolumn{2}{|c|}{$\begin{array}{l}38 \% \text { Scoring at or Above } \\
\text { Grade Level in Math? }\end{array}$} \\
\hline & & Meet AYP - Y/N & 2004 & Meet AYP - Y/N \\
\hline \multicolumn{5}{|l|}{ Race: } \\
\hline White & 63 & $\mathrm{Y}$ & 66 & $\mathrm{Y}$ \\
\hline Black & 33 & $\mathrm{Y}$ & 32 & $\mathrm{~N}$ \\
\hline Hispanic & 41 & $\mathrm{Y}$ & 45 & $\mathrm{Y}$ \\
\hline
\end{tabular}

lower percentages of students eligible for free or reduced lunch score higher on mathematics assessments than students in schools with higher percentages of students eligible for this benefit. Fifty-one of the 68 schools in the District were identified as Title I due to the low socio-economic status of residents in the communities. As such, approximately $21 \%$ of high school students were on free or reduced lunch. A demographic breakdown by race, socio-economic status, and gender for high school students in the District is shown in Table 3.2.

Table 3.2

High School Demographics by Race, Gender, and Socio-Economic Status in 2004-2005.

\begin{tabular}{lrrrr} 
& \multicolumn{4}{c}{ Student Population } \\
\cline { 2 - 5 } Demographic & Percent & Males & Females & Total \\
\hline Race: & & & & \\
$\quad$ Indian/Alaska Native & $0.2 \%$ & 17 & 27 & 44 \\
$\quad$ Asian/Pacific Islander & $1.3 \%$ & 141 & 154 & 295 \\
$\quad$ Hispanic & $35.1 \%$ & 1136 & 1134 & 2270 \\
Black, Non-Hispanic & $27.9 \%$ & 1430 & 1363 & 2793 \\
$\quad$ White, Non-Hispanic & $29.3 \%$ & 7275 & 6935 & 14210 \\
Gender: & N/A & 9999 & 9754 & 19753 \\
Socio-Economic Status: & & & & \\
$\quad$ Free Lunch & $18 \%$ & N/A & N/A & 3593 \\
$\quad$ Reduced Lunch & $3 \%$ & N/A & N/A & 556 \\
\hline NOTE. From Public Elementary/Secondary School Universe Survey: 2004-2005. Copyright 2006 by the National Center for \\
Educational Statistics.
\end{tabular}


Research also indicates that students may experience an achievement loss when transitioning to high school (from $8^{\text {th }}$ grade to $9^{\text {th }}$ grade), but that achievement levels tend to rebound in the year following the transition $\left(10^{\text {th }}\right.$ grade) (Alspaugh, 1998).

\section{Instrumentation}

The Florida Comprehensive Assessment Test (FCAT) is the Florida State Department of Education's norm-referenced measure of student achievement and was used as the measuring instrument for the study. For FCAT reading and mathematics, overall results are reported in three ways: As a scale score on a scale of 100 to 500 for a single grade level; as a Developmental Scale Score (DSS) on a scale of 0 to 3000 for all grade levels; and as 1 of 5 achievement levels, which are ranges of scores based on a series of established cut-off points (Florida Department of Education, 2005; Florida Department of Education, 2008). Achievement levels describing the success a student has realized on the Florida SSS on the FCAT reading and mathematics tests are shown in Table 3.3. The range for $9^{\text {th }}$ and $10^{\text {th }}$ grade achievement levels, based on both scale scores and DSS scores, is shown in Table 3.4. The study data was analyzed using DSS student scores.

For a state achievement test such as FCAT, validity and reliability are paramount for establishing a quality assessment (Human Resource Research Organization, 2002; Human Resource Research Organization, 2006). Measurement errors can result in a test that has validity issues, such that the test may not measure the skills that are intended to be measured. Reliability refers to the consistency of measurement, or the degree to which an instrument measures the same way each time it is used under the same condition with the same subjects. In short, reliability lies in the ability to repeat the 
Table 3.3

FCAT Achievement Level Definitions for Reading and Mathematics.

Achievement Level Definitions

Level 5 This student has success with the most challenging content of the SSS. A student scoring in Level 5 answers most of the test questions correctly, including the most challenging questions.

Level 4 This student has success with the challenging content of the SSS. A student scoring in Level 4 answers most of the test questions correctly, but may have only some success with questions that reflect the most challenging content.

Level 3 This student has partial success with the challenging content of the SSS, but performance is inconsistent. A student scoring in Level 3 answers many of the test questions correctly but is generally less successful with questions that are the most challenging.

Level 2 This student has limited success with the challenging content of the SSS. Level 1 This student has little success with the challenging content of the SSS. NOTE: From FCAT Achievement Levels. Copyright 2008 by the Florida Department of Education.

Table 3.4

Grade 9 and 10 FCAT DSS and Scale Achievement Levels for Reading and

Mathematics.

\begin{tabular}{llllll}
\hline Subject & Level 1 & Level 2 & Level 3 & Level 4 & Level 5 \\
\hline Mathematics: & & & & & \\
DSS/9 & $1238-1781$ & $1782-1900$ & $1901-2022$ & $2023-2141$ & $2142-2596$ \\
Scale/9 & $100-260$ & $261-295$ & $296-331$ & $332-366$ & $367-500$ \\
DSS/10 & $1068-1831$ & $1832-1946$ & $1947-2049$ & $2050-2192$ & $2193-2709$ \\
Scale/10 & $100-286$ & $287-314$ & $315-339$ & $340-374$ & $375-500$ \\
Reading: & & & & & \\
DSS/9 & $772-1771$ & $1772-1971$ & $1972-2145$ & $2146-2297$ & $2298-2943$ \\
Scale/9 & $100-284$ & $285-321$ & $322-353$ & $354-381$ & $382-500$ \\
DSS/10 & $844-1851$ & $1852-2067$ & $2068-2218$ & $2219-2310$ & $2311-3008$ \\
Scale/10 & $100-286$ & $287-314$ & $315-339$ & $340-374$ & $375-500$ \\
\hline NOTE: From FCAT Achievement Levels. Copyright 2008 by the Florida Department of Education. &
\end{tabular}

measurement and maintain consistent results (Trochim, 2006). A brief discussion of the evidence of FCAT reliability and validity follow.

Reliability. FCAT was designed to assess student achievement of the SSS. The test meets all professional standards of psychometric quality traditionally associated 
with standardized achievement tests. FCAT reliability indicates that the test provides consistent measurement of a test taker's knowledge. Reliability measures help users generalize student performances from one test administration to another and coefficients are expressed as a number from zero to one $(0.0$ - 1.00$)$, with zero indicating a lack of reliability and one indicating perfect consistency. Internal consistency reliabilities for the FCAT are reported in Table 3.5 (Florida Department of Education, 2007).

Validity. FCAT was designed to measure a student's achievement of the skills and content described in the SSS. Content-related evidence for FCAT was demonstrated as follows: Educators and citizens determined the standards and skills; test item specifications guided the writing of test items; test items were piloted using randomly selected groups of students; test items were reviewed for cultural, ethnic, language, and gender bias; educational practitioners reviewed the items; test items were again fieldTable 3.5

Cronbach's Alpha Coefficients for FCAT Mathematics and Reading Grades 9 and 10 SSS from 2003-2006 and KR-20 Coefficient for 2005-2006.

\begin{tabular}{lcccccc} 
& \multicolumn{4}{c}{ Cronbach's Alpha SSS } & \multicolumn{2}{c}{ KR-20 } \\
\cline { 2 - 7 } Subject & 2003 & 2004 & 2005 & 2006 & 2005 NRT & 2006 NRT \\
\hline Mathematics: & & & & & & \\
$\quad$ Grade 9 & 0.89 & 0.87 & 0.92 & 0.85 & 0.90 & 0.91 \\
$\quad$ Grade 10 & 0.88 & 0.88 & 0.94 & 0.88 & 0.87 & 0.90 \\
Reading: & & & & & & \\
$\quad$ Grade 9 & 0.89 & 0.87 & 0.92 & 0.85 & 0.90 & 0.91 \\
$\quad$ Grade 10 & 0.88 & 0.88 & 0.94 & 0.88 & 0.87 & 0.90 \\
\hline $\begin{array}{l}\text { NoTE: From Assessment and Accountability Briefing Book. Copyright 2004 and 2007 by the Florida Department of } \\
\text { Education. }\end{array}$
\end{tabular}

tested to determine psychometric properties; tests were carefully constructed with items that met specific psychometric standards; and tests were equated to the base test to match both content coverage and test statistics (Florida Department of Education, 2007). 
Criterion-related evidence was demonstrated through the correlation of scores on the criterion-referenced portion (SSS) of the test with the scores on the norm-referenced portion of the test. As evidenced in Table 3.6, the degree to which the FCAT tests skills that it intended to measure, or construct validity, was medium to high in the study years (Human Resource Research Organization, 2002; Human Resource Research Organization, 2006).

\section{Data Collection and Analysis}

The data source originated from a database of state FCAT test scores for all students in the study District. A second District staff allocation database organized students, teachers, and courses by school year. The researcher, using both the FCAT scores databases for 2003-2004 and 2004-2005, as well as the staff allocation database Table 3.6

FCAT Correlations Between Mathematics and Reading SSS Test and NRT Test

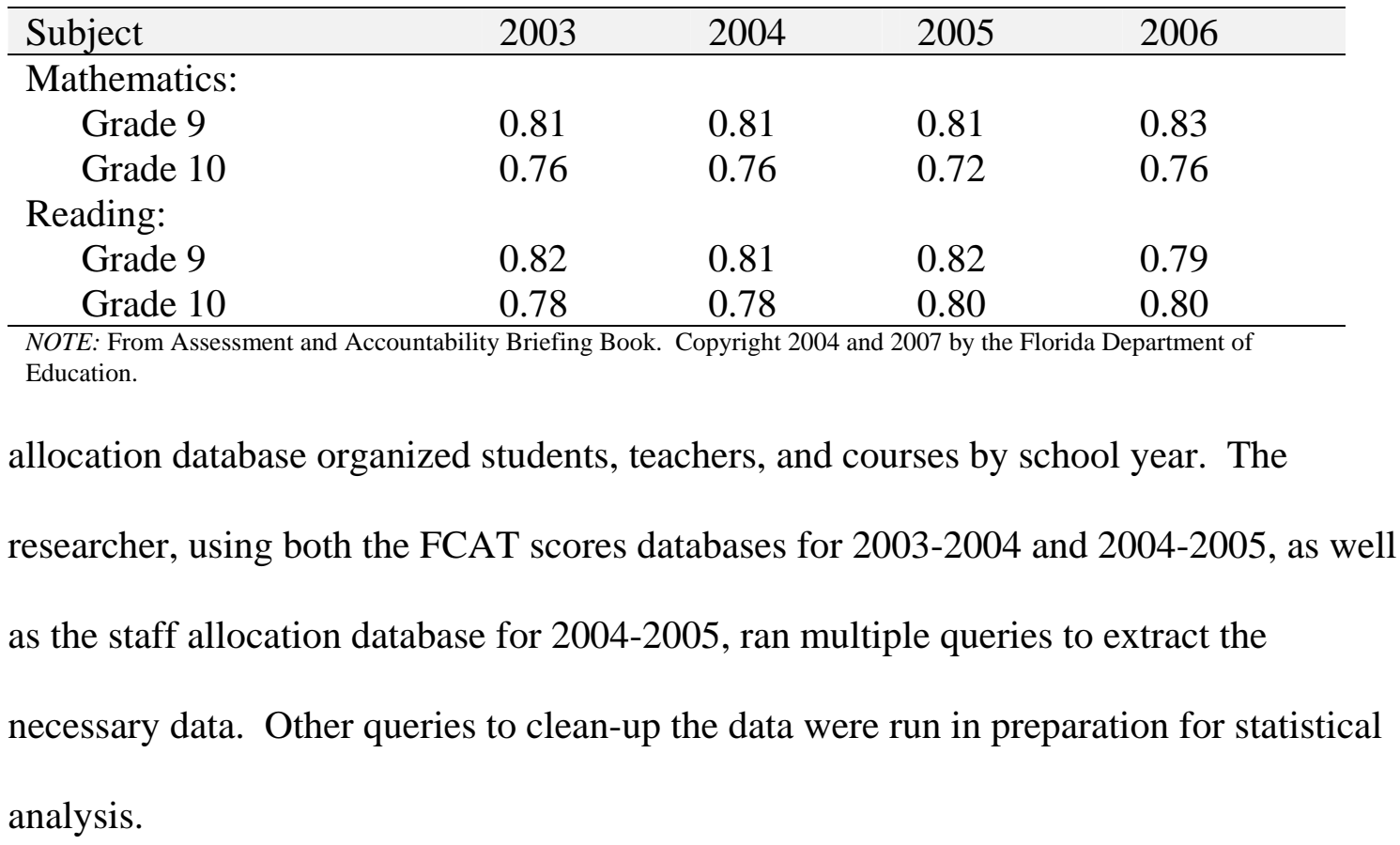


Analysis. Given the non-randomized research design and nature of school effects research, an inferential statistical approach, analysis of co-variance (ANCOVA) and multiple regression were both used to examine study data.

Analysis of co-variance (ANCOVA). ANCOVA combined both regression analysis and analysis of variance to control for extraneous variables called, covariates (Cody \& Smith; 2006; Stevens, 1999). Using this statistical control technique isolated the effects of the covariate(s) not being studied in this non-equivalent group design, thereby reducing error variance and eliminating systematic bias that were likely to occur within the intact educational classroom groups (Bonate, 2000). As indicated, gender, race, socio-economic status, and grade transition are linked to student achievement differences (Department of Education, 2007; Alspaugh, 1998); thus, to control the variability between groups the researcher planned to use these extraneous variables as covariates. However, the study district prohibited the release of student free and reduced lunch data in accordance with the Family Educational Rights and Privacy Act (FERPA) (J. Young, personal communication, August 14, 2012). Moreover, race, with 5 levels, could not be used in the ANCOVA analysis because the inclusion of nominal categorical variables with more than two levels violated the assumptions of normality and variance, resulting in meaningless predictions (Rutherford, 2001).

In the CTE/FCAT Connection study, then, the researcher used ANCOVA to adjust the post-test means for differences among the treatment and control groups by using prior achievement, gender, and grade as covariates; thus, reducing the probability of a Type II error. In summary, ANCOVA increased the signal-to-noise ratio by adjusting for the variability of the covariates and specifically asked the question: Was 
the mean FCAT score, partialing out covariates, different between the treatment and control groups (Campbell \& Stanley, 1963; Rutherford, 2001; Field \& Miles, 2010)? The null hypotheses to be tested were as follows:

- $\mathrm{H}_{\mathrm{o}}{ }^{\prime}: \mathrm{u}_{\mathrm{t}}{ }^{\prime}=\mathrm{u}_{\mathrm{c}}{ }^{\prime}$. The population means of FCAT scores between the mathematics treatment and control group, partialing out the covariates, were the same.

- $\mathrm{H}_{\mathrm{o}}{ }^{\prime}: \mathrm{u}_{\mathrm{t}}{ }^{\prime}=\mathrm{u}_{\mathrm{c}}{ }^{\prime}$. The population means of FCAT scores between the reading treatment and control group, partialing out the covariates, were the same. Using an alpha level of .05, an ANVOCA analysis was conducted to determine whether the post-test FCAT scores for the treatment and control groups differed after the adjustment for covariates (Stevens, 1999). Using the F statistic, the researcher then determined if the mean FCAT gain, partialing out covariates, was different between the reading and mathematics treatment and control groups and if the CTE/FCAT Connection intervention was significant at the .05 alpha level.

ANCOVA assumptions. Most statistical tests rely upon certain assumptions about the variables used in the statistical analysis. When these assumptions are not met the results may not be trustworthy, resulting in a Type I or Type II error, or over- or under-estimation of significance or effect size(s) (Bonate, 2000). As Pedhazur (1997, p. 33) notes, "Knowledge and understanding of the situations when violations of assumptions lead to serious biases, and when they are of little consequence, are essential to meaningful data analysis". However, as Osborne, Christensen, and Gunter (2001) observe, few articles report having tested assumptions of the statistical tests they rely on for drawing conclusions. This has created an environment rich in education and social science literature, but one in which the validity of results may be questioned. Thus, to 
avoid Type I and Type II errors, several general ANCOVA assumptions had to be met prior to running ANCOVA analysis as follows: (a) Independence - the intact classes were a random sample from the population, and the scores on the dependent variable were independent of each other; (b) normality - the dependent variable was normally distributed in the population for any specific value of the covariate(s) and for any one level of an independent variable; (c) homogeneity of variance - the variances of the dependent variable for the conditional distributions were equal (Grimm, 1993;

Rutherford, 2001); and (d) homogeneity of regression slope - the relationship between the dependent variable and the covariate(s) were the same in each treatment group (Bonate, 2000; Field \& Miles, 2010).

Multiple regression. Multiple regression is a multivariate statistical technique used to predict the relationship between a single dependent variable and several independent variables, called predictor variables. Because more than one ANCOVA covariate was found to be statistically significant in determining post-test scores, a forward selection multiple regression model was then used to determine the unique relationship that each significant covariate (predictor) contributed to the model, thereby determining the best predictor of the outcome variable (post-test scores).

Multiple regression assumptions. As with ANCOVA, several assumptions had to be met prior to running multiple regression analysis as follows: (a) Independence - the intact classes were a random sample from the population, and the scores on the dependent variable were independent of each other; (b) multicollinearity - external variables were not correlated with any of the variables included in the regression model; (c) linearity - the mean values of the outcome variable for each increment of the 
predictor(s) presented a straight line; (d) homogeneity of variance (homoscedasticity) the variance of the residuals at any predicted value was the same; (e) independent errors - for any two observations the residual terms were uncorrelated; and (f) normally distributed errors - the differences between the model and the observed data were most frequently zero or very close to zero with only occasional instances greater than zero (Chen, 2011; Rutherford, 2001; Field \& Miles, 2010).

\section{Limitations}

The CTE/FCAT Connection study was limited in methodological design. The researcher was aware of the perils of this non-randomized design and that nonequivalent groups are susceptible to threats of selection bias which can reduce internal validity. The study, then, was limited by interaction between such factors as selection and maturation; selection and history; and selection and pre-testing (Campbell \& Stanley, 1963; Turchim, 2006). Also, participating CTE and academic teachers were not randomly selected, but volunteered to take part in the integrated curriculum development. Furthermore, external validity, or generalizability, was limited to $9^{\text {th }}$ and $10^{\text {th }}$ grade students in the 13 introductory CTE courses. Finally, the study was limited in the ability to statistically control for the socio-economic variability between groups as this data could not be released, and for race as it is a nominal categorical variable with multiple levels. 


\section{CHAPTER FOUR: RESULTS}

The purpose of this study was to determine whether students who participated in CTE courses that integrated core mathematics and reading standards performed better on a test of mathematics and reading skills compared to students who participated in traditional, non-integrated CTE courses. The intervention, coined the CTE/FCAT Connection, tied a series of academic-enhanced CTE lessons to medium and highly tested FCAT SSS to the content of 13 introductory CTE courses. The integrated units were designed by CTE teachers between 2003 and 2004 and implemented during the 2004-2005 school year.

\section{Descriptive Statistics}

Statistical analyses were conducted separately for the reading and mathematics datasets. The reading data set was composed of a total of 1,869 participants, whereas the mathematics data set was composed of 1,853 participants. The total number of participants in the treatment groups was $17 \%$ of the total data set, and in both samples, the male composition (approximately 56\%) slightly exceeded that of females. See Table 4.1 for more detail on the gender distribution of the participants. The ethnic majority of the sample was white with almost $60 \%$ from the $9^{\text {th }}$ grade. See Table 4.2 for more detail on participant ethnic distribution and Table 4.3 for participant grade level distribution. 
Table 4.1

Gender Distribution across Groups

\begin{tabular}{lrrrrrr}
\hline & \multicolumn{3}{c}{ Reading } & \multicolumn{3}{c}{ Mathematics } \\
\cline { 2 - 7 } Gender & Control & Treatment & Total & Control & Treatment & Total \\
\hline Female & 654 & 160 & 814 & 658 & 159 & 817 \\
& $34.9 \%$ & $8.5 \%$ & $43.5 \%$ & $35.4 \%$ & $8.6 \%$ & $44.0 \%$ \\
Male & 886 & 169 & 1055 & 869 & 167 & 1036 \\
& $47.3 \%$ & $9.0 \%$ & $56.3 \%$ & $46.8 \%$ & $9.0 \%$ & $55.8 \%$ \\
Total & 1540 & 329 & 1869 & 1527 & 326 & 1853 \\
& $82.4 \%$ & $17.6 \%$ & $100.0 \%$ & $82.4 \%$ & $17.6 \%$ & $100.0 \%$ \\
\hline
\end{tabular}

Table 4.2

Ethnic Distribution across Groups

\begin{tabular}{lrrrrrr}
\hline & \multicolumn{3}{c}{ Reading } & \multicolumn{3}{c}{ Mathematics } \\
\cline { 2 - 7 } Race & Control & Treatment & Total & Control & Treatment & Total \\
\hline Asian/Pacific & 19 & 6 & 25 & 19 & 6 & 25 \\
Islander & $1.0 \%$ & $.3 \%$ & $1.3 \%$ & $1.0 \%$ & $.3 \%$ & $1.3 \%$ \\
Black/African & 179 & 28 & 207 & 180 & 28 & 207 \\
American & $9.6 \%$ & $1.5 \%$ & $11.1 \%$ & $9.7 \%$ & $1.5 \%$ & $11.2 \%$ \\
Hispanic/ & 163 & 24 & 187 & 164 & 23 & 186 \\
Latino & $8.7 \%$ & $1.3 \%$ & $10.0 \%$ & $8.8 \%$ & $1.2 \%$ & $10.1 \%$ \\
American & 4 & 1 & 5 & 4 & 1 & 5 \\
Indian/Alaska & $.2 \%$ & $.1 \%$ & $.3 \%$ & $.2 \%$ & $.1 \%$ & $.3 \%$ \\
Multi-Racial & 19 & 0 & 19 & 19 & 0 & 19 \\
& $1.0 \%$ & $.0 \%$ & $1.0 \%$ & $1.0 \%$ & $.0 \%$ & $1.0 \%$ \\
White & 1156 & 270 & 1426 & 1145 & 268 & 1411 \\
& $61.7 \%$ & $14.4 \%$ & $76.1 \%$ & $61.7 \%$ & $14.4 \%$ & $76.1 \%$ \\
\hline \multicolumn{1}{c}{ Total } & 1540 & 329 & 1869 & 1527 & 326 & 1853 \\
& $82.4 \%$ & $17.6 \%$ & $100.0 \%$ & $82.4 \%$ & $17.6 \%$ & $100.0 \%$ \\
\hline
\end{tabular}

\section{Data Screening}

Data screening was used to identify cases that differed substantially from the main trend. To ensure that the model fit the observed data, outliers were identified and removed using the Cook's D statistic. Cases with an absolute value greater than 2.0 were removed from both the reading and mathematics datasets. For the mathematics data, 80 cases were removed, whereas 87 cases were removed from the reading data. 
Table 4.3

Grade Distribution across Groups

\begin{tabular}{crrrrrr}
\hline & \multicolumn{3}{c}{ Reading } & \multicolumn{3}{c}{ Mathematics } \\
\cline { 2 - 7 } Grade & Control & Treatment & Total & Control & Treatment & Total \\
\hline 09 & 975 & 123 & 1098 & 972 & 121 & 1093 \\
& $52.2 \%$ & $6.6 \%$ & $58.7 \%$ & $52.4 \%$ & $6.5 \%$ & $59.0 \%$ \\
10 & 565 & 206 & 771 & 555 & 205 & 760 \\
& $30.2 \%$ & $11.0 \%$ & $41.3 \%$ & $30.0 \%$ & $11.1 \%$ & $41.0 \%$ \\
\hline \multirow{2}{*}{ Total } & 1540 & 329 & 1869 & 1527 & 326 & 1853 \\
& $82.4 \%$ & $17.6 \%$ & $100.0 \%$ & $82.4 \%$ & $17.6 \%$ & $100.0 \%$ \\
\hline
\end{tabular}

\section{Examination of ANCOVA Assumptions}

Certain assumptions must be met in order to perform an ANCOVA analysis.

These assumptions are independence, normality, homogeneity of variance, and homogeneity of regression slope. The succeeding sections detail the assessment of these assumptions.

Independence. The design of this study largely induced data independence.

Students in the experimental group and control group did not interact or collaborate on classwork. Teachers in the treatment and control group did not share unit lessons. Also, students were tested using State of Florida FCAT testing procedures to ensure independent results.

Normality. Normality of distribution was assessed by looking at the skewness and kurtosis coefficients of the post-test scores by group. The sample sizes for the study were considered large ( $\mathrm{n}>200)$. In this case, skewness and kurtosis values below 3.29 would conclude that the distribution was normal. The kurtosis coefficients for the reading and mathematics post-test scores were in the normal distribution range, 
indicating the assumption was met. See Table 4.4 for the summary of the skewness and kurtosis statistics.

Table 4.4

Skewness and Kurtosis Statistics for Post-Test Scores

\begin{tabular}{llllll}
\hline Group & Subject & Skewness & SE & Kurtosis & SE \\
\hline Control & Reading $(\mathrm{n}=1,467)$ & -.256 & .064 & .833 & .128 \\
& Mathematics $(\mathrm{n}=1,460)$ & -0.652 & .063 & 1.899 & .126 \\
\multirow{2}{*}{ Treatment } & Reading $(\mathrm{n}=315)$ & -.857 & .137 & 1.581 & .278 \\
& Mathematics $(\mathrm{n}=313)$ & -0.754 & .135 & 2.995 & .273 \\
\hline
\end{tabular}

Homogeneity of variance (homoscedasticity). The assumption of homoscedasticity requires the variance of errors to be the same across all levels of the independent variable. To test the assumption of homogeneity of variance, the variances of the control and treatment group for both the reading and mathematics datasets were subjected to a Levene's test. Results indicated that there were no significant differences in variances of the reading control and treatment group, $F=.42$, $\mathrm{df}=1,1780, p=0.52$. Corresponding variances for the mathematics group also indicated that there were no significant differences in the variances, $F=.80 \mathrm{df}=1,1771, p=.37$. Thus, the homogeneity of variance assumption was satisfied. As shown in Figure 4.1, a visual examination of a plot of the studentized residuals (the errors) by the predicted values revealed a random array of dots centered around zero, also indicating that this assumption was met. 


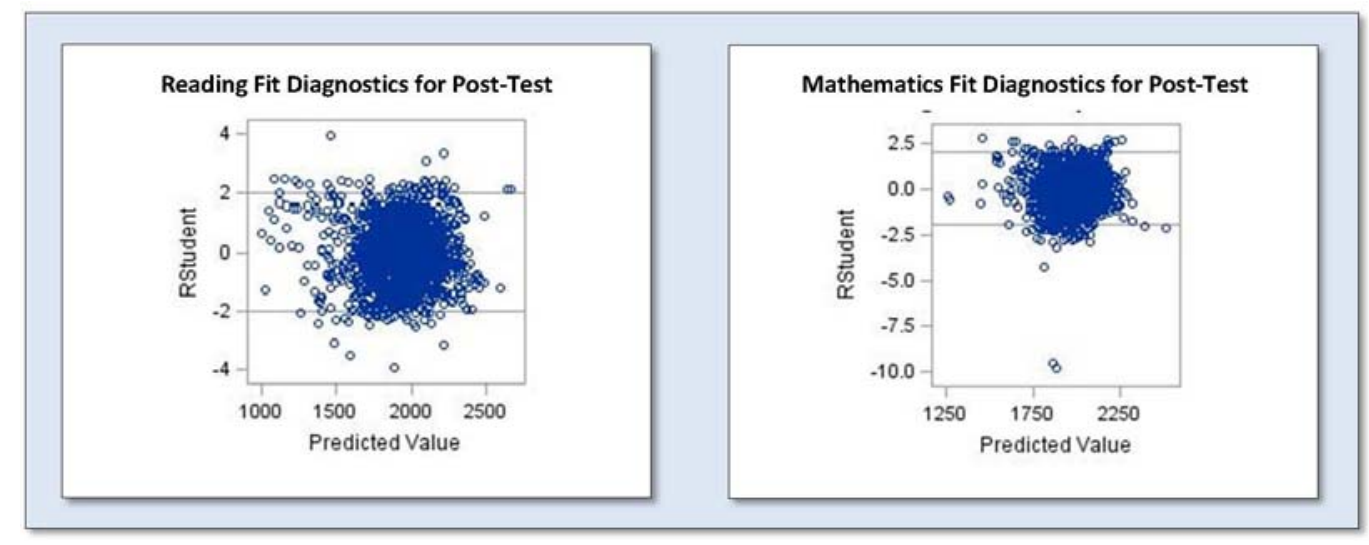

Figure 4.1: Fit diagnostics for reading and mathematics post-test scores

Homogeneity of regression slope. To check for homogeneity of regression, a univariate analysis of variance (ANOVA) was separately conducted for reading and mathematics data by entering the post-test scores as the dependent variable and the group as independent variable. The relevant portion of the analysis was the statistical significance of the interaction between prior achievement and group. If the interaction were statistically significant, then the assumption has been violated. Results of this analysis for reading and mathematics data are summarized in Table 4.5 and Table 4.6. The interaction effect for the reading prior achievement scores and group was not significant, $F=.01, p=.913$. That is, the regression slopes were homogenous and ANCOVA was used for reading data analysis. Moreover, the interaction effect for the mathematics prior achievement scores and group was also not significant, $F=0.02, p=$ .8827; thus, the regression slopes were homogenous and ANCOVA was used for mathematics data analysis. 
Table 4.5

Homogeneity of Regression Slope: Summary of ANOVA Reading

\begin{tabular}{lrrrrr}
\hline Source & df & SS & MS & $F$ & $p$ \\
\hline Group & 1 & 249.14 & 249.14 & 0.01 & 0.913 \\
Prior Achievement & 1 & 47274433.18 & 47274433.18 & 2270.46 & $<.0001$ \\
Group x Prior Achievement & 1 & 3746.35 & 3746.35 & 0.18 & 0.672 \\
Error & 1,778 & 37020740.7 & 20821.6 & & \\
\hline
\end{tabular}

Table 4.6

Homogeneity of Regression Slope: Summary of ANOVA Mathematics

\begin{tabular}{lrrrrr}
\hline Source & $\mathrm{df}$ & $\mathrm{SS}$ & $\mathrm{MS}$ & $F$ & $p$ \\
\hline Group & 1 & 470.23 & 470.23 & 0.10 & 0.7505 \\
Prior Achievement & 1 & 16692501.11 & 16692501.11 & 3590.18 & $<.0001$ \\
Group x Prior Achievement & 1 & 101.33 & 101.33 & 0.02 & 0.8827 \\
Error & 1,769 & 8224939.91 & 4649.49 & & \\
\hline
\end{tabular}

\section{Examination of Multiple Regression Assumptions}

In addition to the ANCOVA assumptions, several assumptions must be met in order to perform multiple regression analysis as follows: No perfect multicollinearity, linearity, independent errors, and normally distributed errors.

Multicollinearity. Multicollinearity exists when two predictor variables are perfectly correlated which can lead to an increase in the standard errors of the $b$ coefficient and also can limit the size of R. As such, a Variance Inflation Factor (VIF) greater than 10 is cause for concern. A review of the VIFs for reading and mathematics data revealed that the variables fell between the values of $1.0 \mathrm{l}$ and 1.05 . Related to the VIF is the reciprocal tolerance statistic. Variables with a tolerance below .1 indicate multicollinearity issues; however, the tolerance levels for the reading and mathematics variables ranged from .95 to .99. Both the VIF and tolerance statistics indicated that the assumption was met. 


\section{Linear relationship between covariates and dependent variable. Scatter plots}

were generated to assess the linear relationship between the dependent variables (reading and mathematics post-test scores) and their corresponding covariates. The scatterplots for reading are shown in Figure 4.2, Figure 4.3, and Figure 4.4. The scatterplots showed that for reading scores, the line of best fit for the control and treatment groups given the covariates of prior achievement, grade, and gender were almost parallel, indicating that the assumption of a linear relationship between the covariates and dependent variable was met.

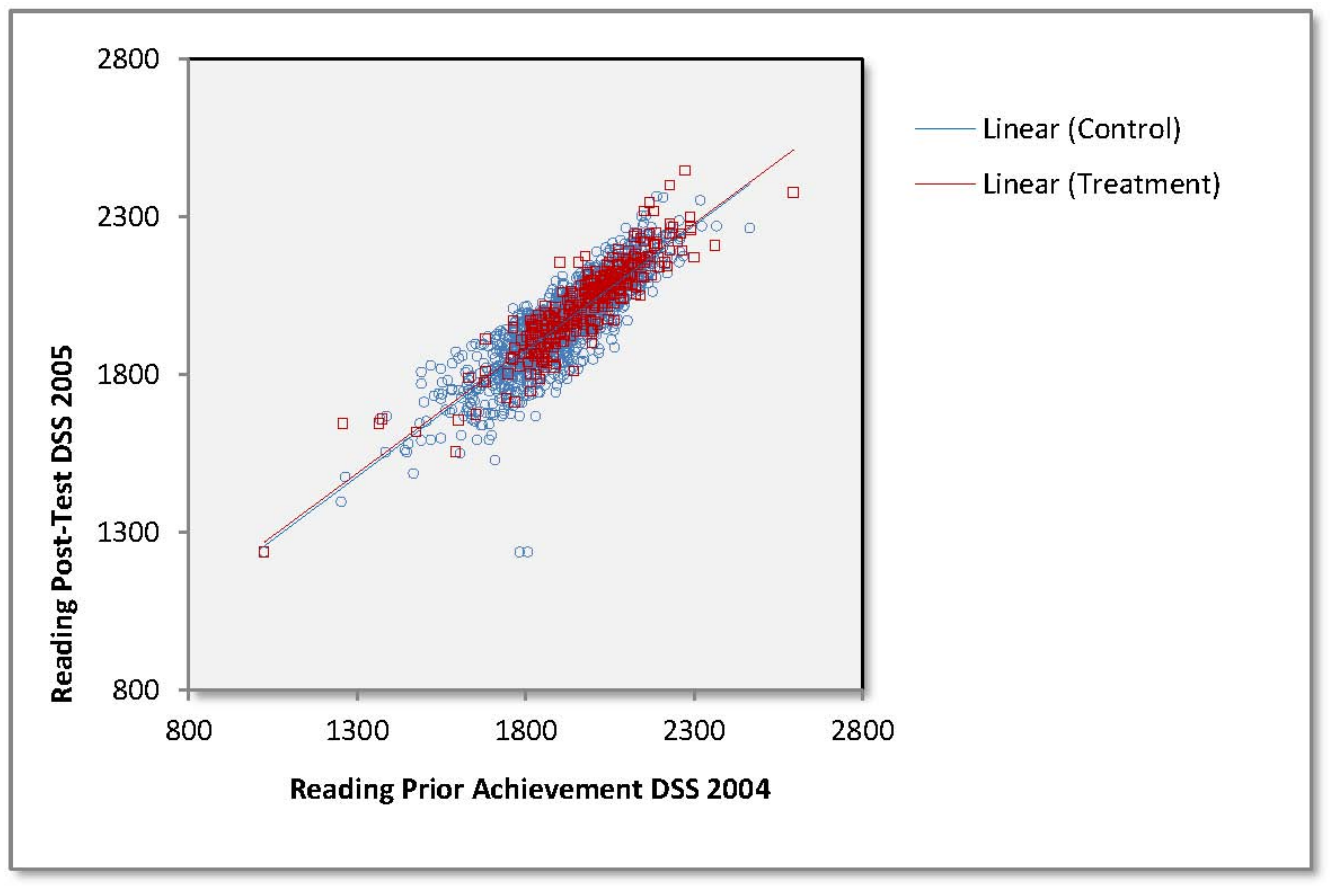

Figure 4.2: Reading data scatterplot: Post-Test scores and prior achievement by group The scatterplots for mathematics data are shown in Figure 4.5, Figure 4.6, and Figure 4.7. The scatterplots revealed that for mathematics scores, the line of best fit for the control and treatment groups, given the covariates of prior achievement, grade, and gender, were almost parallel, indicating that the assumption of a linear relationship between the covariates and dependent variable was met. 


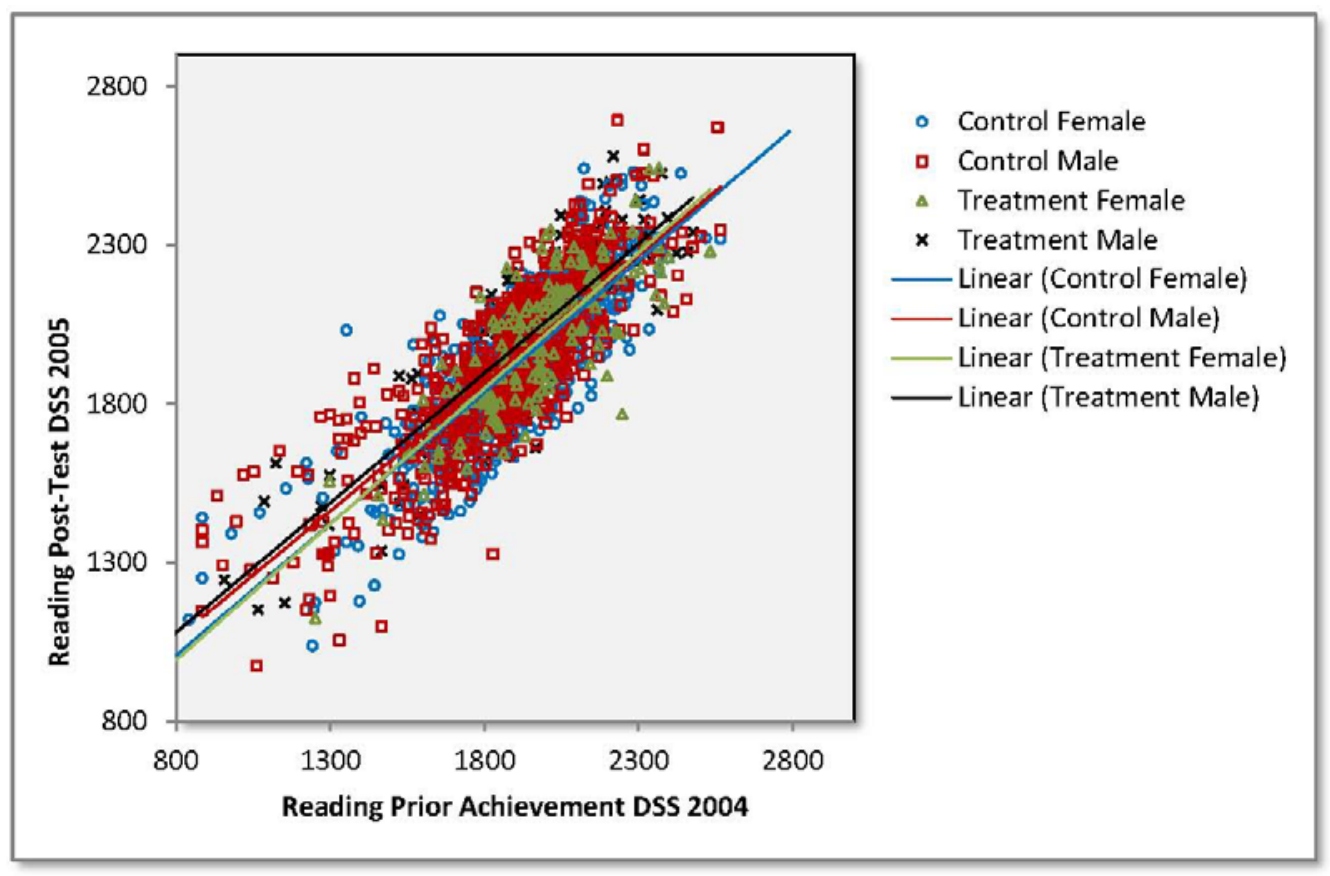

Figure 4.3: Reading data scatterplot: Post-Test scores and prior achievement by gender for control and treatment groups

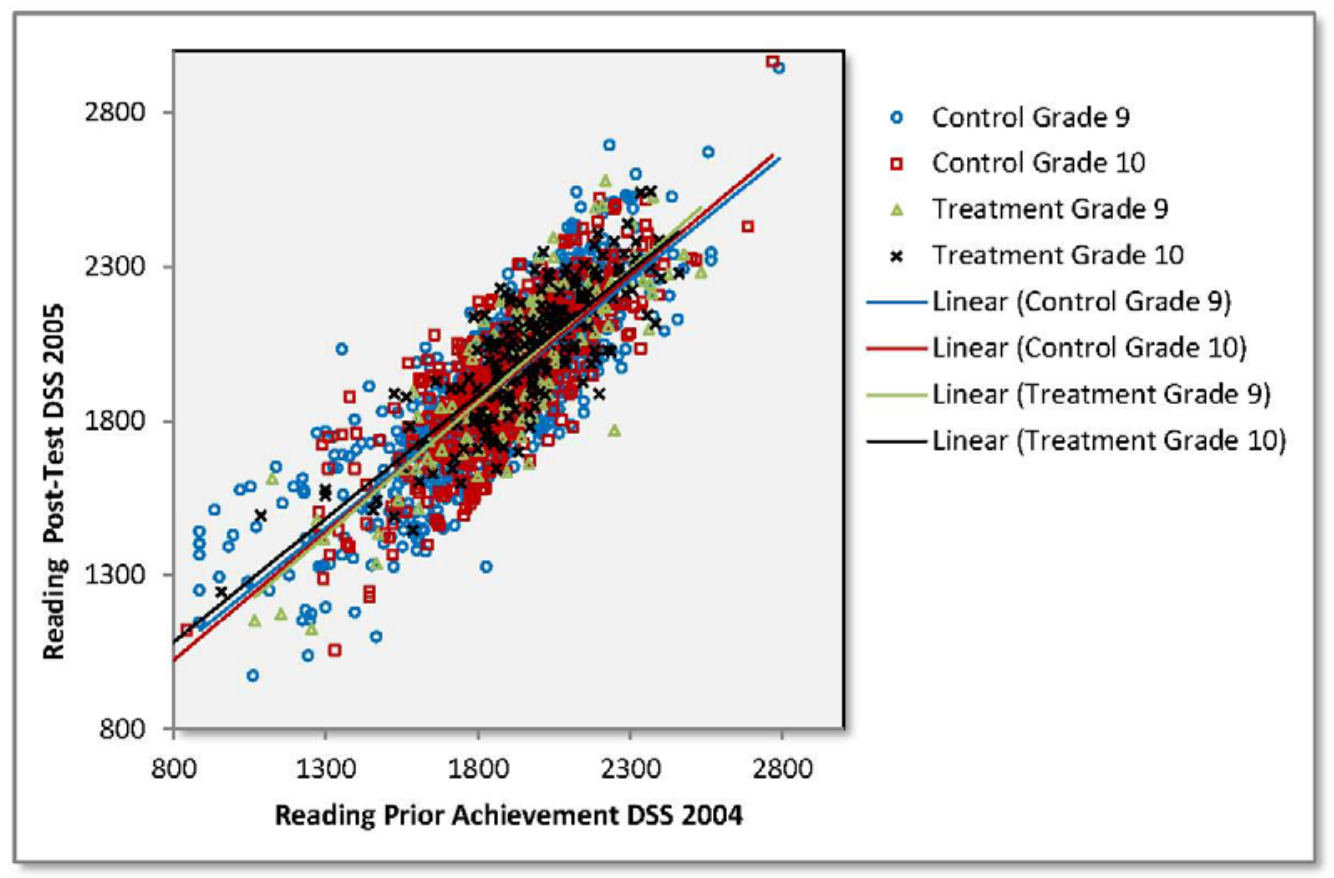

Figure 4.4: Reading data scatterplot: Post-Test scores and prior achievement by grade for control and treatment groups 


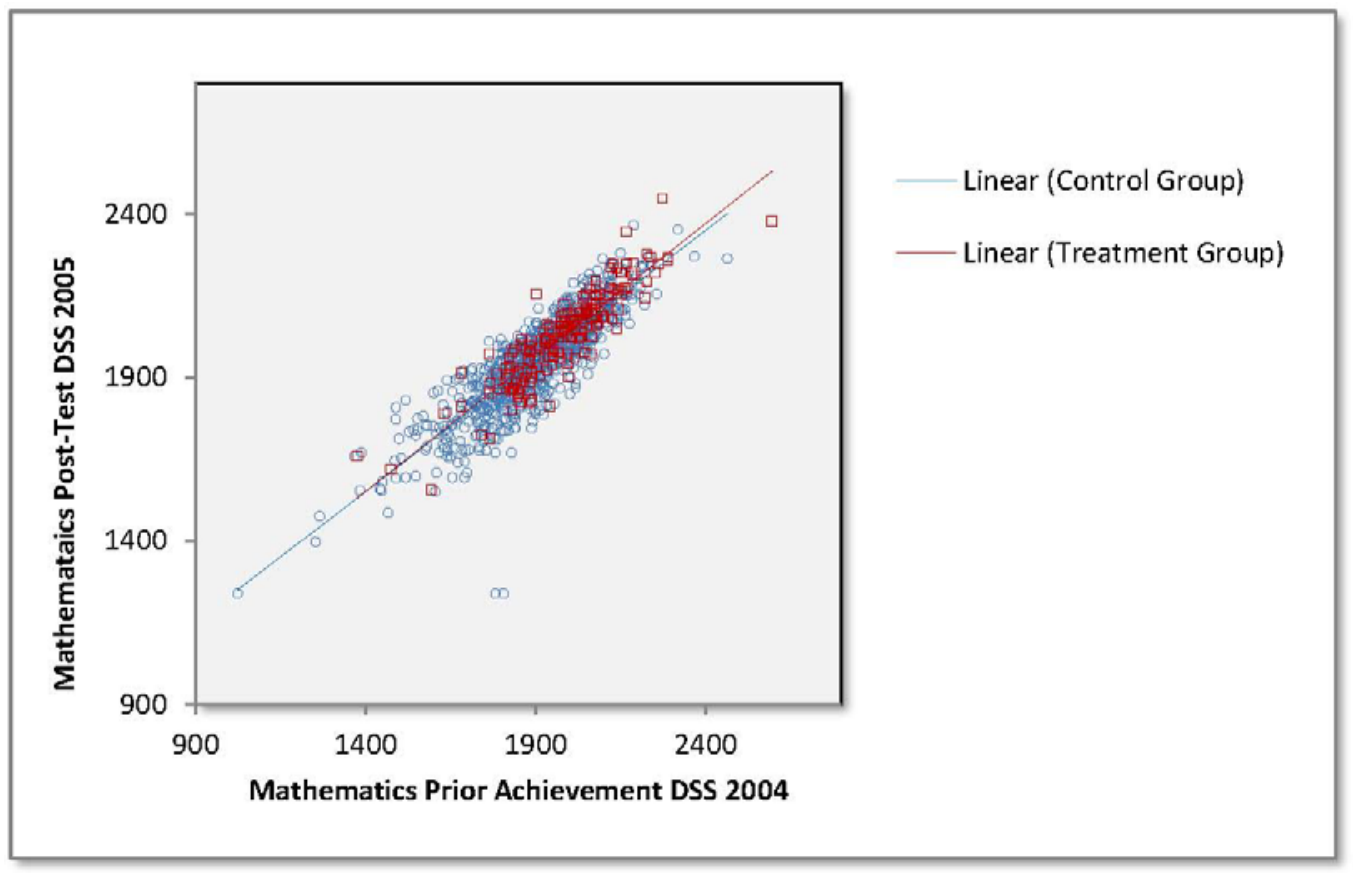

Figure 4.5: Mathematics data scatterplot: Post-Test scores and prior achievement by group

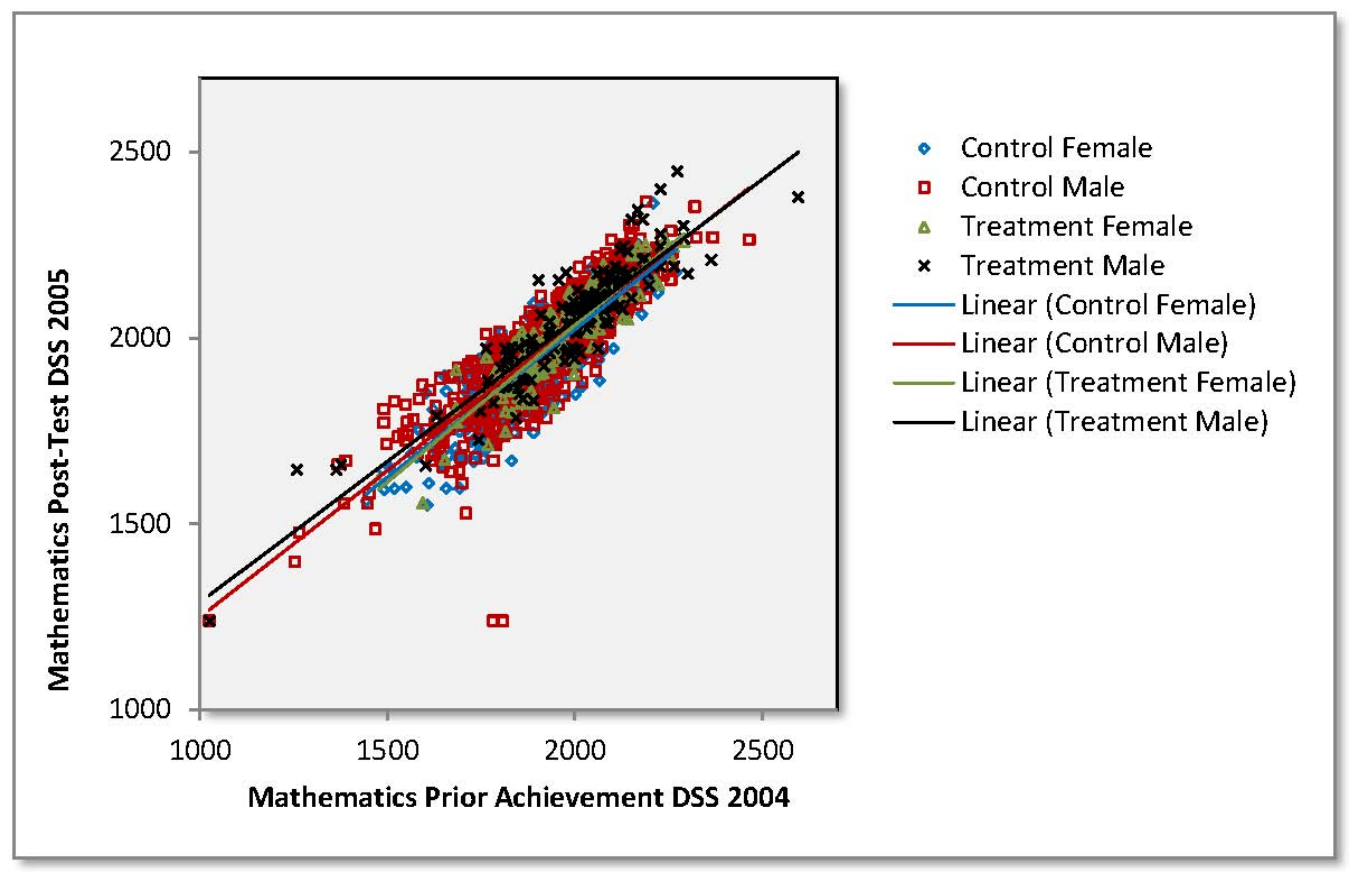

Figure 4.6: Mathematics data scatterplot: Post-Test scores and prior achievement by gender for control and treatment group 


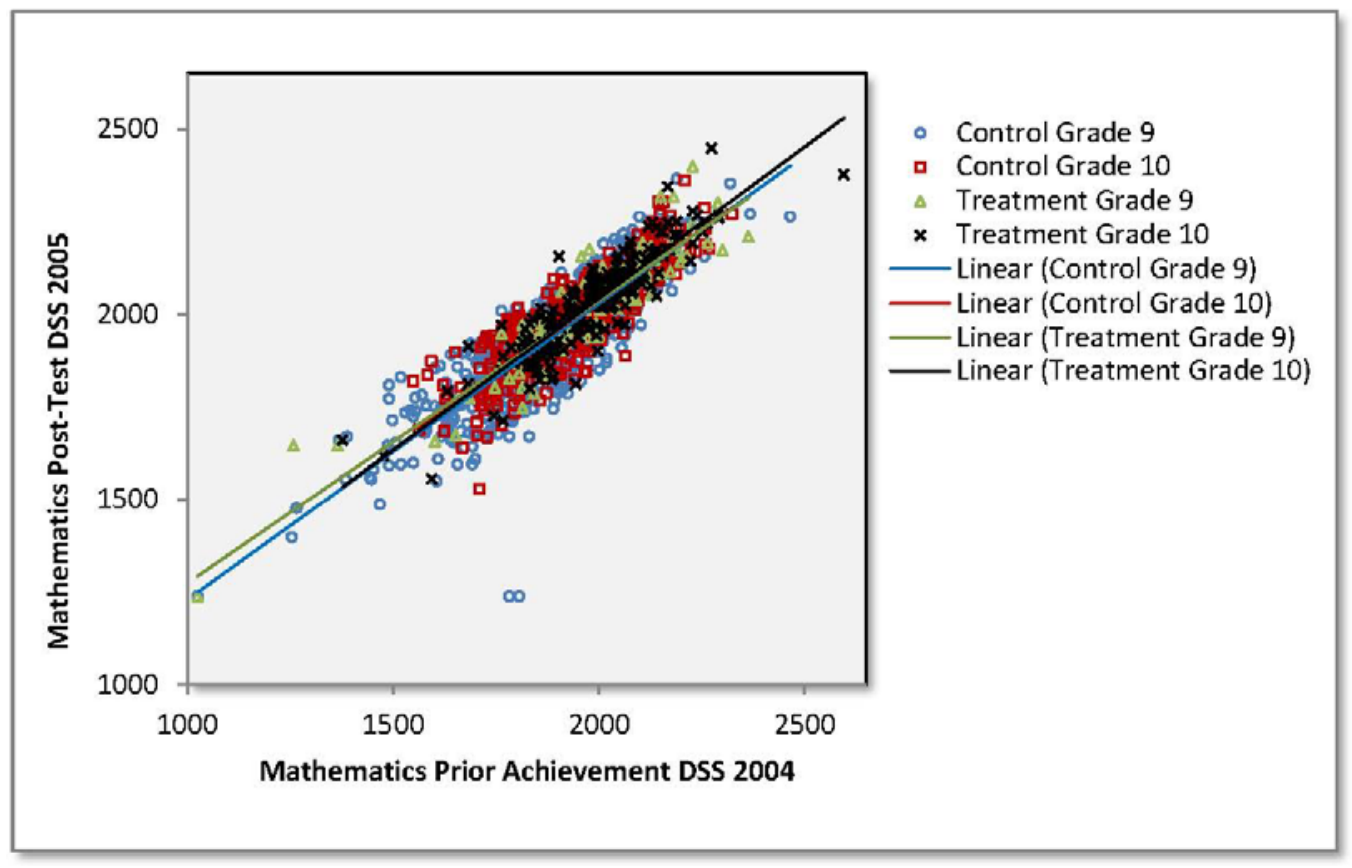

Figure 4.7: Mathematics data scatterplot: Post-Test scores and prior achievement by grade for control and treatment groups

Independent errors. To test for lack of autocorrelation, a regression analysis using group, gender, grade, and prior achievement as the independent variables and posttest as the dependent variable produced the Durbin-Watson test statistic which tested for correlations between errors. This statistic varies between 0 and 4 with a value of 2 indicating that the residuals are uncorrelated. The resulting statistic for the reading data was 1.95 and for the mathematics data 2.0 indicating that the adjacent residuals were uncorrelated; thus, providing further evidence to support that the assumption of independence was met.

Normally distributed errors. The assumption of normality of residuals can be confirmed by viewing histogram and normal probability plots of the errors. As shown in the histograms and probability plots in Figure 4.8 and Figure 4.9 the reading and 
mathematics datasets presented normal bell curves and probability plots; thus indicating the assumption was met.

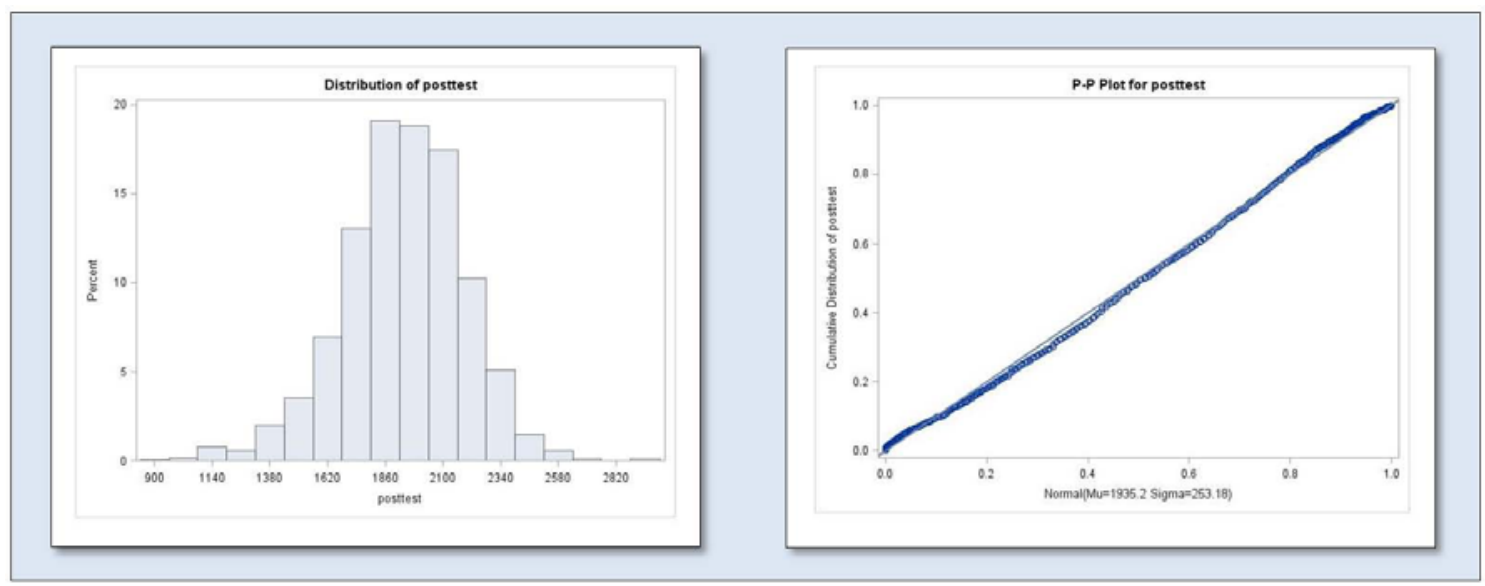

Figure 4.8: Reading data: Histogram and probability plot for post-test scores

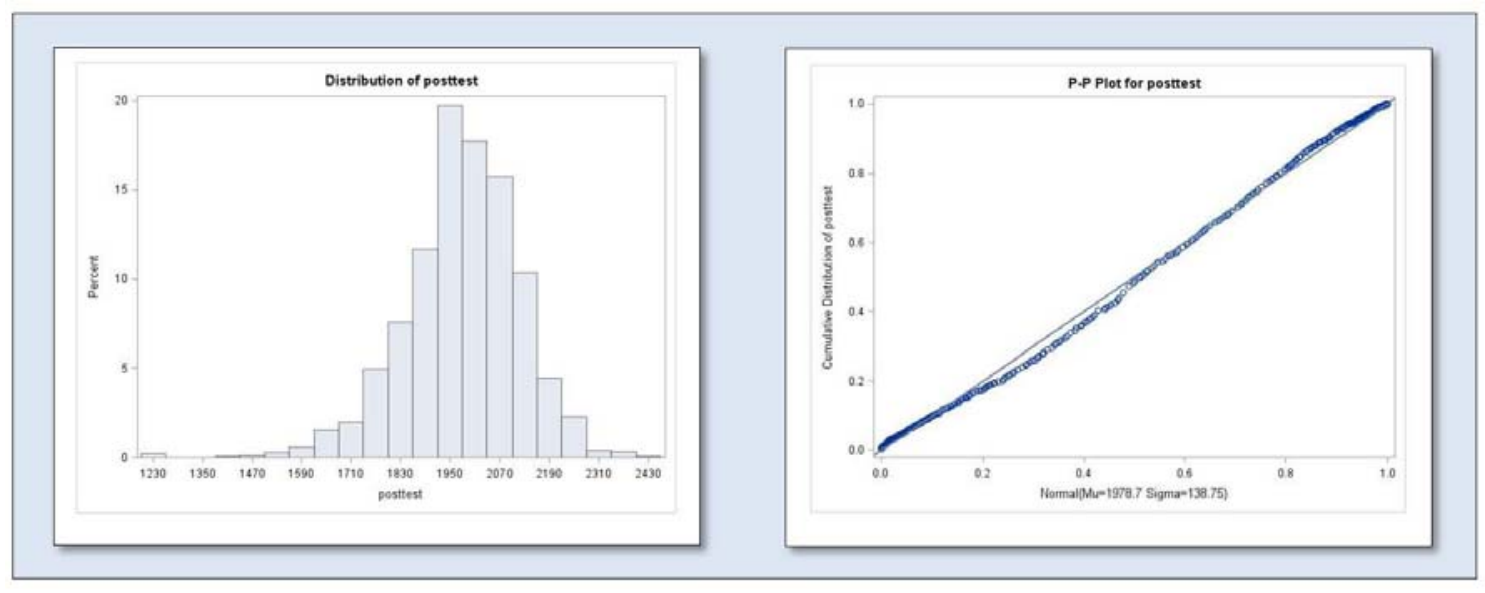

Figure 4.9: Mathematics data: Histogram and probability plot for post-test scores

\section{Data Results}

ANCOVA analysis: Reading. An ANCOVA analysis was conducted for the reading data since all prerequisite assumptions were met. In the analysis grade, gender, and prior achievement were entered as covariates. Descriptive statistics are presented in Table 4.7 and Table 4.8. Descriptive statistics of reading data by covariate and dependent variable in Table 4.7 revealed that the mean of post-test scores $(\mathrm{M}=1935$, 
$\mathrm{SD}=153.179)$ was greater than that of prior achievement scores $(M=1894, \mathrm{SD}=$

253.953).

Table 4.7

Reading Data: Descriptive Statistics by Covariate and Dependent Variable

\begin{tabular}{lrrrrrr}
\hline Variable & N & Mean & Std. Dev. & Sum & Min. & Max. \\
\hline Group & 1782 & 0.177 & 0.382 & 315 & 0 & 1 \\
Grade & 1782 & 9.414 & 0.493 & 16775 & 9 & 10 \\
Gender & 1782 & 0.561 & 0.496 & 1000 & 0 & 1 \\
Prior Achievement & 1782 & 1894 & 253.953 & 3374374 & 772 & 2790 \\
Post-Test & 1782 & 1935 & 253.179 & 3448590 & 844 & 2965 \\
\hline
\end{tabular}

As shown in Table 4.8, the mean change score (from prior achievement to post-test scores) for the control group was an increase of 40 points, whereas the mean change score for the treatment group was an increase of 48 points. The mean difference between the groups was 8 points with the treatment group scoring 20\% higher than the control group.

Table 4.8

Reading Data: Descriptive Statistics by Group

\begin{tabular}{lrrrrr}
\hline Variable & $\mathrm{N}$ & Mean & Std. Dev. & Min. & Max. \\
\hline Group/Control: & 1467 & & & & \\
$\quad$ Prior achievement & & 1881.27 & 250.339 & 772.00 & 2790.00 \\
$\quad$ Post-Test & & 1921.49 & 249.899 & 973.00 & 2965.00 \\
Group/Treatment: & 315 & & & & \\
$\quad$ Prior Achievement & & 1950.96 & 263.051 & 772.00 & 2533.00 \\
$\quad$ Post-Test & & 1999.26 & 258.872 & 844.00 & 2579.00 \\
\hline
\end{tabular}

Pearson correlation coefficients in Table 4.9 indicated that grade, prior achievement, and post-test scores were positively correlated to group, whereas gender was negatively correlated to group. The effect sizes for group were considered small ( \pm .1). The covariate grade was negatively related to gender, but positively related to prior achievement and post-test scores, and the effect sizes for group were also considered 
small. Gender, as a covariate, was negatively related to prior achievement, but positively related to post-test scores; however, effect sizes were again considered small. Prior achievement was positively correlated to post-test scores with a large effect size of .82 .

Table 4.9

Reading Data: Pearson Correlation Coefficients

\begin{tabular}{lrrrrr}
\hline & & & & Prior \\
& Group & Grade & Gender & Achievement & Post-Test \\
\hline Group & 1.00000 & 0.19930 & -0.04971 & 0.10472 & 0.11721 \\
& & $<.0001$ & 0.0359 & $<.0001$ & $<.0001$ \\
Grade & 0.19930 & 1.00000 & -0.09548 & 0.06861 & 0.07106 \\
& $<.0001$ & & $<.0001$ & 0.0038 & 0.0027 \\
Gender & -0.0359 & -0.09548 & 1.00000 & -0.03640 & 0.03124 \\
& 0.0359 & $<.0001$ & & 0.1245 & 0.1875 \\
Prior Achievement & 0.10472 & 0.06861 & -0.03640 & 1.00000 & 0.82140 \\
& $<.0001$ & 0.0038 & 0.1245 & & $<.0001$ \\
Post-Test & 0.11721 & 0.07106 & 0.03124 & 0.82140 & 1.00000 \\
& $<.0001$ & 0.0027 & 0.1875 & $<.0001$ & \\
\hline
\end{tabular}

$\mathrm{N}=1782 ;$ Prob $>|\mathrm{r}|$ under HO: Rho $=0$

ANCOVA results indicated that the overall model was statistically significant, $F(4,1777)=943.25, p<.0001, \eta^{2}=.68$. As shown in Table 4.10, after adjusting for covariates including prior achievement, $t(1777)=60.61, p<.0001$; gender, $t(1777)=$ $4.74, p<.0001$; and grade, $t(1777)=7.53, p=.064$, the variable, group, was significantly related to post-test scores, $t(1777)=1.06, p<.05$. Furthermore, the posttest mean for the reading treatment group $(\mathrm{M}=1,999.26, \mathrm{SE}=14.59)$ was approximately 78 points higher compared to the post-test scores of the reading control group $(\mathrm{M}=1,921.49, \mathrm{SE}=6.53)$. 
Table 4.10

Reading Data: ANCOVA Parameter Estimates

\begin{tabular}{lrrrrrr}
\hline \multicolumn{1}{c}{ Variable } & DF & \multicolumn{1}{c}{$b$} & \multicolumn{1}{c}{ SE } & \multicolumn{1}{c}{$t$} & \multicolumn{1}{c}{$\operatorname{Pr}>|t|$} & \multicolumn{1}{c}{$\beta$} \\
\hline Intercept & 1 & 295.426 & 70.423 & 4.20 & $<.0001$ & 0 \\
Group & 1 & 21.014 & 9.132 & 2.30 & 0.0215 & 0.0317 \\
Grade & 1 & 7.527 & 7.0748 & 1.06 & 0.2874 & 0.0146 \\
Gender & 1 & 32.663 & 6.884 & 4.74 & $<.0001$ & 0.0640 \\
Prior Achievement & 1 & 0.81692 & 0.0135 & 60.61 & $<.0001$ & 0.8194 \\
\hline
\end{tabular}

Multiple regression analysis: Reading. As more than one ANCOVA covariate was significantly related to post-test scores, a forward selection multiple regression model was used to determine the unique relationship that each covariate (predictor) contributed to the model and to reveal the best predictor of post-test scores. Table 4.11 summarizes the forward selection process. The variables entered into the regression model were group, grade, gender, and prior achievement. The forward selection analysis corroborated that group, gender, and prior achievement were significant predictors of post-test scores, while grade was not (i.e. grade did not meet the .05 significance level for entry into the model). The predictor with the highest squared semi-partial correlation with the post-test scores was prior achievement, partial $\eta^{2}=$ .675. After taking into account prior achievement, the predictor variable, gender, produced the next greatest increment, partial $\eta^{2}=.004$. Group, the third predictor, was entered into the equation after partialling out prior achievement and gender, partial $\eta^{2}=$ .001. Although the variable of interest, group (treatment vs. control), was statistically significant at $\mathrm{p}<.05$, multiple regression analysis revealed that prior achievement was the best predictor of post-test scores. 
Table 4.11

Reading Data: Summary of Multiple Regression - Forward Selection

\begin{tabular}{|c|c|c|c|c|c|c|}
\hline Step & Variable & Partial $\eta^{2}$ & Model $\eta^{2}$ & (p) & $\mathrm{F}$ & $\operatorname{Pr}>F$ \\
\hline 1 & Prior Achiev & 0.675 & 0.675 & 27.41 & 3691.9 & $<.0001$ \\
\hline 2 & Gender & 0.004 & 0.678 & 8.636 & 20.71 & $<.0001$ \\
\hline 3 & Group & 0.001 & 0.679 & 4.132 & 6.50 & 0.011 \\
\hline
\end{tabular}

ANCOVA analysis: Mathematics. An ANCOVA analysis was conducted for the mathematics data since all prerequisite assumptions were met. In the analysis grade, gender, and prior achievement were entered as covariates. Descriptive statistics are presented in Table 4.12 and Table 4.13. Descriptive statistics of mathematics data by covariate and dependent variable in Table 4.12 revealed that the mean of post-test scores $(\mathrm{M}=1979, \mathrm{SD}=138.747)$ was greater than that of prior achievement scores $(\mathrm{M}=1931$, $\mathrm{SD}=151.496)$

Table 4.12

Mathematics Data: Descriptive Statistics by Covariate and Dependent Variable

\begin{tabular}{lrrrrrr}
\hline Variable & $\mathrm{N}$ & Mean & Std. Dev. & Sum & Min. & Max. \\
\hline Group & 1773 & 0.177 & 0.382 & 313 & 0 & 1 \\
Grade & 1773 & 9.418 & 0.493 & 16698 & 9 & 10 \\
Gender & 1773 & 0.553 & 0.497 & 980 & 0 & 1 \\
Prior Achievement & 1773 & 1931 & 151.496 & 3424328 & 1025 & 2596 \\
Post-Test & 1773 & 1979 & 138.747 & 3508291 & 1238 & 2447 \\
\hline
\end{tabular}

However, as shown in Table 4.13, the mean change score (from prior achievement to post-test scores) for the control group was an increase of 48 points, whereas the mean change score for the treatment group was an increase of 45 points. The mean difference between the groups was 3 points with the control group scoring $7 \%$ higher than the treatment group. 
Table 4.13

Mathematics Data: Descriptive Statistics by Group

\begin{tabular}{lrrrrr}
\hline Variable & $\mathrm{N}$ & Mean & Std. Dev. & Min. & Max. \\
\hline Group/Control: & 1460 & & & & \\
$\quad$ Prior achievement & & 1921.00 & 146.618 & 1025.00 & 2466.00 \\
$\quad$ Post-Test & & 1968.92 & 135.750 & 1238.00 & 2365.00 \\
Group/Treatment: & 313 & & & & \\
$\quad$ Prior Achievement & & 1979.77 & 164.231 & 1025.00 & 2596.00 \\
$\quad$ Post-Test & & 2024.52 & 143.546 & 1238.00 & 2447.00 \\
\hline
\end{tabular}

Pearson correlation coefficients in Table 4.14 indicated that grade, prior achievement, and post-test scores were positively correlated to group, whereas gender was negatively correlated to group. The effect sizes for group were considered small ( \pm .1). The covariate grade was negatively related to gender, but positively related to prior achievement and post-test scores, and the effect sizes for group were also considered small. Gender, as a covariate, was positively related to prior achievement and post-test scores; however, effect sizes were again considered small. Prior achievement was positively correlated to post-test scores with a large effect size of .87 .

Table 4.14

Mathematics Data: Pearson Correlation Coefficients

\begin{tabular}{lrrrrr}
\hline & & & \multicolumn{3}{c}{ Prior } \\
& Group & Grade & Gender & Achievement & Post-Test \\
\hline Group & 1.00000 & 0.20451 & -0.04762 & 0.14794 & 0.15284 \\
& & $<.0001$ & 0.0450 & $<.0001$ & $<.0001$ \\
Grade & 0.20451 & 1.00000 & -0.09102 & 0.14157 & 0.15511 \\
& $<.0001$ & & .0001 & $<.0001$ & $<.0001$ \\
Gender & -0.04762 & -0.09102 & 1.00000 & 0.06382 & 0.10897 \\
& 0.0450 & .0001 & & 0.0072 & $<.0001$ \\
Prior Achievement & 0.14794 & 0.14157 & 0.06382 & 1.00000 & 0.87080 \\
& $<.0001$ & $<.0001$ & 0.0072 & & $<.0001$ \\
Post-Test & 0.15284 & 0.15511 & 0.10897 & 0.82140 & 1.00000 \\
& $<.0001$ & $<.0001$ & $<.0001$ & $<.0001$ & \\
\hline
\end{tabular}

$\mathrm{N}=1773 ;$ Prob $>|\mathrm{r}|$ under HO: Rho $=0$ 
ANCOVA results indicated that the overall model was statistically significant, $F(4,1768)=1423.12, p<.0001, \eta^{2}=.76$. As shown in Table 4.15, after adjusting for other variables, the covariates gender, $t(1768)=5.00, p<.0001$; grade, $t(1768)=2.88$, $p=.004$; and prior achievement, $t(1768)=72.65, p<.0001$ were significantly related to post-test scores. However, after adjusting for these covariates, the variable of interest, group, was not statistically significant, $t(1768)=1.80, p=.072$. Although the post-test mean for the mathematics treatment group $(\mathrm{M}=2024.52, \mathrm{SD}=143.546)$ was 56 points higher compared to that of the mathematics control group (M=1968.92, SD=135.750). Table 4.15

Mathematics Data: ANCOVA Parameter Estimates

\begin{tabular}{lrrrrrr}
\hline \multicolumn{1}{c}{ Variable } & DF & \multicolumn{1}{c}{$b$} & \multicolumn{1}{c}{ SE } & \multicolumn{1}{c}{$t$} & \multicolumn{1}{c}{$\operatorname{Pr}>|t|$} & \multicolumn{1}{c}{$\beta$} \\
\hline Intercept & 1 & 357.726 & 35.738 & 10.01 & $<.0001$ & 0 \\
Group & 1 & 7.818 & 4.339 & 1.80 & 0.078 & 0.022 \\
Grade & 1 & 9.678 & 3.362 & 2.88 & 0.004 & 0.035 \\
Gender & 1 & 16.264 & 3.356 & 5.00 & $<.0001$ & 0.058 \\
Prior Achievement & 1 & 0.786 & 0.011 & 72.65 & $<.0001$ & 0.859 \\
\hline
\end{tabular}

Multiple regression analysis: Mathematics. As more than one ANCOVA covariate was significantly related to post-test scores, a forward selection multiple regression model was used to determine the unique relationship that each covariate (predictor) contributed to the model and to reveal the best predictor of post-test scores. Table 4.16 summarizes the forward selection process. The variables entered into the regression model were group, grade, gender, and prior achievement. The forward selection analysis corroborated that grade, gender, and prior achievement were significant predictors of post-test scores, while group was not (i.e. group did not meet the .05 significance level for entry into the model). The predictor with the highest squared semi-partial correlation with post-test scores was prior achievement, partial $\eta^{2}$ 
$=.758$. After taking into account prior achievement, the predictor variable, gender, produced the next greatest increment, partial $\eta^{2}=.003$. Grade, the third predictor, was entered into the equation after partialling out prior achievement and gender, partial $\eta^{2}=$ .001. The variable of interest for the mathematics data, group (treatment vs. control), was not statistically significant at $\mathrm{p}<.05$. That is, multiple regression analysis indicated that prior achievement was the best predictor of post-test scores.

Table 4.16

Mathematics Data: Summary of Multiple Regression - Forward Selection

\begin{tabular}{llccccc}
\hline Step & Variable & Partial $\eta^{2}$ & Model $\eta^{2}$ & $(\mathrm{p})$ & $\mathrm{F}$ & $\mathrm{Pr}>\mathrm{F}$ \\
\hline 1 & Prior Achievement & 0.758 & 0.758 & 34.25 & 5556.1 & $<.0001$ \\
2 & Gender & 0.003 & 0.761 & 14.89 & 21.21 & $<.0001$ \\
3 & Grade & 0.001 & 0.763 & 6.25 & 10.63 & 0.0011 \\
\hline
\end{tabular}




\section{CHAPTER FIVE: DISCUSSION, IMPLICATIONS, AND RECOMMENDATIONS}

In light of the uninspiring trends in student achievement over the past two decades, curriculum integration resurfaced as a potential educational reform strategy. Proponents of curriculum integration have suggested that integrative learning can improve student engagement, motivation, and retention of learning because it builds upon higher-order thinking skills through problem-solving, collaboration, innovation, and creativity (Caine \& Caine, 1991; Faunce \& Bossing, 1958). As such, integrative learning can impact achievement as students become actively engaged in the learning process (Dewey, 1916; Vars, 1997). Further, curriculum integration can also support the sociological needs of students by preparing them for work and life in the $21^{\text {st }}$ century (Beane, 1995; Beane, 1997; Vars, 1993). Yet, although the body of research indicates numerous advantages associated with integrative learning, the many variations in curriculum integration and implementation issues have produced mixed results over the years regarding the impact on student outcomes. A general pattern of results has emerged from the literature though, suggesting that curriculum integration models featuring higher levels of connections between subjects, may support more advanced construction and transfer of knowledge, and result in more pronounced advantages (i.e., achievement).

The conceptual framework for the CTE/FCAT Connection study was rooted in constructivist educational theory and contextual teaching and learning (CTL) strategies. Constructivist pedagogy focuses on cognitive development and deep understanding in an 
active, emergent process. Building on constructivist principles, CTL is a constructivist teaching and learning strategy that unites concept and practice, thereby fostering understanding for the retention of knowledge and skills. The CTE/FCAT Connection intervention was a series of mathematics and reading enhanced CTE lessons that tied medium and highly tested FCAT Sunshine State Standards (SSS) to the content of 13 introductory CTE courses. As noted previously, the CTE/FCAT Connection model fell at the low end of the integration continuum. Based on this modest level of integration, it was expected that students in the treatment group would perform equally or slightly better compared to students in the control group on the state standardized mathematics and reading test (i.e., FCAT).

In this study, the integrated CTE courses did improve CTE student achievement in reading as measured by FCAT scores. That is, the post-test scores of the reading treatment group were statistically significant when compared to the reading control group. The mean difference between the groups (from prior achievement scores to posttest scores) was 8 points with the treatment group scoring 20\% higher than the control group. Further, it was found that prior achievement, gender, and group assignment were significant predictors of post-test scores $(\mathrm{p}<.05)$ with prior achievement carrying 99.2\% of the variance in the model. However, the integrated CTE courses did not significantly improve FCAT scores of the mathematics treatment group as compared to the mathematics control group. Although the post-test mean score for the mathematics treatment group was 56 points higher than the mathematics control group, the difference was not statistically significant. The mean difference between the groups (from prior achievement scores to post-test scores) was only 3 points with the control group scoring 
$7 \%$ higher than the treatment group. In turn, for mathematics, prior achievement, gender, and grade were significant predictors of post-test scores $(\mathrm{p}<.05)$ with prior achievement carrying $99.4 \%$ of the variance in the model.

\section{Discussion of Findings}

Study findings aligned with other results reported in the literature suggesting that students participating in integrated curricula can perform at similar levels, if not better depending on the nature of the curriculum and instruction, compared to students in traditional curriculum designs. What makes a difference, though? How do the findings compare to benchmark studies in the field? What follows is a discussion of study findings on mathematics and reading.

\section{Negligible differences in mathematics achievement. The CTE/FCAT}

Connection study resulted in small differences between the mathematics treatment and control groups. Although, on the average, students in the treatment group scored 56 points higher compared to students in the control group, the mean of prior achievement for the treatment group was 1979.77 and control group was 1921.00; thus, nonsignificant results could have been because students with higher achievement were in the treatment group Further, much of the variance in the model was attributable to prior achievement suggesting only marginal impact of the integrated curriculum model on mathematics achievement. In general, these results aligned with related literature on the role of prior achievement and results from other studies that featured integrated curricula. The role of prior achievement as a predictor of achievement has been well documented in the literature, and it is not surprising to see similar results in this study (Dochy, Segers, \& Buehl, 1999; Hailikari, Nevgi, \& Komulainen, 2008; Reynolds \& 
Wahlberg, 1992). However, the alignment with other research of integrated models warranted further discussion.

The results of CTE/FCAT Connection study paralleled findings from several previous studies, including two prominent projects that have received national attention: The NRCCTE: Math-in-CTE, and the Manpower Demonstration Research Corporation (MDRC) study. As with the CTE/FCAT Connection study, the Math-in-CTE study produced no statistically significant differences, although students in the experimental group scored higher on the average on the mathematics component of the WorkKeys test compared to students in the control group. In another similarity, the Math-in-CTE study also engaged teams of CTE and mathematics teachers and real-world lessons tied to specific CTE courses. However, the Math-in-CTE study used CTE teachers from 12 states, rather than one district, and the integrated lessons were taught for a one-year period, rather than 26 weeks. Moreover, the Math-in-CTE students were tested on three different tests of mathematical ability, whereas the CTE/FCAT Connection students were tested on only one (Stone, Alfeld, Pearson, Lewis, \& Jensen, 2006). In the context of these similarities and differences, the CTE/FCAT Connection mathematics results were remarkably comparable to the Math-in-CTE results in that prior achievement explained most of the variance in the model when assessing mathematical ability. These results further aligned with findings from a Manpower Demonstration Research Corporation (MDRC) longitudinal study on the impact of career academies on high school student outcomes. In assessing the broader impact of integrated curricula underlying the concept of career academies on academic outcomes, the MDRC study 
essentially revealed that students in a career academy environment performed as well as or better-in some cases - than students in regular instruction (Fletcher \& Cox, 2012).

Based on representative results from relevant literature, the CTE/FCAT Connection results confirmed the potential promise of integrated curricula, but also pointed to the need for higher level integrated curricular models to sharpen differences in mathematics achievement. The literature indicated that variations in the level of integration can produce differing results on student understanding and, in turn, standardized outcomes. That is, students exposed to a sequence of integrated courses that infuse contextual teaching and learning strategies should have increased opportunities for establishing the cognitive connections required for deep understanding of mathematical concepts (Stone, Alfeld, Pearson, Lewis, \& Jensen, 2006). Learning mathematics in context can facilitate the transfer of knowledge so that students are able to apply learning in new and unpredictable situations. As such, all students should have an opportunity to learn mathematics with understanding, rather than as a series of 'rules without reason' (Stylianides \& Stylianides, 2007). Mathematics taught contextually promotes learning with understanding because it requires students "to wonder why things are, to inquire, to search for solutions, and to resolve incongruities” (Hiebert et al., 1996). To this end, on the commenting on the notion of mathematics classrooms that promote understanding, Fennema et al. (1999) suggested that:

"A mathematical idea or procedure or fact is understood if it is part of an internal network. More specifically, the mathematics is understood if its mental representation is part of a network of representations. The degree of understanding is determined by the number and the strength of the connections. A mathematical idea, procedure, or fact is understood thoroughly if it is linked to 
existing networks with stronger or more numerous connections" (as cited in Stylianides \& Stylianides, 2007).

In this context, it is clear that single lessons, albeit implemented in a sequence of CTE courses (e.g., CTE/FCAT Connection and Math-in-CTE studies), may not be coherent enough for sustained promotion of higher level understanding that can translate into improved student achievement. In a review of the effectiveness of mathematics interventions in middle and high school, Slavin, Lake, and Groff (2009) reinforced this idea reporting that interventions that require more frequent contextual applications in the classroom and promote higher student interactions through projects and problemsolving, typically result in larger impacts on achievement compared to textbook-oriented or technology-based instruction. With the caveats on the extent of integration models and building upon the practical significance of marginal differences in mathematics performance, the National Council of Teachers of Mathematics (2000) has suggested that learning mathematics with understanding is both essential and possible. Essential because all students must be able to think and solve interrelated problems, and possible because all students can understand and apply mathematics when connections are made between concepts and procedures.

Significant differences in reading achievement. The CTE/FCAT Connection study revealed small but statistically significant differences between the reading treatment and control groups, indicating that integrated instruction can yield results greater than regular instruction. However, prior achievement scores were also strongly related to post-test scores and explained the bulk (99.2\%) of observed differences. As such, it appeared that good readers were more likely to benefit from contextualized and integrated curricular activities which may have translated into better test scores. 
These results largely aligned with the literature, although the comparative framework was much more limited regarding teaching and learning in CTE context. One study though, the NRCCTE Authentic Literacy in CTE, provided a useful frame of reference for comparative purposes. The NRCCTE study was conducted as a half-year pilot followed by a yearlong study to determine the impact of disciplinary literacy strategies on the reading comprehension and vocabulary development of students enrolled in CTE courses, using a well-known framework as the intervention. The MAX Teaching framework used the application of literacy strategies before, during, and after reading and also incorporated both cooperative learning and skills acquisition. In the Authentic Literacy in CTE study, the experimental student groups scored between 7\% and $17 \%$ higher than the control groups, paralleling the significant reading results of the CTE/FCAT Connection study, in which the experimental group scored $20 \%$ better than the control group (National Research Center for Career and Technical Education, 2011; Pearson et al., 2010).

Although the nature of the CTE/FCAT Connection study lessons had a much narrower focus and only addressed targeted reading standards in a single CTE course, CTE/FCAT Connection study teachers varied the number and combination of literacy strategies from course-to-course to best "fit" the CTE curriculum. Another shared factor in both studies was the authentic nature of curricular activities grounded in CTE contexts and problem situations. Research also indicated that teachers who rely on content area textbooks for reading instruction can unwittingly undermine integrative efforts, as these texts were not designed for authentic reading comprehension instruction (Snow, 2002). In this regard, CTE/FCAT Connection teachers selected readings from 
multiple sources including, trade journals, periodicals, websites, blogs, and careerrelated books that represented authentic situations. This approach paralleled the literature on reading suggesting that related improvements require much more than changes in curriculum and instruction. According to Snow (2002), teachers of reading must embrace a broad range of contextual factors that influence reading comprehension including community and school wide factors; the culture of the classroom; and the nature of the interaction between teacher and students. Moreover, teaching reading comprehension skills is a complex, cognitive process that involves more than using individual strategies in a single unit design. That is, teaching reading comprehension requires constant, ongoing adaptation of many teaching strategies and student cognitive processes.

In this context, another potential explanation for observed results was the purposeful CTE/FCAT Connection study link to standardized testing (i.e. through reading and writing responses formatted similar to the FCAT), to help students benefit from test format familiarity and performance on reading tests. In some instances, part of the approach was to use strategies that translated into "teaching to the test". That is, students were able to better understand the curriculum and how to approach the test. On the other hand, the nature of professional development may have played a role on the extent of results as well. Bandura’s conceptualization of self-efficacy suggests that in order to bring about positive change in student performance, a teacher must believe in his/her ability and skills to do so (Gibson and Dembo, 1984). In the case of the CTE/FACT Connection study, although reading post-test scores of the treatment group were statistically significant, the lack of formal training and the complexity involved in 
implementing successful reading instruction may have contributed to the small effect size of said scores. Although on-going professional development was part-in-parcel during the study, it may not have been enough to promote the delivery of more effective reading instruction that could further enhance student outcomes on the FCAT test of reading comprehension.

\section{General Implications}

The CTE/FCAT Connection study reinforced the notion that embedding mathematics and academic standards into 13 CTE courses can yield results at least on par with non-integrated coursework, which parallels what the literature has generated from other studies on curriculum integration between CTE and academics. Curriculum integration, as evidenced in this study, has promising implications for teaching and learning. However, as indicated in the literature review, integration was represented on a continuum, with higher levels of integration more likely to elicit enhanced student understanding and—possibly—achievement (Kysilka, 1998). Per the integration continuum, the CTE/FCAT Connection study represented a low integrative model, and may not have fostered the contextual teaching and learning environment suitable for deep understanding of academic content required for the application of that knowledge to unpredictable situations. What are the general implications derived from the study?

The following section brings to the forefront a discussion on lessons learned and general implications for successful implementation.

Value beyond academic achievement. The results of the study suggested that developing a district-wide, integrated curriculum is achievable and mutually beneficial to teachers and students. Integrative environments can improve teacher job satisfaction 
and self-efficacy through the establishment of collegial professional learning communities and subject-area understanding, both within and across disciplines. Students who participate in sustainable integrated programs gain benefits that they might not otherwise receive, such as interpersonal support, career planning and development, contextual understanding, work-based opportunities, and long-term labor market outcomes (Fletcher \& Cox, 2012; Kemple \& Snipes, 2000). All of these constructs are key to further education and work, and indications are that an integrated learning framework is a good fit if education is going to meet demands of increased accountability measures and of the technologically complex workforce. This outlook aligned with concerns from the mathematics community indicating a lack of student preparation for the workforce and life. Skill mastery and application of mathematical skills in a straightforward way within an isolated educational setting does not promote mathematical connections. Instead, students should be allowed to make meaningful connections through mathematical problem-solving (Hiebert et al, 1996). Accordingly, the value of curriculum integration may be shortchanged when only measured by gains in academic achievement, while other important benefits—as noted above—may be overlooked.

Curriculum and instruction implications. A back-to-basics pedagogy has again introduced essentialism in educational reform resulting in the use of mental discipline teaching and learning strategies, enhanced subject-centeredness, and uniformity through standards. The CTE/FCAT Connection study, as a product of the accountability and standards era, focused on the creation of integrated units that tied medium and highly tested FCAT reading and mathematics standards to the content of 13 
CTE courses. CTE Lead Teachers simulated the testing environment by using FCAT “look alike” response forms and rubrics, as well as FCAT formatted questions. This teach-to-the-test strategy may have narrowed the focus of the curriculum, thereby, resulting in limited cognitive connections and understanding.

Furthermore, the opportunity to teach high level mathematics skills through the 13 introductory CTE courses may have been limited. For example, the course frameworks for Building Construction/Construction Technology 1 required students to solve job-related problems by adding, subtracting, multiplying and dividing numbers and use fractions, decimals and whole numbers; to change numbers to percent; to read a ruler and a tape measure; to compute feet, inches and yards; to construct charts/tables/graphs using functions and data; to determine ratios and proportions; solve problems for volume, weight, area, circumference and perimeter measurements for rectangles, squares, and cylinders; and to measure tolerance(s) on horizontal and vertical surfaces using millimeters, centimeters, feet, and inches. In another example, students in Marketing Essentials applied mathematical problem-solving techniques to sales related transactions including cash, checks, debit cards, credit cards, discounts, layaway, COD, returns, gift certificates, and automatic fee withdrawals; to interpret quantitative information from tables, charts, and graphs; too calculate tax, gratuity, commission, and miscellaneous charges; to collect and analyze sales information for the purpose of understanding stock turnover and stock-sales ratio; to apply standard industry formula for the purpose of computing markup and markdown on merchandise; and to compute and analyze a break-even point. However, courses such as Agriculture Foundations 1, Digital Design 1, Early Childhood Education 1, and Health Science 1 had fewer 
opportunities within the CTE framework for teaching higher-level mathematics. Furthermore, the reading standards were more broad-based in nature; thus, the opportunity to reinforce reading competencies in the 13 CTE courses may have been more prevalent. In short, it is important not to force fit standards that do not inherently lend themselves to the CTE coursework. This practice is counterproductive to the development of integrated units and inclusion of such content can undermine integrated learning.

The role of high-stakes testing. In the years since A Nation at Risk, state and national standards besieged education and led to an emphasis on standardized tests as a measure of student achievement. However, standardized tests measure verbal-linguistic and logical-mathematical skills, but not the higher order thinking and application skills, such as the ability to respond appropriately in unpredictable situations; the effectiveness of student collaboration in solving problems; or the capacity for weighing evidence while balancing emotions. Other soft skills such as work ethic, responsibility, selfdiscipline, motivation, and persistence, as well as human capital skills, such as creativity and imagination are also not measurable through standardized testing. Such higher order thinking and application skills require authentic assessment through the use of portfolios, projects, performances, and extended written responses (Johnson, 2002). Although our educational environment is structured for high-stakes accountability, in developing integrated units, developers should look beyond test implications. Highstakes testing is merely a "snapshot” of student performance, and as such, may or may not represent an accurate portrayal of student achievement (Snow, 2002). In this context, broadening the scope of the integrated curriculum to include authentic 
assessment of knowledge and skills should generate alternative evidence to high-stakes testing on what students know and are able to do.

\section{Recommendations for Practice}

Several recommendations for practice are indicated for development of integrated initiatives including district support and a clear sense of purpose; a professional development plan; a focus on contextual teaching and learning; and alignment with standards.

District support. To develop integrative policy and framework at the school level, a district level integrative curriculum development strategy is an essential requirement for successful implementation. Unless a clear mission and vision for reform is established at the district level, implementation of an integrated curriculum intervention can be difficult to manage and sustain. In this study, district CTE staff spent several months planning and developing a proposal that became the CTE/FCAT Connection project. The project was presented to the school board who then endorsed

the idea and gave consent to proceed. School board approval for this initiative conveyed a message of unified district support and was vital to school administrator and teacher buy-in, as well as in the sustainability of this district-wide initiative.

Professional development. A systemic professional development plan is strongly recommended. Assuredly, the plan must clearly outline district and school level training, both in the short and long-term. The CTE/FCAT Connection planning and development workshops were held throughout a year-long project development phase and on-going professional development occurred during unit implementation. Yet, the most significant aspect of the professional development plan was not the 
number of project development workshops, guest speakers, or follow-up trainings, but in the development of human relationships. Prior to unit planning and development all CTE and Academic Lead Teachers, as well as the district superintendent, district administrators, and school administrators, were given the opportunity to attend national and state conferences that highlighted the vital components of an integrative partnership between CTE and academics. The group met as a team both formally and informally during and after these conferences, building both personal relationships and professional respect for one another. This "human development" was the cornerstone of the CTE/FCAT Connection initiative, creating a professional learning community that remains intact today. As an outcome of strong team, the scope of the project widened to embrace additional CTE and academic teachers that ultimately led to 220 integrated units being developed in over 50 high school and middle CTE courses. The CTE/FCAT Connection professional development and project development framework was adopted by Florida Association for Career and Technical Education (FACTE) and funding allocated for "train the trainer" workshops throughout the state. This approach empowered CTE and Academic Lead Teachers as state-wide project leaders, who over a 5-year period, trained teachers in over 20 other districts. The CTE/FCAT Connection initiative became a state FACTE best-practice and a national ACTE best-practice with units still being accessed by teachers around the country.

Standards focus and alignment. A clear connection between standards across disciplines is also required. For the CTE/FCAT Connection initiative, a crosswalk database connected each CTE performance standard to related SSS and essential work skills. In addition, the crosswalk linked CTE course frameworks to the medium and 
high frequency SSS tested on FCAT and the high essential skills necessary for employment (see Appendix A/Figures A1 \& A2). The full-course crosswalk report of standards for each course was the "road map" CTE and Academic Lead Teachers used to prioritize and select standards for unit development. This crosswalk report was the backbone for organizing and developing units. Current and future integrative unit development should also include connections to the Common Core State Standards for Career and College Readiness. The Common Core State Standards were developed to provide a nationally concise understanding of what students are expected to learn and "are designed to be relevant to the real world, reflecting the knowledge and skills that our young people need for success in college and careers” (Common Core State Standards Initiative, 2012).

Emphasis on contextual teaching and learning. Curriculum integration initiatives in the second decade of the $21^{\text {st }}$ century should go beyond unit development with predetermined outcomes to incorporate highly integrative contextual teaching and learning strategies. An integrative curriculum must embrace student-centered learning through contextual teaching and learning strategies that fall at the high end of the integration continuum, such as project or problem-based learning (PBL). PBL, as a framework for integrative unit development, can afford students the experience of examining complex problems from multiple perspectives and from all disciplines as questions and issues rarely encompass only one subject area. Project or problem-based learning is “an inquiry process that resolves questions, curiosities, doubts, and uncertainties about complex phenomena in life” (Barell, 2007, p. 37). That is, for curriculum to be highly integrative, it must focus on questions or problems related to the 
principles of a discipline(s), involve constructive inquiry, provide for student autonomy, and embody realistic characteristics (Bender, 2012; Thomas, 2000). Another inclusion for current practice is to ground PBL units to the Framework for Learning in the $21^{\text {st }}$ Century as developed by the Partnership for $21^{\text {st }}$ Century Skills (see figure 5.1).

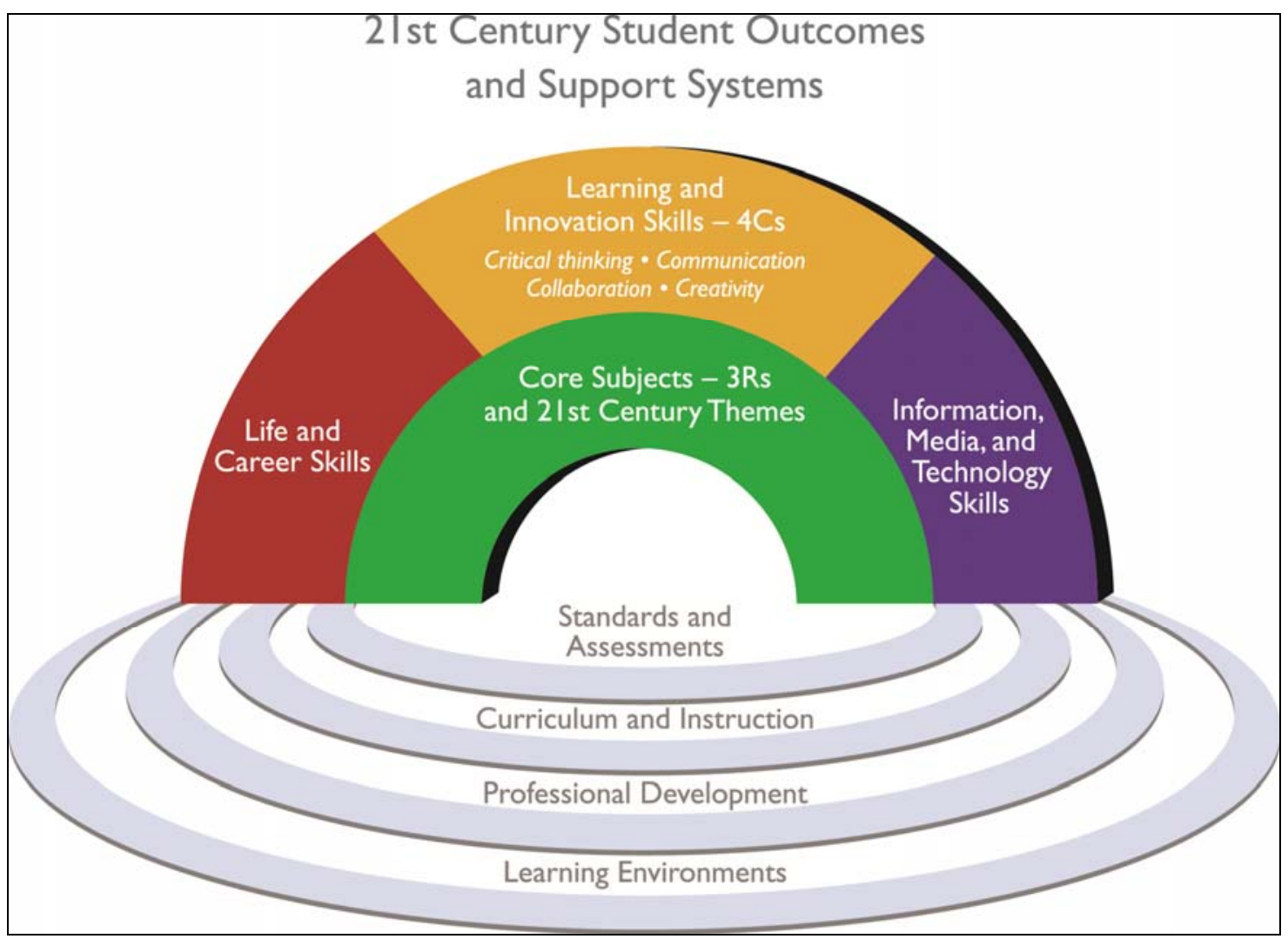

Figure 5.1: The Framework for Learning in the $21^{\text {st }}$ Century as developed by the Partnership for $21^{\text {st }}$ Century Skills (www.p21.org).

The partnership identified key elements of $21^{\text {st }}$ century learning including core subjects and topics relevant to contemporary life and work, life and career skills, learning and innovation skills; and information, media and technology skills. (Partnership for $21^{\text {st }}$ Century Skills, 2011). As such, this skills framework provides a relevant platform for PBL applications in potential curriculum integration endeavors. 


\section{Recommendations for Research}

The CTE/FCAT Connection project was designed as a practical classroom application, not as a scientifically-based research study and as such, some statistical controls were not introduced, and the data was compiled ex-post facto. Although procedures were put in place to ensure the use of integrated units, no controls were developed to safeguard the conformity of teaching reading and mathematics and the proper use of academic teaching strategies. Also, 9 of the 19 CTE Lead Teachers began their careers in the private sector, and then transitioned into teaching. Consequently, almost half of them had little or no formal teacher education training in mathematics or reading, except for the professional development provided during CTE/FCAT

Connection intervention development. Based on this experience and results of the study, some recommendations for further research are outlined below.

First, it is suggested that future research studies adhere, as much as possible, to scientifically-based research methods. Further analysis of CTE/FCAT Connection data, or similar data, should isolate the effects of the treatment and control groups by prior achievement scores using the achievement levels of the indicated standardized test (i.e. FCAT uses levels $1-5$, pp. 109). Pinpointing group effects by achievement level using grade and gender as covariates, should contribute to clarifying whether curriculum integration benefits one achievement level over another. An additional opportunity for future research is to isolate the mathematical effects using the Common Core mathematical domains: Number and quantity; algebra; functions, modeling; geometry; statistics and probability. These effects could be broken down by the Common Core Standards for Mathematical Practice. The Practices are a combination of the NCTM's 
process standards including problem-solving; reasoning and proof, communication, representation, and connections or by the strands of mathematical proficiency specified in the National Research Council's report Adding It Up including adaptive reasoning, strategic competence, conceptual understanding, procedural fluency, and productive disposition (Common Core State Standards Initiative, 2012). This quasi experimental analysis could help disaggregate student achievement by domain and/or standard.

Further, educating the knowledge society may require extreme integration that disregards traditional disciplinary boundaries. Therefore, another recommendation for research is to focus on the level of integration (rather than integration vs. no integration) and its impact on student performance. Complex school-within-school designs have emerged as promising frameworks for transdisciplinary curriculum integration using contextual teaching and learning strategies such as project-based and problem-based learning and experiential education. Although studies have been conducted on the impact of such models (i.e. career academies, magnet high schools, and small learning communities) on attendance, discipline, and other long-term economic outcomes (Fletcher \& Cox, 2012; Kemple, 2008; Kemple \& Snipes, 2000; Stern, Raby, \& Dayton, 2000; Elliott, Hanser, \& Gilroy, 2000; and Hughes, Karp, \& Orr, 2005), none have focused on the link between student performance and the degree of integration (from low to high).

Much recent conversation about student achievement from CTE educators addresses the importance of the middle school years in preparing students for high level academic and career and technical courses in high school. Integrated learning from this perspective should begin during the middle school years, and perhaps, this is a logical 
starting point for integrative research. Longitudinal analysis examining the influence of integrated learning beginning in the middle school could explore the achievement impact on students once they reach high school (Vars, 1997; Lynch, 2000).

Finally, another recommendation for research is to look at longitudinal studies and analyze cumulative effects or developmental effects of students in integrated environments. Such qualitative research targeting student perception, student engagement, and career readiness can measure the impact of student experiences in integrated vs. non-integrated learning environments. Qualitative studies can also target demographic data by gender, ethnicity, SES, and ESE to examine the participation trends of students in integrated programs (Kemple, 2008; Kemple \& Snipes, 2000). 


\section{REFERENCES}

Adelman, N. E. (1989). The case for integrating academic and vocational education. Retrieved from ERIC database. (ED315513).

Aguilera, M. D. (2011). The impact of mathematics integration into business computer information systems curriculum on mathematics achievement of high school students at a south Texas school (Doctoral dissertation). Available from ProQuest Digital Dissertations and Theses database. (UMI No. 3462587).

Akos, P., Lambie, G., Milsom, A., \& Gilbert, K. (2007). Early adolescents’ aspirations and academic tracking: An exploratory investigation. Professional School Counseling, (11)1, 57-64. doi:1341803151

Albear, G. D. (2007). Essentialism [PowerPoint slides]. Retrieved from http://www.library.eiu.edu/ersvdocs/4458.pdf

Alberty, H. (1947). The emerging design of the general education program of the high school. In Reorganizing the high school curriculum (2nd ed., Rev., pp. 159-199). New York, NY: The Macmillan Company.

Alspaugh, J. W. (1998). Achievement loss associated with the transition to middle school and high school. Journal of Educational Research, 92(1), 20-25. doi:10.1080/00220679809597572

Anderle, S. T. (2008). The integration of academics into career-technical education in two California charter schools (Doctoral dissertation). Available from ProQuest Digital Dissertations and Theses database. (UMI No. 304462532)

Anderson, R. C., Hiebert, E. H., Scott, J. A., \& Wilkinson, I. A. (1985). Becoming a nation of readers: The report of the commission on reading. Retrieved from ERIC database. (ED253865).

Andrew, E. N., \& Grubb, W. N. (1995). The power of curriculum integration. In N. Grubb (Ed.), Education through occupations in American high schools (pp. 3956). New York, NY: Teacher College Press.

Applebee, A. N., Adler, M., \& Flihan, S. (2007). Interdisciplinary curricula in middle and high school classrooms: Case studies of approaches to curriculum and instruction. American Educational Research Journal, 44(4), 1002-1039. doi:30069420 
Arhar, J. M. (1997). The effects of interdisciplinary teaming on teachers and students. In J.L. Irvin (Ed.), What current research says to the middle level practitioner (pp. 49-56). Westerville, OH: National Middle School Association.

$\mathrm{Au}, \mathrm{W}$. (2007). High-stakes testing and curricular control: A qualitative metasynthesis. Educational Researcher, 36(5), 258-267. doi:10.3102/0013189X07306523

Austin, J. T., \& Mahlman, R. A. (2002). High-stakes testing: Implications for career and technical education. Retrieved from ERIC database. (ED465073).

Badley, K. (1986). Integration and the integration of faith and learning (Doctoral dissertation). Available from ProQuest Digital Dissertations and Theses database. (UMI No. 303541139)

Bailey, T. (1991). Jobs of the future and the education they will require: Evidence from occupational forecasts. Retrieved from ERIC database. (ED423943).

Bailey, T. (1992). School/work: Economic change and educational reform. Retrieved from ERIC database. (ED465073).

Bailey, T. R. (1995). The integration of work and school: Education and the changing workplace. In N. Grubb (Ed.), Education through occupations in American high schools: Approaches to integrating academic and vocational education (pp. 2638). New York, NY: Teachers College Press.

Barefield, A. L. (2005). Are middle school educators ready for curriculum integration? In J.S. Etim (Ed.), Curriculum integration K-12 (pp. 12-26). Lanham, MD: University Press of America, Inc.

Barell, J. (2007). Problem-Based learning: An inquiry approach. Thousand Oakes, CA: Sage Publications Ltd.

Beane, J. (n.d.). Organizing the middle school curriculum. Retrieved from the Association for Middle Level Education website: http://www.amle.org

Beane, J. (1975). The case for core in the middle school. Middle School Journal, 6(2), 33-34, 38. Retrieved from http://www.jstor.org/stable/23022822

Beane, J. A. (1995). Curriculum integration and the disciplines of knowledge. The Phi Delta Kappan, 76(8), 616-622. Retrieved from http://www.jstor.org/stable/20405413

Beane, J. (1996). On the shoulders of giants! The case for curriculum integration. Middle School Journal, 28(1), 6-11. Retrieved from http://www.jstor.org/stable/23024059 
Beane, J. A. (1997). Curriculum Integration: Designing the core of democratic society. New York, NY: Teachers College Press.

Beaton, A. E., Mullis, I. V., Martin, M. O., Gonzalez, E. J., Kelly, D. L., \& Smith, T. A. (1999). Mathematics achievement in the middle school years: IEA's third international mathematics and science study. Retrieved from ERIC database. (ED406419).

Bellack, A. A. (1969). History of curriculum thought and practice. Review of Educational Research, 39(3), 283-292. doi:10.3102/00346543039003283

Bender, W. N. (2012). Project-Based learning: Differentiating instruction for the 21st century. Thousand Oakes, CA: Corwin: A SAGE Company.

Benson, C. S. (1991). The current state of occupational and technical training Retrieved from ERIC database. (ED337666).

Berlin, D. F. (1991). Integrating science and mathematics in teaching and learning. A bibliography (School Science and Mathematics Association Topics for Teachers Series No. 6). Retrieved from ERIC database. (ED348233).

Berlin, D.F, \& Lee, H. (2005). Integrating science and mathematics education. Historical analysis. School Science and Mathematics. (105)1, 15-24. doi:10.1111/j.19498594.2005.tb18032.x

Berns, R. G., \& Erickson, P. M. (2001). Contextual teaching and learning: Preparing students for the new economy. Retrieved from the National Research Center for Career and Technical Education (NRCCTE) website: http://www.nrccte.org

Blyth, A. (1981). From individuality to character: The Herbartian sociology applied to education. British Journal of Educational Studies, 29(1), 69-79. doi:10.1080/00071005.1981.9973586

Bodilly, S., Ramsey, K., Stasz, C., \& Eden, R. (1992). Integrating academic and vocational education: Lessons from eight early innovators. Retrieved from ERIC database. (ED353407).

Boe, E. E., \& Shin, S. (2005). Is the United States really losing the international horse race in academic achievement? Phi Delta Kappan, 86(9), 688-695. Retrieved from http://www.jstor.org/stable/20441882

Bonate, P. L. (2000). Analysis of pretest-posttest designs. Boca Raton, FL: CRC Press LLC.

Borman, K. M. (Ed.). (1996). Implementing educational reform: Sociological perspectives on educational policy. Norwood, NJ: Ablex Publishing Corporation. 
Bottoms, G., \& Sharpe, D. (1996). Teaching for understanding through integration of academic and technical education. Retrieved from ERIC database. (ED409291).

Bowden, J. A. (2000). Competency-Based education: Neither a panacea nor a pariah. Retrieved from http://crm.hct.ac.ae/events/archive/tend/018bowden.html

Bragg, D. D. (1999). Reclaiming a lost legacy: Integration of academic and vocational education. In A.J. Pautler (Ed.), Workforce education: Issues for the new century (pp. 181-196). Ann Arbor, MI: Prakken Publications, Inc.

Brodinsky, B. (1977). Back to the basics: The movement and its meaning. Phi Delta Kappan , 58(7), 522-527. Retrieved from http://www.jstor.org/stable/20298677

Brown, B. L. (1998). Applying constructivism in vocational and career education. Retrieved from ERIC database. (ED428298).

Bruner, J. (1960). The process of education. Cambridge, MA: Harvard University Press.

Bruner, J. (1971). The relevance of education. New York, NY: W.W. Norton and Company, Inc.

Buck Institute for Education (2013). Project Based Learning for the $21^{\text {st }}$ Century. Retrieved from http://www.bie.org

Bullough, R. V. (1999). Past solutions to current problems in curriculum integration: The contributions of Harold Alberty. Journal of Curriculum and Supervision, 14(2), 156-170. Retrieved from http://www.ebscohost.com

Caine, R. N., \& Caine, G. (1991). Making connections: Teaching the human brain. Retrieved from ERIC database. (ED335141).

Campbell, D.T., \& Stanley, J.C. (1963). Experimental and quasi-experimental designs for research. Hopewell, NJ: Houghton Mifflin Company.

Campbell, J., Hombo, C., \& Mazzeo, J. (2000). NAEP 1999 trends in academic progress: Three decades of student performance (NCES 2000-469). Retrieved from the National Center for Educational Statistics (NCES) website: http://nces.ed.gov

Carnevale, A. P. (1991). America and the new economy. Retrieved from ERIC database. (ED333246).

Case, R. (1991). Anatomy of curricular integration. Canadian Journal of Education, 16(2), 215-224. doi:10.2307/1494974 
Castellano, M., Stone, J., Stringfield, S., Farley, E., Wayman, J. (2004). The effect of CTE-enhanced whole-school reform on student course taking and performance in English and science. Retrieved from the National Research Center for Career and Technical Education (NRCCTE) website: http://www.nrccte.org

Castellano, M., Stringfield, S., \& Stone, J. R. (2003). Secondary career and technical education and comprehensive school reform: Implications for research and practice. Review of Educational Research, 73(2), 231-272. doi:10.3102/00346543073002231

Cavanagh, S. (2005). Poor math scores on world stage trouble. Education Week, 24(16), 1-2. Retrieved from http://www.ebscohost.com

Center on Education Policy (2007). Answering the question that matters most: Has student achievement increased since No Child Left Behind? Retrieved from http://www.cep-dc.org

Chen, Y. (2011). Two-Way ANOVA [PowerPoint slides].

Cody, R. P., \& Smith, J. K. (2006). Applied statistics and the SAS programming language (5th ed.). Upper Saddle River, NJ: Prentice Hall.

Common Core State Standards (2012). Implementing the Common Core State Standards. Retrieved from http://www.corestandards.org

Conference Board of the Mathematical Sciences (1983). What is fundamental and what is not? Retrieved from http://mathcurriculumcenter.org

Congleton, J. W. (1964). Three decades of social trends and their influences on the high school curriculum. The High School Journal, 48(1), 18-24. Retrieved from http://www.jstor.org/stable/40368002

Context. (n.d.). In Miriam-Webster free dictionary. Retrieved from http://www.merriamwebster.com/Context

Corcoran, T., \& Silander, M. (2009). Instruction in high schools: The evidence and the challenge. The Future of Children, 19(1), 157-183. Retrieved from http://www.jstor.org/stable/27795039

Council on Advancing Adolescent Literacy (2009). Time to act: An agenda for advancing adolescent literacy for college and career success. Retrieved from http://carnegie.org

Cox, W. M., \& Alm, R. (2003). The evolution of work. Retrieved from Dallas Federal Reserve website: http://www.dallasfed.org 
Cremin, L. A. (1959). John Dewey and the progressive education movement, 1915 1952. The School Review, 67(2), 160-173. doi:10.1086/442489

Cresswell, J.W. (2009). Research design: Qualitative, quantitative, and mixed methods approaches ( $3^{\text {rd }}$ ed.). Los Angeles, CA: Sage Publications, Inc.

Curren, R. (2010). Aristotle's educational politics and the Aristotelian renaissance in philosophy of education. Oxford Review of Education, 36(5), 543-559. doi:10.1080/03054985.2010.514433

Cutshall, S. (2003). CORE Connection. Techniques, 78(6). Retrieved from http://www.acteonline.org

Czerniak, C. M., Weber, W. B., Sandmann, A., \& Ahern, J. (1999). Literature review of science and mathematics integration. School Science and Mathematics, 99(8), 421-430. doi: 10.1111/j.1949-8594.1999.tb17504.x

Dewey, J. (1916). Democracy and education: An introduction to the philosophy of education. New York, NY: The Macmillan Company.

Dochy, F., Segers, M., \& Buehl, M.M. (1999). The relation between assessment practices and outcomes of studies: The case of research on prior knowledge. Review of Educational Research, 69(2), 145-186. Retrieved from http://www.jstor.org/stable/1170673

Doolittle, P. E., \& Camp, W. G. (1999). Constructivism: The career and technical education perspective. Journal of Vocational and Technical Education, 16(1). Retrieved from http://scholar.lib.vt.edu/ejournals/JVTE

Drake, S. (1991). Integrating the curriculum: How our team dissolved the boundaries. Educational Leadership, 49(2), 20-22. Retrieved from http://www.ebscohost.com

Drake, S. (1993). Planning integrated curriculum: The call to adventure. Alexandria, VA: Association for Supervision and Curriculum Development.

Drake, S. M. (2000). Major trends and issues: Current directions in education. Retrieved from http://www.ascd.org

Drake, S. (2007). Creating standards-based integrated curriculum (2nd ed.). Thousand Oaks, CA: Corwin Press.

Dressel, P. L. (1958). The meaning and significance of integration. In N.B. Henry (Ed.), The integration of educational experiences: The fifty-seventh yearbook of the National Society for the Study of Education (pp. 3-25). Chicago, IL: The University of Chicago Press. 
Educational Development Center (2001). Mathematics in context. Retrieved from http://www2.edc.org

Elliott, M.N., Hanser, L.M., and Gilroy, C.L. (2002). Career academies: Additional evidence of positive student outcomes. Journal of Education for Students Placed at Risk 7(1),71-90. doi:10.1207/S15327671ESPR0701_5

Etim, J. S. (Ed.). (2005). Curriculum integration K-12: Theory and practice. Lanham, MD: University Press of America, Inc.

Faunce, R.C. \& Bossing, N.L. (1958). Developing the core curriculum. Englewood Cliffs, N.J.: Prentice Hall, Inc.

Feller, R., \& Daly, J. (1992). Counselors tackle the new basics: New workplace basics and academic/vocational integration change counseling's role. Retrieved from ERIC database. (ED438712).

Fennema, E., Sowder, J., \& Carpenter, T. (1999). Creating classrooms that promote understanding. In E. Fennema \& T. Romberg (Eds.), Mathematics classrooms that promote understanding (pp. 185-199). Mahway, NJ: Lawrence Erlbaum Associates.

Fetterhoff, W. M., \& Bossing, N. L. (1959). What are the trends in providing for blocktime classes in today's curriculum. NASSP Bulletin, 43, 29-37. doi:10.1177/019263655904324608

Field, A. \& Miles, J. (2010). Discovering Statistics Using SAS. Thousand Oaks, CA: Sage Publications Ltd.

Finch, C. R. (1999). Vocational teacher education. In A.J. Pautler (Ed.), Workforce education: Issues for a new century (pp. 199-209). Ann Arbor, MI: Prakken Publications, Inc.

Fleischman, H. L., Hopstock, P. J., Pelczar, M. P., \& Shelley, B. E. (2010). Highlights from PISA 2009: Performance of U.S. 15 year old students in reading, mathematics, and science literacy in an international context (NCES 2011-004). Retrieved from the National Center for Educational Statistics (NCES) website: http://nces.ed.gov

Fletcher, E. C. (2006). No curriculum left behind: The effects of the No Child Left Behind legislation on career and technical education. Career and Technical Education Research, 31(3), 157-174. doi:10.5328/CTER31.3.157 
Fletcher, E.C. \& Cox, E.D. (2012). Exploring the meaning African American students ascribe to their participation in high school career academies and the challenges they experience. The High School Journal, 96(1), 4-19. doi: 10.1353/hsj.2012.0017

Florida Department of Education (2004). Assessment and accountability briefing book: FCAT 2004. Retrieved from http://fcat.fldoe.org

Florida Department of Education (2005). FCAT handbook: A resource for educators. Retrieved from http://fcat.fldoe.org

Florida Department of Education (2006). 2006 guide to No Child Left Behind (NCLB) adequate yearly progress (AYP) determinations technical assistance paper. Retrieved from http://schoolgrades.fldoe.org

Florida Department of Education (2007). Assessment and accountability briefing book: FCAT 2007. Retrieved from http://fcat.fldoe.org

Florida Department of Education (2008). FCAT Achievement levels. Retrieved from http://fcat.fldoe.org

Fogarty, R. (1991a). Ten ways to integrate curriculum. Educational Leadership, 49(2), 61-65. Retrieved from http://www.ebscohost.com

Fogerty, R. (1991b). How to integrate the curricula (2nd ed.). Glenview, IL: Pearson Education, Inc.

Fosnot, C. T., \& Perry, R. S. (2005). Constructivism: A psychological theory of learning. In C.T. Fosnot (Ed.), Constructivism: Theory, perspectives, and practice (2nd ed., pp. 8-38). New York, NY: Teachers College Press.

Foster, J. C. (1997). The relationship between integration strategies and student achievement scores in science among the non-college bound in Pennsylvania. (Doctoral dissertation). Available from ProQuest Digital Dissertations and Theses database. (UMI No. 9802633).

Gehrke, N. J. (2006). A look at curriculum integration from the bridge. Curriculum Journal, 9(2), 247-260. doi:10.1080/0958517970090209

Gemici, S., \& Rojewski, J. W. (2007). Evaluating research in career and technical education using scientifically-based research standards. Career and Technical Education Research, 32(3), 143-159. doi:10.5328/CTER32.3.143

Gibson, S. \& Dembo, M.H. (1984). Teacher efficacy: A construct validation, Journal of Educational Psychology, 76(4), 569-582. Retrieved from http://www.ebscohost.com 
Gonzales, P., Williams, T., Jocelyn, L., Roey, S., Kastberg, D., \& Brenwald, S. (2008). Highlights from TIMSS 2007: Mathematics and science achievement of U.S. fourth-and eighth-grade students in an international context (NCES 2009-001). Retrieved from the National Center for Educational Statistics (NCES) website: http://nces.ed.gov

Gonzales, P., Guzmán, J.C., Partelow, L., Pahlke, E, Jocelyn, L., Kastberg, D., \& Williams, T. (2004). Highlights from the trends in international mathematics and science study (TIMSS) 2003 (NCES 2005-005). Retrieved from the National Center for Educational Statistics (NCES) website: http://nces.ed.gov

Goode, A. L. (1998). An analysis of secondary teachers' use of integrated curriculum in English and social studies classroom. Available from ProQuest Digital Dissertations and Theses database. (UMI No. 9920849).

Goodman, K. S. (1989a). Access to literacy: Basals and other barriers. Theory into Practice, 28(4), 274-281. doi:10.1080/00405848909543421

Goodman, K. S. (1989b). Whole-language research: Foundations and development. The Elementary School Journal, 90(2), 207-221. doi:10.1086/461613

Goodman, Y. M. (1989). Roots of the whole language movement. The Elementary School Journal, 90(2), 113-127. doi:10.1086/461607

Gordon, H. R. (2006). The history and growth of career and technical education in America (3rd ed.). Prospect Heights, IL: Waveland Press, Inc.

Gowin, D. B. (1959). Is Dewey's experimentalism compatible with Gestalt theory? The School Review, 67(2), 195-212. doi:10.1086/442492

Grady, J. B. (1996). Interdisciplinary curriculum: A fusion of reform ideas. Retrieved from ERIC database. (ED375980).

Grigg, W., Donahue, P., \& Dion, G. (2007). The nation's report card: $12^{\text {th }}$ th grade reading and mathematics (NCES 2007-468). Retrieved from the National Center for Educational Statistics (NCES) website: http://nces.ed.gov

Grimm, L. G. (1993). Statistical applications for the behavioral sciences (4th ed.). Hoboken, NJ: John Wiley and Sons, Inc.

Grossman, P., Wineburg, S., \& Beers, S. (2000). When theory meets practice in the world of school. In S. Wineburg \& P. Grossman (Eds.), Interdisciplinary curriculum: Challenges to implementation (pp. 1-16). New York, NY: Teachers College Press. 
Grubb, W. N. (1995a). The Cunning hand the cultured mind: Sources of support for curriculum integration. In N. Grubb (Ed.), Education through occupations in American high schools (pp. 11-25). New York, NY: Teacher College Press.

Grubb, W. N. (1995b). A continuum of approaches to curriculum integration. In N. Grubb (Ed.), Education through occupations in American high schools (pp. 5981). New York, NY: Teacher College Press.

Grubb, W. N. (1995c). Coherence for all students. In N. Grubb (Ed.), Education through occupations in American high schools (pp. 96-113). New York, NY: Teacher College Press.

Grubb, W. N. (1997). Not there yet: Prospects and problems for "education through occupations". .Journal of Vocational Education Research, 22(2), 77-94. Retrieved from http://scholar.lib.vt.edu/ejournals/JVER

Grubb, W. N., Davis, G., Lum, J., Plihal, J., \& Morgaine, C. (1991). The cunning hand, the cultured mind: Models for integrating vocational and academic education. Retrieved from ERIC database. (ED334421).

Guisbond, L., \& Neill, M. (2004). Failing our children: No child left behind undermines quality and equity in education. The Clearing House: A Journal of Educational Strategies, Issues, and Ideas, 78(1), 12-16. doi:10.3200/TCHS.78.1.12-16

Hailikari, T., Nevgi, A., \& Komulainen, E. (2008). Academic self-beliefs and prior knowledge as predictors of student achievement in mathematics: A structural model. Educational Psychology, 28(1), 59-71. doi: 10.1080/01443410701413753

Halbach, A. (2000). Promise and practice of curriculum integration (Doctoral dissertation). Available from ProQuest Digital Dissertations and Theses database. (UMI No. 9964940).

Harden, R. M. (2000). Integration ladder: A tool for curriculum planning and evaluation. Medical Education, 34, 551-557. doi:10.1046/j.1365-2923.2000.00697.x

Harrell, P. E. (2010). Teaching an integrated science curriculum. Issues in Teacher Education, 19(1), 145-165. Retrieved from http://www.ebscohost.com

Harris, A., \& Wakelyn, D. (2007). Retooling career and technical education. Retrieved from National Governors Association (NGA) website: http://www.nga.org

Hartzler, D. H. (2000). Meta-analysis of studies conducted on integrated curriculum programs and their effects on student achievement (Doctoral dissertation). Available from ProQuest Digital Dissertations and Theses database. (UMI No. 9967119). 
Hayes, W. (2011). The progressive education movement: Is it still a factor in today's schools? Retrieved from Public Education Network website: http://www.publiceducation.org

Hayward, G. C., \& Benson, C. S. (1993). Vocational-technical education: Major reforms and debates - 1917 to present. Retrieved from ERIC database. (ED369959).

Heebner, A. (1995). The voices of students at magnet schools. In N. Grubb (Ed.), Education through occupations in American high schools (pp. 148-166). New York, NY: Teacher College Press.

Hernandez, V. M., \& Brendefur, J. L. (2003). Developing authentic, integrated, standards-based mathematics curriculum: [More than just] An interdisciplinary collaborative approach. Journal of Vocational Education Research, 28(3), 259283. Retrieved from http://scholar.lib.vt.edu/ejournals/JVER

Hidi, S., \& Harackiewicz, J. M. (2000). Motivating the academically unmotivated: A critical issue for the 21st century. Review of Educational Research, 70(2), 151179. doi:10.3102/00346543070002151

Hiebert, J., Carpenter, T.P., Fennema, E., Fuson, K., Human, P., Murray, H.,...Wearne, D. (1996). Problem-solving as a basis for reform in curriculum and instruction: The case of mathematics. Educational Researcher, 25(4), 12-21. doi: 10.3102/0013189X025004012

Hoachlander, G. (1999). Integrating academic and vocational curriculum: Why is theory so hard to practice. Retrieved from ERIC database. (ED433454).

Hopkins, T. L. (1941). Interaction: The democratic process. Boston, MA: D.C. Heath and Company.

Hughes, K. L., Karp, M. M., \& Orr, M. T. (2005). Business Partnerships for American Education: Employer Involvement in the National Academy Foundation's High School Career Academies. Journal of Vocational Education and Training, 54(3). doi:10.1080/13636820200200205

Hull, D. (2003). Redefining CTE: Seizing a unique opportunity to help the "neglected majority" become world-class students, workers, and citizens. Techniques, 78(5). Retrieved from http://www.acteonline.org

Hull, D. (2005). Career pathways: Education with a purpose. Waco, TX: CORD.

Human Resource Research Organization (2002). Florida Comprehensive Assessment Test (FCAT) for reading and mathematics: Technical report for test administrations of FCAT 2002. Retrieved from http://fcat.fldoe.org 
Human Resource Research Organization (2006). Mathematics and reading: Technical report for the 2006 FCAT. Retrieved from http://fcat.fldoe.org

Institute of Education Sciences (2008). What works clearinghouse: Mathematics in context. Retrieved from the IES website: http://ies.ed.gov

Integration. (n.d.). In Dictionary.com (Ed.), Retrieved from http://dictionary.com

International Center for Leadership in Education (2013). Rigor and relevance framework. Retrieved from http://www.leadered.com/pdf/R\&Rframework.pdf

Jacobs, H. H. (1989). Interdisciplinary curriculum: Design and implementation. Retrieved from ERIC database. (ED316506).

Jenks, T. W. (1998). Curriculum integration and improvement of student learning (Master's thesis). Available from ProQuest Digital Dissertations and Theses database. (UMI No. 1391215).

Jennings, J. \& Rentner, D. (2006). Ten big effects of the No Child Left Behind Act on public schools. Retrieved from ERIC database. (ED758121).

Johnson, A. B., Charner, I., \& White, R. (2003). Curriculum integration in context: An exploration of how structures and circumstances affect design and implementation. Retrieved from National Research Center for Career and Technical Education (NRCCTE) website: http://www.nrccte.org

Johnson, E. B. (2002). Contextual teaching and learning: What it is and why it's here to stay. Thousand Oaks, CA: Sage Publications Ltd.

Johnson, J. A., Dupuis, V. L., Musial, D., \& Hall, G. E. (1994). Introduction to the foundations of American education (9th ed.). Boston, MA: Allyn and Bacon.

Katz, R. H., Jackson, L. J., Reeves, K., \& Benson, C. S. (1995). Urban career magnet high schools. In N. Grubb (Ed.), Education through occupations in American high schools (pp. 114-133). New York, NY: Teacher College Press.

Kaufman, P., Bradby, D., \& Teitelbaum, P. (2000). High Schools That Work and whole school reform: Raising academic achievement of vocational completers through the reform of school practice. Retrieved from ERIC database. (ED438418).

Kemple, J.J. \& Snipes, J.C. (2000). Career academies: Impacts on student's engagement and performance in high school. Retrieved from Manpower Demonstration Research Corporation (MDRC) website: http://www.mdrc.org 
Kemple, J.J. (2008). Career academies: Long-Term impacts on labor market outcomes, educational attainment, and transitions to adulthood. Retrieved from Manpower Demonstration Research Corporation (MDRC) website: http://www.mdrc.org

Kilpatrick, J. (2009). TIMSS 2007 mathematics: Where are we? MAA Focus: The Newsmagazine of the Mathematical Association of America, 29(7), 4-7. Retrieved from the Mathematical Association of America (MAA) website http://www.maa.org

Kilpatrick, W. H. (1918). Project method. Teachers College Record, 19(4), 319-335. Retrieved from University of Massachusetts website: http://people.umass.edu

Klein, J.T. (1990). Interdisciplinarity: History, theory, \& practice. Detroit, MI: Wayne State University Press. Retrieved from http://www.ebscohost.com

Klein, J. T. (2005). Integrative learning and interdisciplinary studies. peerReview, 7(4), 8-10. Retrieved from http://www.ebscohost.com

Klein, J. T. (2006). Platform for a shared discourse of interdisciplinary education. Journal of Social Science Education, 6(2), 10-18. Retrieved from http://www.jsse.org

Knoll, M. (1997). Project method: Its vocational education origin and international development. Journal of Industrial Teacher Education, 34(3). Retrieved from http://scholar.lib.vt.edu/ejournals/JITE

Kovalik, S. \& Olsen, K (1993). ITI - The model: Integrated thematic instruction (2nd ed.). Village Of Oak Creek, AZ: Books for Educators.

Kysilka, M. L. (1998). Understanding integrated curriculum. Curriculum Journal, 9(2), 197-209. doi:10.1080/0958517970090206

Lambeth, J. M., Joerger, R. M., \& Elliot, J. (2009). Implications for focusing research in career and technical education and workforce development. Career and Technical Education Research, 34(3), 137-153. doi:10.5328/CTER34.3.137

Lederman, N. G., \& Niess, M. L. (1998). 5 Apples +4 oranges =? School Science and Mathematics, 98(6), 281-284. doi:10.1111/j.1949-8594.1998.tb17422.x

Lee, V. E., \& Ready, D. D. (2009). U.S. high school curriculum: Three phases of contemporary research and reform. The Future of Children, 19(1), 135-156. Retrieved from http://www.jstor.org/stable/27795038 
Lekes, N., Bragg, D. D., Loeb, J. W., Oleksiw, C. A., Marszalek, J., Brooks-LaRaviere, M.,...Hood, L. K. (2007). Career and technical education pathway programs, academic performance, and the transition to college and career. Retrieved from the National Research Center for Career and Technical Education (NRCCTE) website: http://www.nrccte.org

Lemke, M., Sen, A., Pahlke, E., Partelow, L., Miller, D., Williams, T., Jocelyn, L. (2004). International outcomes of learning in mathematics literacy and problemsolving: PISA 2003 results from the U.S. perspective (NCES 2005-003).

Retrieved from the National Center for Educational Statistics (NCES) website: http://nces.ed.gov

Levesque, K., Laird, J., Hensley, E., Choy, S. P., Cataldi, E. F., \& Hudson, L. (2008). Career and technical education in the United States, 1990 - 2005: Statistical Analysis Report (NCES 2008-035). Retrieved from the National Center for Educational Statistics (NCES) website: http://nces.ed.gov

Levesque, K., Lauen, D., Teitelbaum, P., Alt, M., \& Librera, S. (2000). Vocational education in the United States toward the year 2000 (NCES 2000-029). Retrieved from the National Center for Educational Statistics (NCES) website: http://nces.ed.gov

Levit, M. (1959). Context of a contextualist philosophy. The School Review, 67(2), 246257. doi:10.1086/442495

Lewis, A. (2004). NAVE issues final report. Tech Directions, (64)2, p. 4. Retrieved from http://www.ebscohost.com

Lewis, T. (1998). Toward the 21st century: Retrospect, prospect for American vocationalism. Retrieved from ERIC database. (ED423421).

Lipka, R. (1997). Enhancing self-concept/self-esteem in young adolescents. In J.L. Irvin (Ed.), What current research says to the middle level practitioner (pp. 31-39). Columbus, OH: National Middle School Association.

Loepp, F. L. (1999). Models of curriculum integration. Journal of Technology Studies, 25(2). Retrieved from http://www.ebscohost.com

Lynch, R. L. (2000). New directions for high school career and technical education in the 21st century. Retrieved from ERIC database. (ED444037).

Markham, T., Larmer, J., \& Ravitz, J. (2003). Project-based learning handbook: A guide to standards-focused project-based learning for middle and high school teachers (2nd ed.). Novato, CA: Wilsted and Taylor Publishing Services. 
Marlow, E. (1996). Activity centered and subject matter curricula. College Student Journal, 30(3), 284-286. Retrieved from http://www.ebscohost.com

Marsella, A. J. (2010). Evaluation of factors that contribute to improving academic achievement of career and technical education students in Rhode Island (Doctoral dissertation). Available from ProQuest Digital Dissertations and Theses database. (UMI No. 3402119).

Martin, A. R. (2011). Curriculum integration, learner-centered, and curriculum centered approaches in a high school mathematics course (Doctoral dissertation). Available from ProQuest Digital Dissertations and Theses database. (UMI No. 3492242).

Mason, T. C. (1996). Integrated curricula: Potential and problems. Journal of Teacher Education, 47(4), 263-270. doi: 10.1177/0022487196474004

Mathison, S., \& Freeman, M. (1997). The logic of interdisciplinary studies. Retrieved February from National Research Center on English Learning and Achievement website: http://www.albany.edu

Maurer, R. (1994). Designing interdisciplinary curriculum. Needham Heights, MA: Allyn \& Bacon.

Maxwell, N. L. (2001). Step to college: Moving from the high school career academy through the 4-year university. Evaluation Review, 25(6), 619-654. doi: 10.1177/0193841X0102500603

McBrien, J. L., \& Brandt, R. S. (1997). The language of learning: A guide to education terms. Alexandria, VA: Association for Supervision and Curriculum Development.

McKenna, M. C., Robinson, R. D., \& Miller, J. W. (1990). Whole language: A research agenda for the nineties. Educational Researcher, 19(8), 3-6. doi:10.3102/0013189X019008003

McMurrer, J., \& Kober, N. (2011). State test score trends through 2008-09, part 5 : Progress lags in high school, especially for advanced achievers. Retrieved from Center for Education Policy (CEP) website: http://www.cep-dc.org

Mills, S. (1997). Grouping students for instruction: Issues of equity and effectiveness. In J.L. Irvin (Ed.), What current research says to the middle school practitioner (pp. 87-94). Westerville, OH: National Middle School Association.

Moorman, G. B., Blanton, W. E., \& McLaughlin, T. (1994). Rhetoric of whole language. Reading Research Quarterly, 29(4), 308-329. Retrieved from http://www.jstor.org/stable/747780 
Morse, H. T. (1958). Administrative Organization and Processes. In N.B. Henry (Ed.), The Integration of Educational Experiences: The fifty-seventh yearbook of the National Society for the Study of Education (pp. 143-170). Chicago, IL: University of Chicago Press.

Mullis, I. V., Martin, M. O., Gonzalez, E. J., Gregory, K. D., Garden, R. A., O'Connor, K. M.,...Smith, T. A. (2000). TIMSS 1999: International Mathematics Report (NCES 1-889938-15-7). Retrieved from the National Center for Educational Statistics (NCES) website: http://nces.ed.gov

Murphy, E. (1997). Constructivism: From philosophy to practice. Retrieved from http://www.ucs.mun.ca/ emurphy/stemnet/cle.html

National Center for Educational Statistics. (2007). Public Elementary/Secondary School Universe Survey: 2004-2005 (NCES 2007-309). Retrieved from the National Center for Educational Statistics (NCES) website: http://nces.ed.gov

National Center for Research in Vocational Education (1989). Proceedings for forum on integrating occupational and academic education. Retrieved from ERIC database. (ED318869).

National Commission on Excellence in Education (1983). A nation at risk: The imperative for educational reform. Retrieved from ERIC database. (ED226006).

National Council of Teachers of Mathematics (1989). Curriculum and evaluation: Standards for school mathematics. Reston, VA: National Council of Teachers of Mathematics, Inc.

National Council of Teachers of Mathematics (2000). Principles and standards for school mathematics. Retrieved from the NCTM website: http://www.nctm.org

National Research Center for Career and Technical Education (2011). Report to the Congress of the United States: Program year 4, August 1, 2010 to July 31, 2011. Retrieved from NRCCTE website: http://www.NRCCTE.org

Neiman, A. (1991), Ironic schooling: Socrates, Pragmatism and the higher learning. Educational Theory, 41: 371-384. doi: 10.1111/j.1741-5446.1991.00371.

Newmann, F. M., Bryk, A. S., \& Nagaoka, J. K. (2001, January). Authentic intellectual work and standardized tests: Conflict or coexistence. Retrieved from ERIC database. (ED470299).

Noskin, D. P. (1995). Coherence through interdisciplinary teaching. American Secondary Education, 24(1), 34-40. Retrieved from http://www.jstor.org/stable/41064128 
Null, J. W. (2007). William C. Bagley and the founding of Essentialism: An untold story in American educational history. Teachers College Record, 109(4), 1013-1055. Retrieved from University of Massachusetts website: http://people.umass.edu

Oakes, J., Selvin, M., Karoly, L., \& Guiton, G. (1992). Academic and vocational tracking in comprehensive high schools (R-4189). Santa Monica, CA: RAND.

Partnership for $21^{\text {st }}$ Century Skills (2011). A Framework for $21^{\text {st }}$ Century Learning. Retrieved from http://www.p21.org

Pearson, D. P. (1989). Reading the whole-language movement. The Elementary School Journal, 90(2), 230-241. doi:10.1086/461615

Pearson, D., Sawyer, J., Park, T., Santamaria, L., Mandele, E., Keene, B., \& Taylor, M. (2010, March). Capitalizing on context: Curriculum integration in career and technical education: A joint report of the NRCCTE curriculum integration workshop. Retrieved from National Research Center for Career and Technical Education (NRCCTE) website: http://www.nrccte.org

Penn, A. (1992). Integrating high school English and vocational education through teacher collaboration, cross-curricular activities, and applied communications database (Doctoral dissertation). Retrieved from ERIC. (ED350396).

Phillips, R. C. (1964). An examination of the meaning of core curriculum. The High School Journal, 48(1), 13-17. Retrieved from http://www.jstor.org/stable/40368001

Piaget, J. (1969). The psychology of the child. New York, NY: Basic Books, Inc.

Plank, S. (2001). Career and technical education in the balance: An analysis of high school persistence, academic achievement, and postsecondary destinations. Retrieved from the National Center for Research in Career and Technical Education (NRCCTE) website: http://www.nrccte.org

Plank, S., DeLuca, S., \& Estacion, A. (2005). Dropping out of high school and the place of career and technical education: A survival analysis of surviving high school. Retrieved from the National Center for Educational Statistics (NCES) website: http://nces.ed.gov

Planty, M., Provasnik, S., Hussar, W., \& Snyder, T. (2006). The condition of education 2007 (NCES 2007-064). Retrieved from the National Center for Educational Statistics (NCES) website: http://nces.ed.gov

Plihal, J., Johnson, M. A., Bentley, C., Morgaine, C., \& Liang, T. (1992, July). Integration of academic and vocational education: Theory and practice Retrieved from ERIC database. (ED348491). 
Post, T. R., Ellis, A. K., Humphreys, A. H., \& Buggey, L. J. (1997). Interdisciplinary approaches to curriculum: Themes for teaching. Upper Saddle River, NJ: Prentice-Hall.

Prescott, C. A. (1996). Education and work: Toward an integrated curriculum framework. A report on the integrated system for workforce education curricula project. Retrieved from ERIC database. (ED396095).

Pritz, S. G. (1989). Role of vocational education in the development of students' academic skills: An implementation guide. Retrieved from ERIC database. (ED326692).

Raby, M. (1995). The career academies. In N. Grubb (Ed.), Education through occupations in American high schools (pp. 82-96). New York, NY: Teacher College Press.

Rampey, B. D., \& Donahue, P. L. (2009). NAEP 2008 trends in academic progress (NCES 2009-479). Retrieved from the National Center for Educational Statistics (NCES) website: http://nces.ed.gov

RAND (1992). High school vocational education: Low esteem, little clout (RB8001). Washington, DC: U.S. Government Printing Office.

Ravitch, D. (2008). American children left behind [Online forum comment]. Retrieved from Forbes website: http://www.forbes.com

Reese, W. J. (2001). Origins of progressive education. History of Education Quarterly, 41(1), 1-24. doi:10.1111/j.1748-5959.2001.tb00072.x

Reese, S. (2003). A role to play in school reform. Techniques, 78(6), 39-41. Retrieved from http://www.acteonline.org

Resnick, L., \& Berger, L. (2010). An American examination system. Education Week, 29(30), 10-11. Retrieved from http://www.ebscohost.com

Reynolds, A.J. \& Wahlberg, H.J. (1992). A structural model of high school mathematics outcomes. The Journal of Educational Research, 85, 150-158. doi: 10.1080/00220671.1992.9944431

Richardson, V. (2003). Constructivist Pedagogy. Teachers College Record, 105(9), 1623-1640. Retrieved from University of Massachusetts website: http://people.umass.edu

Roberson, D. L., Flowers, J., \& Moore, G. E. (2000). Status of integration of academic and agricultural education in North Carolina. Journal of Career and Technical Education, 17(1). Retrieved from http://scholar.lib.vt.edu/ejournals/JCTE 
Roberts, P. L., \& Kellough, R. D. (1996). A guide for developing interdisciplinary thematic units (4th ed.). Upper Saddle River, NY: Merrill Prentice Hall

Roberts, T. G., \& Harlin, J. F. (2007). Project method in agricultural education. Journal of Agricultural Education, 48(3), 46-56. doi:10.5032/jae.2007.03046

Roebuck, K. I., \& Warden, M. A. (1998). Searching for the center on the mathematicsscience continuum. School Science and Mathematics, 98(6), 328-333. doi:10.1111/j.1949-8594.1998.tb17428.x

Rojewski, J. W. (2002). Preparing the workforce of tomorrow: A conceptual framework for career and technical education. Journal of Vocational and Technical Education, 27(1). Retrieved from http://scholar.lib.vt.edu/ejournals/JVTE

Romberg, T. A. (2001). Designing Middle-school mathematics materials using problems set in context to help students progress from informal to formal mathematical reasoning. Retrieved from National Center for Improving Student Learning and Achievement in Mathematics and Science website: http://ncisla.wceruw.org

Rumberger, R. W., \& Palardy, G. J. (2005). Does segregation still matter? The impact of student composition on academic achievement in high school. Teachers College Record, 107(9), 1999-2045. Retrieved from University of Massachusetts website: http://people.umass.edu

Rutherford, A. (2001). Introducing ANOVA and ANCOVA: A GLM approach. Thousand Oaks, CA: SAGE Publications, Inc.

Schmidt, B. J., Beeken, L. A., \& Jennings, C. L. (1992). Integrating academic and vocational education: Guidelines for secondary school principals. Retrieved from ERIC database. (ED355424).

Schmidt, B.J., Finch, C.R., \& Faulkner, S.L. (1995). The role of teachers. In N. Grubb (Ed.), Education through occupations in American high schools: The challenges of implementing curriculum integration (pp. 82-101). New York, NY: Teachers College Press.

Schmidt, W., Roehler, L., Caul, J., Buchmann, M., Diamond, B., Solomon, D., \& Cianciolo, P. (1985). Uses of curriculum integration in language arts instruction: A study of six classrooms. Journal of Curriculum Studies, 17(4), 305-320. doi:10.1080/0022027850170306

Schumacher, D. H. (1992). Multiple case study of curriculum integration by middle school interdisciplinary teams of teachers (Doctoral dissertation). Available from ProQuest Digital Dissertations and Theses database. (UMI No. 9234247). 
Secretary's Commission on Achieving Necessary Skills (SCANS) (1991). What work requires of schools: A SCANS report for America 2000. Retrieved from the U.S. Department of Labor website: http://wdr.doleta.gov

Shoemaker, B. J. (1991). Education 2000 integrated curriculum. The Phi Delta Kappa, 72(10), 793-797. Retrieved from http://www.jstor.org/stable/20404539

Short, E. C. (1986). Historical look at curriculum design. Theory into Practice, 25(1), 39. doi:10.1080/00405848609543191

Silverberg, M., Warner, E., Fong, M., \& Goodwin, D. (2004). National assessment of vocational education: Final report to Congress: Executive Summary. Retrieved from U.S. Department of Education website: http://www.ed.gov

Sinan, G., \& Rojewski, J. W. (2007). Evaluating research in career and technical education using scientifically-based research standards. Career and Technical Education Research, 32(3), 143-159. doi:10.5328/CTER32.3.143

Slavin, R.E., Lake, C., \& Groff, C. (2009). Effective programs in middle and high school mathematics: A best-evidence synthesis. Review of Educational Research, 79(2), 839-911. Retrieved from http://www.jstor.org/stable/40469058

Smith, M. K. (2002). Jerome Bruner and the process of education. Retrieved from http://www.infed.org/thinkers/bruner.htm

Snow, C. (2002). Reading for understanding: Toward an $R \& D$ program in reading comprehension. Santa Monica, CA: RAND.

Stasz, C., McArthur, D., Lewis, M., \& Ramsey, K. (1990). Teaching and learning generic skills for the workplace (Report R-4004-NCRVE/UCB). http://ncrve.berkeley.edu

Stasz, C., \& Grubb, W. N. (1991). Integrating academic and vocational education: Guidelines for assessing a fuzzy reform. Retrieved from ERIC database. (ED334420).

Stasz, C., Kaganoff, T., \& Eden, R. A. (1994). Integrating academic and vocational education: A review of literature, 1987-1992 (RP-445). Santa Monica, CA: RAND.

Stasz, C. (1995). The economic imperative behind school reform: A review of literature (DRU-1064-NCRVE/UCB). Retrieved from RAND website: http://www.rand.org 
Stasz, C., Ramsey, K., \& Eden, R. (1995). Teaching generic skills. In N. Grubb (Ed.), Education through occupations in American high schools: Approaches to integrating academic and vocational education (pp. 169-191). New York, NY: Teachers College Press.

Stern, D., Raby, M., \& Dayton, C. (1992). Career academies: Partnerships for reconstructing American high schools. San Francisco, CA: Jossey-Bass.

Stem, D., Dayton, C., Paik, I., \& Weisburgq, A. (1989). Benefits and costs of dropout prevention in a high school program combining academic and vocational education: Third-year results from replications of the California peninsula academies. Educational Evaluation and Policy Analysis, 11(4), 405-416. doi:10.3102/01623737011004405

Stevens, J.P. (1999). Intermediate statistics: A modern approach. Mahway, NJ: Lawrence Erlbaum Associates.

Stevenson, C., \& Carr, J. (Eds.). (1993). Integrated studies in the middle school: Dancing through walls. New York, NY: Teachers College Press.

Stone, J. (2003). Standing still in a time of change. Techniques,78(8), 24-25. Retrieved from http://www.acteonline.org

Stone, J., Alfeld, C., Pearson, D., Lewis, M., \& Jensen, S. (2006). Building academic skills in context: Testing the value of enhanced mathematics learning in CTE. Retrieved from National Research Center for Career and Technical Education (NRCCTE) web site: http://www.nrccte.org

Stowell, L. P., \& McDaniel, J. E. (1997). The changing face of assessment. In J.L. Irvin (Ed.), What current research says to the middle level practitioner (pp. 137-150). Columbus, OH: National Middle School Association.

Stylianides, A.J. \& Stylianides, G.J. (2007). Learning mathematics with understanding: A critical consideration of the learning principle in the Principles and Standards for School Mathematics. The Montana Mathematics Enthusiast, 4(1), 103-114. Retrieved from http://www.math.umt.edu/TMME/

Tanner, D., \& Tanner, L. (1980). Determining the structure of the curriculum. In Curriculum development: Theory into practice (4th ed., pp. 251-278). Upper Saddle River, NJ: Pearson/Merrill Prentice Hall.

Tchudi, S., \& Lafer, S. (1996). The interdisciplinary teacher's handbook: Integrating teaching across the curriculum. Portsmouth, NH: Boynton/Cook Publishers, Inc.

Thomas, J. W. (2000). A review of research on project-based learning. Retrieved from the Buck Institute website: http://www.bie.org 
Threeton, M.D. (2007). Carl D. Perkins Career and Technical Education (CTE) Act of 2006 and the roles and responsibilities of CTE teachers and faculty members. Journal of Industrial Teacher Education, 44(1). Retrieved from http://scholar.lib.vt.edu/ejournals/JITE

Toepfer, C. F. (1997). Middle level curriculum's serendipitous history. In J. Irvin (Ed.), What current research says to the middle level practitioner (pp. 163-177). Columbus, OH: National Middle School Association.

Trefler, D. (2005). Off shoring of services: Issues and implications. Retrieved from Canadian Institute for Advanced Research website: http://www.brookings.edu

Trochim, W. M. (2006). Social Research Methods. Retrieved from http://www.socialresearchmethods.net

Turnipseed, B. Y. (2008). Teachers' perceptions of integrating academics and career and technical education across the curriculum (Doctoral dissertation). Available from ProQuest Digital Dissertations and Theses database. (UMI No. 3337368).

Tyack, D., \& Tobin, W. (1994). "Grammar" of schooling: Why has it been so hard to change? American Educational Research Journal, 31(3), 453-479. doi:10.3102/00028312031003453

U.S. Department of Education (2005). Overview: Four pillars of NCLB. Retrieved from http://www.ed.gov

U.S. Department of Education (2011). Schools not making adequate yearly progress. Retrieved from Retrieved from http://www.ed.gov

Usher, A. (2011). AYP Results for 2010-11. Retrieved from Center on Education Policy (CEP) website: http://www.cep-dc.org

Vaites, G. (2003). Improving reading proficiency through CTE. Techniques, (78)6. Retrieved from http://www.acteonline.org

Vars, G. F. (1993). Interdisciplinary teaching: Why and how (2nd ed.). Columbus, OH: National Middle School Association.

Vars, G. F. (1997). Effects of integrative curriculum and instruction. In J.L. Irvin (Ed.), What current research says to the middle level practitioner (pp. 179-186).

Columbus, OH: National Middle School Association.

Vars, G. F. (2001). Can curriculum integration survive in an era of high-stakes testing? Middle School Journal, 33(2), 7-17. Retrieved from http://www.jstor.org/stable/23043475 
Vars, G. F., \& Beane, J. A. (2000). Integrative curriculum in a standards-based world. Retrieved from ERIC database. (ED441618).

Venville, G. J., Wallace, J., Rennie, L. J., \& Malone, J. A. (2002). Curriculum integration: Eroding the high ground of science as a school subject. Studies in Science Education, 37(1), 43-83. doi:10.1080/03057260208560177

Von Glasersfeld, E. V. (2005). Introduction: Aspects of Constructivism. In C.T. Fosnot (Ed.), Constructivism: Theories, perspectives, and practice (2nd ed., pp. 3-7). New York, NY: Teachers College Press.

Walker, D. (1995). Integrative education. Retrieved from ERIC database. (ED390141).

Wasike, G. N. (1995). Integration of language arts skill development into secondary school family and consumer sciences curriculum: A causal model for predicting teacher practices (Doctoral dissertation). Available from ProQuest Digital Dissertations and Theses database. (UMI No. 9531805).

Weiner, R., \& Hall, D. (2004). Accountability under No Child Left Behind. The Clearing House: A Journal of Educational Strategies, Issues, and Ideas, 78(1), 17-21. doi:10.3200/TCHS.78.1.17-21

What Did The Eight Year Study Reveal? (1942). The High School Journal, 25(7), 305309. Retrieved from http://www.jstor.org/stable/40367588

Wonacott, M. (2003). History and evolution of vocational and career and technical education. Retrieved from ERIC database. (ED482359).

Wraga, W. G. (1997). Patterns of interdisciplinary curriculum organization and professional knowledge of the curriculum field. Journal of Curriculum and Supervision, 12(2), 98-117. Retrieved from http://www.ebscohost.com

Wraga, W. G. (1993). The interdisciplinary imperative for citizenship education. Theory and Research in Social Education, 21(3), 201-231. doi:10.1080/00933104.1993.10505702

Wright, G. S. (1958). Block-time classes and the core program in the junior high school (No. 6). Washington, DC: U.S. Government Printing Office.

Zirkle, C. (2004). Integrating occupational and academic skills across the curriculum. Techniques, 79(6), 24-26. Retrieved from http://www.acteonline.org 
APPENDICES 
Course SPS Crosswalks

\section{Business Computer Programming 1}

Outcome \# 10.0 ASSESS PERSONAL STRENGTHS AND WEAKNESSES AS THEY RELATE TO JOB OBJECTIVES, CAREER EXPLORATION, PERSONAL DEVELOPMENT, AND LIFE GOALS-THE STUDENT WILL BE ABLE TO:

Performance Task\# 10.06 Investigate specific job opportunities in computer programming in the local job market.

\begin{tabular}{l|l} 
SSS Strand: Reading & Essential Work Skills
\end{tabular}

\begin{tabular}{|c|c|c|c|}
\hline \multirow[t]{3}{*}{ LA.A 2.4.1 H } & \multirow[t]{2}{*}{$\begin{array}{l}\text { Determines the main idea and identifies relevant details, methods of } \\
\text { development, and their effectiveness in a variety of types of written } \\
\text { material. }\end{array}$} & \multirow{2}{*}{ e24 } & \multirow{2}{*}{$\begin{array}{l}\text { Discriminate important ideas from unimportant ideas } \\
\text { while reading. } \\
\text { Summarize, synthesize and organize information while } \\
\text { reading. }\end{array}$} \\
\hline & & & \\
\hline & & e46 & $\begin{array}{l}\text { Apply, extend, and expand on information while } \\
\text { reading. }\end{array}$ \\
\hline LA.A 2.4.6 L & $\begin{array}{l}\text { Selects and uses appropriate study and research skills and tools according } \\
\text { to the type of information being gathered or organized, including } \\
\text { almanacs, government publications, microfiche, news sources, and } \\
\text { information services. }\end{array}$ & e03 & $\begin{array}{l}\text { Gather information from a variety of sources, } \\
\text { including electronic sources, and summarize, analyze, } \\
\text { and evaluate its use for a report. }\end{array}$ \\
\hline \multicolumn{4}{|c|}{ Performance Task\# 10.07 Identify tasks performed by computer programming personnel } \\
\hline \multicolumn{2}{|c|}{ SSS Strand: Reading } & \multicolumn{2}{|c|}{ Essential Work Skills } \\
\hline LA.A 2.4.6 L & $\begin{array}{l}\text { Selects and uses appropriate study and research skills and tools according } \\
\text { to the type of information being gathered or organized, including } \\
\text { almanacs, government publications, micofiche, news sources, and } \\
\text { information services. }\end{array}$ & e03 & $\begin{array}{l}\text { Gather information from a variety of sources, } \\
\text { including electronic sources, and summarize, analyze, } \\
\text { and evaluate its use for a report. }\end{array}$ \\
\hline \multicolumn{4}{|c|}{ 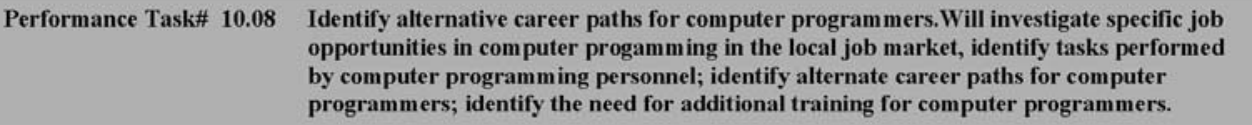 } \\
\hline \multicolumn{2}{|c|}{ SSS Strand: Writing } & \multicolumn{2}{|c|}{ Essential Work Skills } \\
\hline \multirow[t]{3}{*}{ LA.B 1.4.2 H } & $\begin{array}{l}\text { Drafts and revises writing that: is focused, purposeful, and reflects insight } \\
\text { into the writing situation; has an organizational pattern that provides for a } \\
\text { logical progression of ideas, has effective use of transitional devices that } \\
\text { contribute to a sense of completcness, has support that is substantial, } \\
\text { specific, relevant, and concrete; demonstrates a commitment to and } \\
\text { involvement with the subject; uses creative writing strategies as } \\
\text { appropriate to the purposes of the paper; demonstrates a mature command } \\
\text { of language with fresiness of expression; has varied sentence structure; } \\
\text { has few, if any, convention errors in mechanics, usage, punctuation and } \\
\text { spelling. }\end{array}$ & e12 & $\begin{array}{l}\text { Draft a report that engages an audience and is concise, } \\
\text { clear, well organized, accurate, and informative. }\end{array}$ \\
\hline & & e14 & $\begin{array}{l}\text { Use editing and revising skills to improve } \\
\text { effectiveness and accuracy of drafts. }\end{array}$ \\
\hline & & e27 & $\begin{array}{l}\text { Define a position on a controversial topic and write a } \\
\text { persuasive essay or make an oral presentation likely to } \\
\text { persuade a specific audience to change an opinion or } \\
\text { take a particular action. }\end{array}$ \\
\hline
\end{tabular}

Figure A1: Business Computer Programming 1 course crosswalk report, page 1 
Course SPS Crosswalks

\section{Digital Design 1}

Outcome \# 20.0 PARTICIPATE IN WORK-BASED LEARNING EXPERIENCES, THE STUDENT WILL BE ABLE TO:

Performance Task\# 20.38 Discuss the use of technology in a digital publishing environment

\begin{tabular}{|c|c|c|c|}
\hline \multicolumn{2}{|c|}{ SSS Strand: Writing } & \multicolumn{2}{|c|}{ Essential Work Skills } \\
\hline LA.B 2.4.2 L & Organizes information using appropriate systems. & e12 & $\begin{array}{l}\text { Draft a report that engages an audience and is concise, } \\
\text { clear, well organized, accurate, and informative. }\end{array}$ \\
\hline \multirow[t]{2}{*}{ LA.B 2.4.3 L } & $\begin{array}{l}\text { Writes fluently for a variety of occasions, audiences, and purposes, } \\
\text { making appropriate choices regarding style, tone, level of detail, and } \\
\text { organization. }\end{array}$ & e22 & $\begin{array}{l}\text { Understand and produce a variety of informative } \\
\text { formats such as business letters, memos, reports, news } \\
\text { articles, brochures, proposals and critiques. }\end{array}$ \\
\hline & & eso & $\begin{array}{l}\text { Understand and use a variety of organizational formats } \\
\text { such as compare/contrast, cause/effect, } \\
\text { inductive/deductive, most important to least important, } \\
\text { and least important to most important. }\end{array}$ \\
\hline LA.B 2.4.4 L & $\begin{array}{l}\text { Selects and uses a variety of electronic media, such as the Intemet, } \\
\text { information services, and desktop publishing software programs, to } \\
\text { create, revise, retrieve, and verify information. }\end{array}$ & e03 & $\begin{array}{l}\text { Gather information from a variety of sources, } \\
\text { including electronic sources, and summarize, analyze, } \\
\text { and evaluate its use for a report. }\end{array}$ \\
\hline \multicolumn{2}{|c|}{ SSS Strand: Listening, Viewing and Speaking } & \multicolumn{2}{|c|}{ Essential Work Skills } \\
\hline LA.C 3.4.4 L & $\begin{array}{l}\text { Applies oral communication skills to interviews, group presentations, } \\
\text { formal presentations, and impromptu situations. }\end{array}$ & e10 & $\begin{array}{l}\text { Prepare and deliver individual speeches by gathering } \\
\text { information, rehearsing, making eye contact, speaking } \\
\text { loudly enough, delivering information in a well } \\
\text { organized fashion, and appealing to the needs of the } \\
\text { target audience. }\end{array}$ \\
\hline \multicolumn{2}{|c|}{ SSS Strand: Literature } & \multicolumn{2}{|c|}{ Essential Work Skills } \\
\hline LA.E 2.4.4 L & $\begin{array}{l}\text { Understands the use of images and sounds to elicit the reader's emotions } \\
\text { in both fiction and nonfiction. }\end{array}$ & e72 & $\begin{array}{l}\text { Evaluate the way an author uses language and text } \\
\text { characteristics such as plot, setting, theme, character, } \\
\text { point of view, genre etc. to evoke a response in a } \\
\text { reader. }\end{array}$ \\
\hline \multicolumn{2}{|c|}{ SSS Strand: The Nature of Science } & \multicolumn{2}{|c|}{ Essential Work Skills } \\
\hline SC.H 3.4.2 H & $\begin{array}{l}\text { Knows that technological problems often create a demand for new } \\
\text { scientific knowledge and that new technologies make it possible for } \\
\text { scientists to extend their research in a way that advances science. }\end{array}$ & s116 & $\begin{array}{l}\text { (Not Ranked) Understand the impact upon society and } \\
\text { the environment of scientific and technological } \\
\text { discoveries and the contributions of scientiss. } \\
\text { Understand how society may accept or reject scientific } \\
\text { discoveries based upon need or refusal to change. }\end{array}$ \\
\hline SC.H 3.4.5 H & $\begin{array}{l}\text { Knows that the value of a technology may differ for different people and } \\
\text { at different times. }\end{array}$ & s116 & $\begin{array}{l}\text { (Not Ranked) Understand the impact upon society and } \\
\text { the environment of scientific and technological } \\
\text { discoveries and the contributions of scientiss. } \\
\text { Understand how society may accept or reject scientific } \\
\text { discoveries based upon need or refusal to change. }\end{array}$ \\
\hline SC.H 3.4.6 H & $\begin{array}{l}\text { Knows that scientific knowledge is used by those who engage in design } \\
\text { and technology to solve practical problems, taking human values and } \\
\text { limitations into account. }\end{array}$ & $\$ 115$ & $\begin{array}{l}\text { (Not Ranked) Plan and apply real or hypothetical } \\
\text { models and constructions to facilitate investigation and } \\
\text { learning and the solution to practical problems. }\end{array}$ \\
\hline
\end{tabular}
$\begin{array}{ll}\text { and technology to solve practical problems, taking human values and } & \text { models and constructions to facilitate investigation : } \\ \text { limitations into account. } & \text { learning and the solution to practical problems. }\end{array}$

Outcome \# 48.0 DEMONSTRATE PROFICIENCY IN COMPUTER SKILLS, THE STUDENT WILL BE ABLE TO:

Performance Task\# $\mathbf{4 8 . 0 1}$ Identify all computer parts (e.g., RAM, ROM)

Figure A2: Digital Design 1 course crosswalk report, page 1 


\section{Appendix B: CTE Lead Teacher Agreement and Compensation Documents}

\section{CAREER \& TECHNIECAL EDUCATION: THE CTE/FCAT CONNECTION CTE LEAD TEACHER AGREEMENT COMPENSATION}

1. The District will compensate me at my personal daily rate for the $02-03$ school year for the five all-day work sessions (June 2-6, 2003). Mileage to and from the workshop will be my responsibility.

2. Volusia County Schools will pay my conference fees, double occupancy hotel room, \$21 per day meal fee, and \$36 round trip mileage for attending and participating in the June 28, 2003 thru July 2, 2003 Willard Daggett Conference in Orlando. There will be no additional compensation for attending the conference.

3. The District will pay me a stipend for the delivery of acceptable FCAT Connection Projects, attendance at workshops and presentation at in-service for CTE teachers by the following schedule:

Completion of Project \#1 - \$500.00 - to be paid on August 30, 2003

Completion of Project $\# 2-\$ 500.00$ - to be paid on November 15, 2003

Completion of Project \#3 - \$500.00 - to be paid on February 15, 2004

Completion of Project \#4 - \$500.00 - to be paid on April 15, 2004

Completion of Project \#5 - \$500.00 - to be paid on June 15, 2004

4. Sixty staff development points will awarded for the completion of this agreement. Additional staff development points may be earned for participation in the June 28 - July 2, 2003 Daggett Conference in Orlando. (Responsibility for paperwork for the points will be mine.)

I the CTE/FCAT Connection Project.

, CTE Lead Teacher agree to the compensation guidelines for

School

Figure B1: CTE Lead Teacher Compensation document 


\section{Appendix B: CTE Lead Teacher Agreement and Compensation Documents}

\section{CAREER \& TECHNICAL EDUCATION: THE CTE/FCAT CONNECTION CTE LEAD TEACHER AGREEMENT}

1. Attend the CTE Lead Teacher orientation workshop on May 6, 2003.

This is a regular school day, and a substitute will be provided for my classes. Mileage to and from the workshop will be my responsibility.

2. Between May 6,2003 and June 2, 2003 review crosswalks of highly tested FCAT standards and Essential Skills for Gold Seal Lesson development. Gather instructional materials and resources to be used for planning the first project

3. Attend the June 2, 2003 Lead Teacher Workshop in conjunction with the District's Career Connection Facilitators; attend the June 3, 2003 and June 4, 2003 research /writing sessions and develop one crosswalked FCAT project. Attend the June 5, 2003 and June 6, 2003 reporting, critique, and demonstration sessions for the presentation of my project.

4. Attend the entire June 28, 2003 and June 29, 2003 Willard Daggett Rigor and Relevance Curriculum Workshop in Orlando. Enhance the FCAT project completed during the June work sessions. Discuss the project with Daggett curriculum specialists and note comments. Attend the entire June 29, 2003 thru July 2, 2003 Willard Daggett Model Schools Conference in Orlando.

5. Research and write 5 FCAT Connection Projects for the subject assigned and deliver approved projects to the district.

- Project \# 1 - Deliver the completed FCAT Project on July 24, 2003 and attend a July 24, 2003 and July 25, 2003 workshop to prepare for my CTE area in-service for CTE Teachers at the August $6^{\text {th }}$ preplanning day.

- Project \#2 - Deliver the completed FCAT Project and attend an October 10, 2003 workshop to prepare for my CTE area in-service for CTE Teachers on the October 17, 2003 teacher duty day.

- Project \#3 - Deliver the completed FCAT Project and attend a December 10, 2003 evening (4:00 to 8:00) workshop to prepare for my CTE area in-service for CTE teachers on January 14, 2004 evening (4:00 to $8: 00)$.

- Project \#4 - Deliver the completed FCAT Project and attend a March 5, 2004 evening (4:00 to 8:00) workshop to prepare for my CTE area in-service for CTE teachers on March 12, 2004.

- Project \#5 - Deliver the completed FCAT Project and attend a Saturday, May 8, 2004 workshop.

I , as a CTE Lead Teacher, agree to the above terms, conditions, and duties:

$\begin{array}{llc}\text { Lead Teacher } & \text { School } & \text { Date }\end{array}$

I support 's participation in the FCAT Connection Project.

Figure B2: CTE Lead Teacher Agreement document 
Appendix C: Project Development Worksheets

\begin{tabular}{|c|}
\hline $\begin{array}{l}\quad \text { PROJECT FOUNDATIONS WORKSHEET } \\
\text { Project Concepts---CTE Frameworks---FCAT Skills \& Work Skills---Project/Lesson Development } \\
\text { Program Area: } \\
\text { Course Title: } \\
\text { Grade Level: } \\
\text { Teacher Names: }\end{array}$ \\
\hline $\begin{array}{l}\text { 1. Think about your course content, list five concepts (big } \\
\text { ideas) that will be the focus of project development and list } \\
\text { those concepts below in the order to be taught. } \\
\text { 1. } \\
\text { 2. } \\
3 . \\
4 . \\
5 .\end{array}$ \\
\hline $\begin{array}{l}\text { 2. Choose one concept for the Project } 1 \text { development. } \\
\text { 3. Using your course crosswalk, find the CTE performance } \\
\text { standards that support the first concept and highlight them. } \\
\text { 4. Next, highlight the high and medium tested FCAT skills (SSS) } \\
\text { and the high essential skills (numbers 1-35) that follow each } \\
\text { highlighted CTE performance standard. }\end{array}$ \\
\hline $\begin{array}{l}\text { 5. The highlighted CTE performance standards that have either } \\
\text { medium or high FCAT skill(s)highlighted and/or high essential } \\
\text { work skill(s) highlighted are the CTE performance standards } \\
\text { that you will use to develop project } 1 \text { lessons. }\end{array}$ \\
\hline $\begin{array}{l}\text { 6. For each CTE course, Project } 1 \text { lessons will contain at least } \\
\text { one lesson as named below that integrates relevant CTE course } \\
\text { content (i.e. highlighted performance standards from above) } \\
\text { with rigorous academic skills (i.e. highlighted SSS standards } \\
\text { from above): } \\
\begin{array}{l}\text { Pre Reading } \\
\text { Reading Connection } \\
\text { Math Connection } \\
\text { Science Connection } \\
\text { Research Presentation } \\
\text { Presentation Connection }\end{array}\end{array}$ \\
\hline $\begin{array}{l}\text { 7. Place each lesson for the project in a quadrant of the Rigor } \\
\text { and Relevance Framework. Project } 1 \text { lessons must contain a } \\
\text { progression of activities from A quadrant to D quadrant, with } \\
\text { at least one D lesson per project. }\end{array}$ \\
\hline $\begin{array}{l}\text { 8. Please use the Project Templates from your CD for all project } \\
\text { lessons. }\end{array}$ \\
\hline
\end{tabular}

Figure C1: Project Foundations worksheet 
Appendix C: Project Development Worksheets

\title{
PROJECT CONNECTION
}

\author{
Project Title: \\ Program Area: \\ Course Title: \\ Timeline for Use: \\ Grade Level: \\ Duration of Project \\ Submitted By
}

\section{Lesson Summary}

\section{Instructional Focus}

Lesson Topic:

Language Arts Strands:

Math Strands:

Science Strands:

\section{Rigor/Relevance Framework}

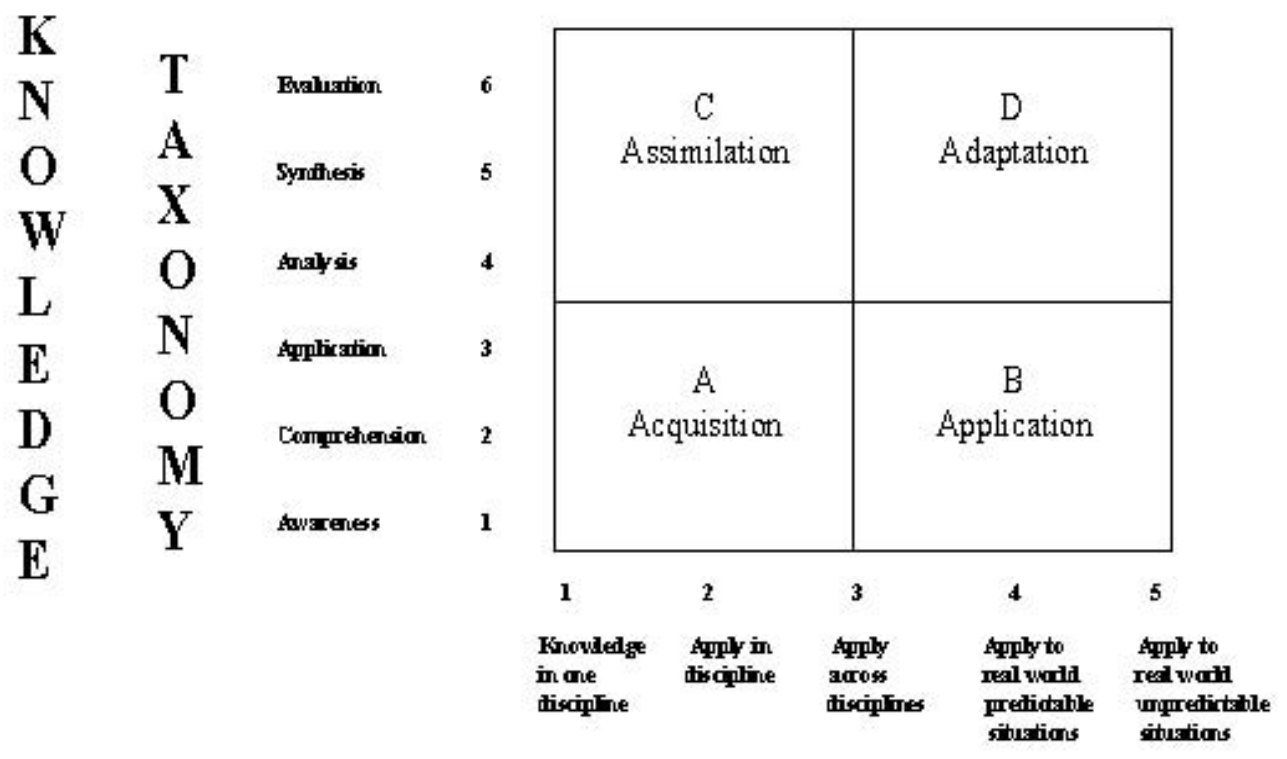

Figure C2: Project Connection worksheet 
Appendix C: Project Development Worksheets

\section{MATH CONNECTION}

\section{Title:}

Performance Tasks:

Sunshine State Standards (LA, MA, and SC):

Essential Skills (e, m, and s):

Rigor and Relevance (quadrant):

Instructions to Teacher:

Instructions to Students:

Instructions for Learning Styles Modifications:

Assessment for Activity:

Approximate Length of Time for Activity:

Materials Needed:

Resources Needed:

Activity:

Attachments:

Figure C3: Math Connection worksheet 


\section{Appendix C: Project Development Worksheets}

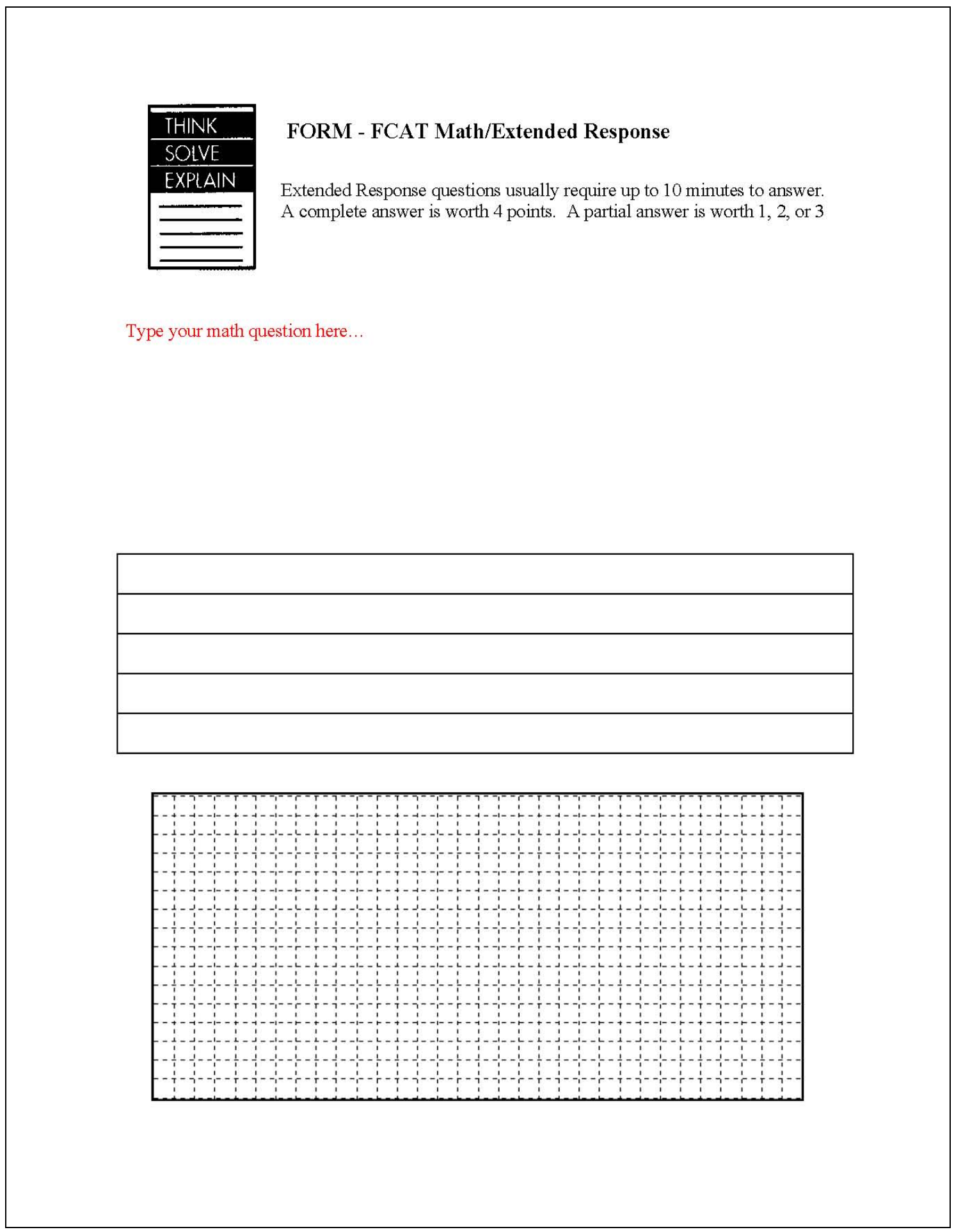

Figure C4: FCAT Math Extended Response worksheet 
Appendix C: Project Development Worksheets

\section{RUBRIC- FCAT Math/Extended Response}

\begin{tabular}{|c|c|}
\hline Score & Description \\
\hline 4 & $\begin{array}{l}\text { The response indicates that the student demonstrates a thorough } \\
\text { understanding of the mathematics concepts and/or procedures } \\
\text { embodied in the task. The student has responded correctly to the } \\
\text { task, used mathematically sound procedures, and provided clear and } \\
\text { complete explanations and interpretations. } \\
\text { The response may contain minor flaws that do not detract from a } \\
\text { demonstration of a thorough understanding. }\end{array}$ \\
\hline 3 & $\begin{array}{l}\text { The response indicates that the student demonstrates an } \\
\text { understanding of the mathematics concepts and/or procedures } \\
\text { embodied in the task. Although the student may have used the } \\
\text { correct approach to obtaining a solution or may have provided a } \\
\text { correct solution, the student's work lacks an essential understanding } \\
\text { of the underlying mathematical concepts. } \\
\text { The response contains errors related to misunderstanding important } \\
\text { aspects of the task, misuse of mathematical procedures, or faulty } \\
\text { interpretations of results. }\end{array}$ \\
\hline 2 & $\begin{array}{l}\text { The response indicates that the student demonstrates only a partial } \\
\text { understanding of the mathematics concepts and/or procedures } \\
\text { embodied in the task. Although the student may have used correct } \\
\text { approach to obtaining a solution or may have provided a correct } \\
\text { solution, the student's work lacks an essential understanding of the } \\
\text { underlying mathematical concepts. }\end{array}$ \\
\hline 1 & $\begin{array}{l}\text { The response indicates that the student demonstrates a very } \\
\text { limited understanding of the mathematics concepts and/or } \\
\text { procedures embodied in the task. The student's response is } \\
\text { incomplete and exhibits many flaws. Although the student's } \\
\text { response has addressed some of the conditions of the task, the } \\
\text { student reached an inadequate conclusion and/or provided } \\
\text { reasoning that was faulty or incomplete. } \\
\text { The response exhibits many flaws or may be incomplete. }\end{array}$ \\
\hline 0 & $\begin{array}{l}\text { The response indicates that the student provides a completely } \\
\text { incorrect solution or uninterpretable response, or no response at all. }\end{array}$ \\
\hline
\end{tabular}

Figure C5: FCAT Mathematics Extended Response Rubric worksheet 